\title{
Useless Architecture
}

\author{
By \\ Ryan Stec
}

\begin{abstract}
A thesis submitted to the Faculty of Graduate and Postdoctoral Affairs in partial fulfillment of the requirements for the degree of
\end{abstract}

\author{
Master of Architecture \\ in \\ Architecture \\ Carleton University \\ Ottawa, Ontario \\ (C) 2014 Ryan Stec
}




\section{The Hunting of the Snark}

\section{Fit the Second. The Bellman's Speech}

He had bought a large map representing the sea, without the least vestige of land.

And the crew were much pleased when they found it to be

a map they could all understand.

"What's the good of Mercator's

North Poles and Equators,

Tropics, Zones, and Meridian Lines?"

so the Bellman would cry, and the crew would reply:

"They are merely conventional signs!"

"Other maps are such shapes, with their islands and capes!

But we've got our brave Captain to thank,"

(so the crew would protest)

"that he's bought us the best -

a perfect and absolute blank!"

Lewis Carroll 1876 


\section{(Concrete) Abstract}

Useless Architecture is driven by three principal goals: the first is to re-examine, both philosophically and politically, the primacy of utility as a measure of value; the second is to explore and understand the role of useless space within the fabric of the city and the public realm, and the third is to consider what meaning and application the notion of uselessness has for architecture. The Useless Architecture thesis is divided into four sections. It begins with a focus on utility in language, philosophy, politics and economics. The second portion includes a creative consideration of useless space in the city complemented by the possibilities offered within dysfunctional tools of mapping and representation. This is followed by an exploration of instrumentality and utility in an architectural context through a consideration of artistic projects, monuments and ruins. In the final section, the research is manifested as an architectural proposal for a stair to nowhere, added to the Chaudière Ring Dam on the Ottawa River in the heart of Canada's national capital region. 


\section{(Supplementary) Abstraction}

At a ten meter drop in the rock, at the bottom of a once great sea, a dam now sits. An industrial caress across the brow of the rocks restrains the rhythm. There has always been energy here. It started wide. It pooled itself in fissures. It disappeared under the shore. Now it runs through very useful architecture and unfolds as streams of the harnessed world running for every outlet it can find. What do we desire from a place such as this in the heart of the city? How do we see it? How do we perceive it? How do we experience it? Can architecture write a new story for a falls that has lost its voice? If architecture is unable, can it lay the foundation for others to build and rebuild? 


\section{Acknowledgements}

It is difficult to know where our ideas begin. It is difficult to identify the contributions of friends, family, collaborators and mentors in any singular form. This makes the experience of writing and designing dense and complicated, but also an easy and delightful place to get lost. And when you endeavour, so willfully, to lose your way, it is best to have good company. I have been very fortunate in this regard. There are many thanks to many people, but I'll start with these important ones.

To Véronique Couillard, I cannot quantify the generosity, nor describe the humor, that has kept me buoyant for so many years. Our lives have straddled many categories together, and I am so very glad she is always up for a new adventure, especially the one that has involved our son Arlo. His lightness is always uplifting, and I would like to offer a particular thanks for how he finds such laughter in "...les escaliers qui va nuls-part!"

For my parents, Dennis and Sandra, support is hardly an adequate word to describe their unflinching kindness, and my brother, Deryk, for his reassuring perspectives. I learned how to ask questions amongst this family, for better or worse it is deep in my bones and leads me to many interesting places. To my extended family, the Couillards, I thank them for their incredible hearts. In particular, my sister and friend, Geneviève Couillard and her son Maxime, deserve my most gracious thanks for caring for me and Véronique and Arlo throughout this adventure. 
To everyone involved with Artengine, and in particular Remco Volmer for the many conversation and for all of the support in this expansion of endeavours. To my friend and collaborator Jessie Fyfe-Loose, who is here in between life and the life of school, I thank her for teaching me about new ways to question the world and for questioning the world with me. I will always try to go forward with grace and openness.

To all my fellow students, who shared all of the layers of an architectural education. Specifically, Kyle for his generosity; Mike for his incredible spirit; Andrew for his charming questions and questionable charm; Amir for his poetic pragmatism and all of them for so much laughter.

To Paul Holmquist and Claudio Sgarbi for opening up a new world of thinking about architecture, and for their dedication to teaching and thinking and doing and making.

To thank Roger Connah is tricky. A simple thank you seems inappropriate for the poet among us. Always challenging and complex, his unorthodox leadership will take you on great adventures. On the other hand, perhaps the simplest thank you is best. To thank Federica Goffi is easy. All of the words one hopes to find in a mentor appear with her: supportive, open, inquisitive, generous, insightful and full of wonder. Both Federica and Roger have been wonderful in both leading and following in this dance between the very useful and the utterly useless. 


\section{Table of Contents}

(Concrete) Abstract..................................................................................................

(Supplementary) Abstraction ...............................................................................iv

Acknowledgements ..............................................................................................v

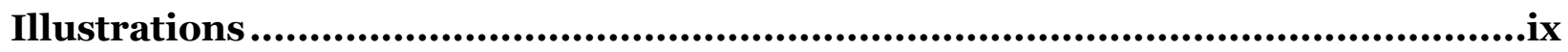

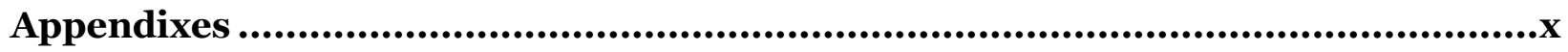

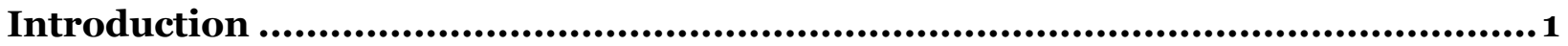

Chapter 1: Towards a useless theory …...................................................................... 3

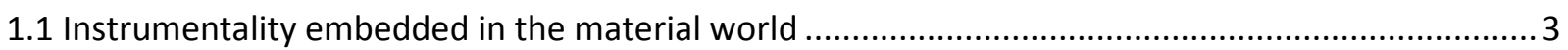

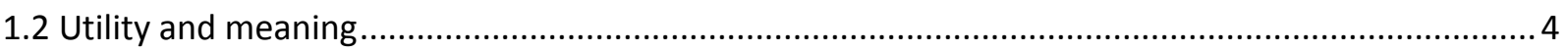

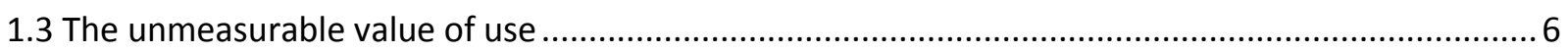

Chapter 2: Useless space ................................................................................10

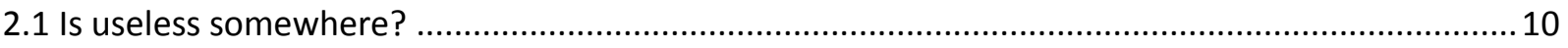

2.2 Not unused, not misused, not yet to be used, but useless......................................................... 12

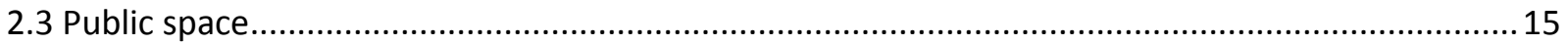

2.4 Narrowing of purpose and the instrumentalization of space ...................................................... 18

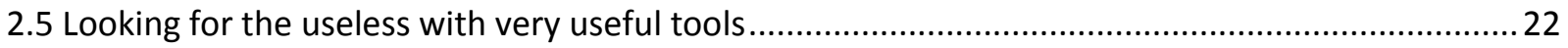

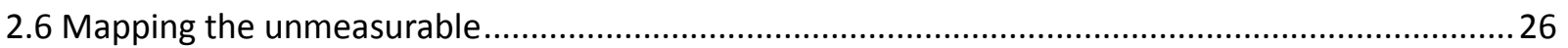

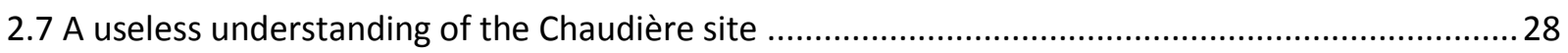

Chapter 3: Useless architecture ........................................................................... 34

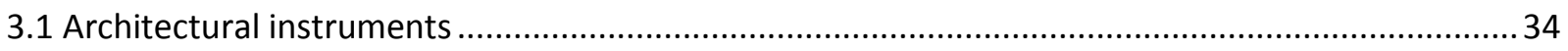

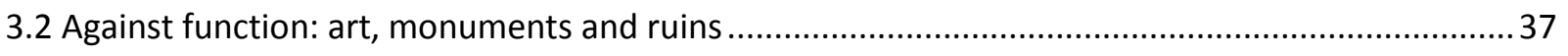

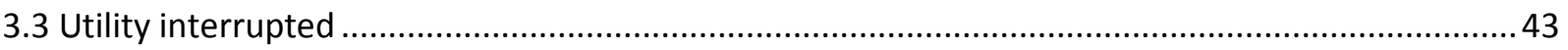

Chapter 4: A useless project ................................................................................... 44

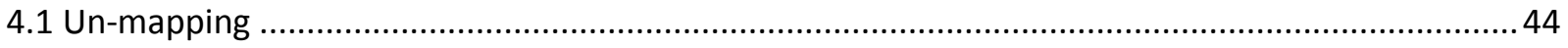

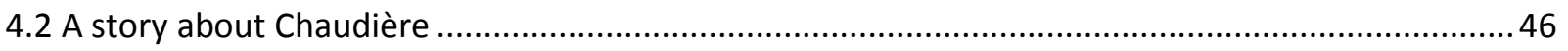

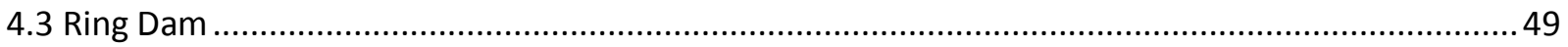

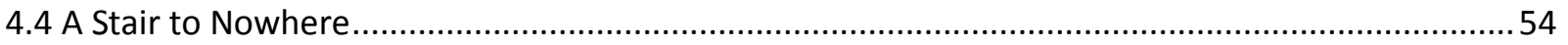

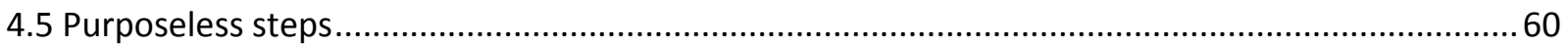

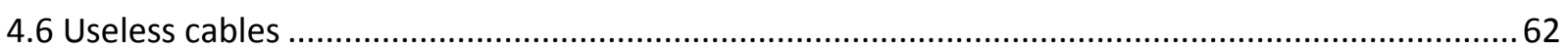

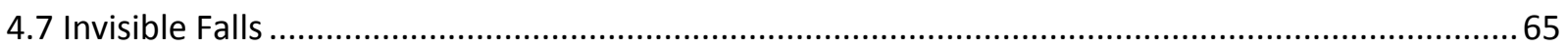




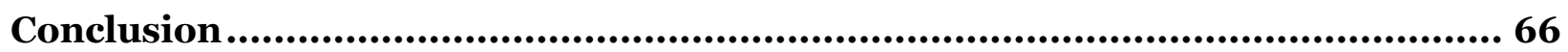

Post Script: Project Drawings ..............................................................................667

Appendix A ............................................................................................................ 77

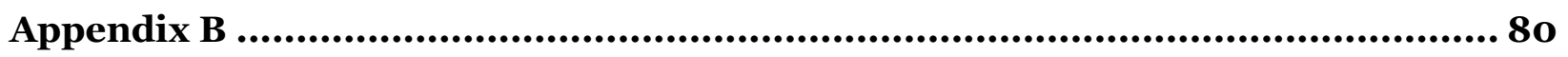

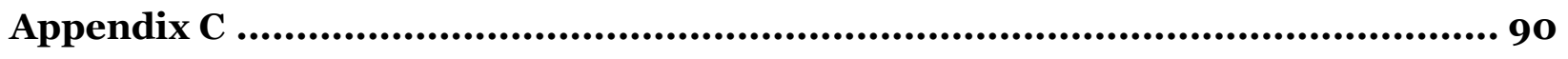

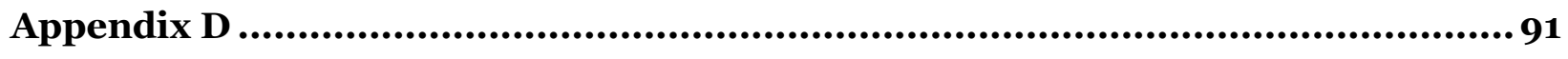

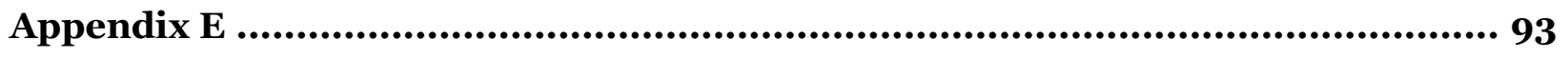

Works Cited ............................................................................................................ 94 


\section{Illustrations}

Figure 1 Gordon Matta-Clark, Reality Properties: Fake Estates, ....................................14

Figure 2 Ethan Eisenberg, Toronto Pride Parade...........................................................19

Figure 3 Maps of the center of Ottawa getting in the way of each other ......................... 23

Figure 4 Terry Atkinson and Michael Baldwin, Map To Not Indicate... ........................ 25

Figure 5 Lewis Carroll, Ocean Chart, The Hunting of the Snark.................................... 25

Figure 6 Map of Sensation(s) for the Chaudière/Asticou Falls .................................... 27

Figure 7 Paper model of Map of Sensation(s) ......................................................... 27

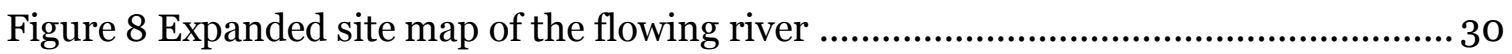

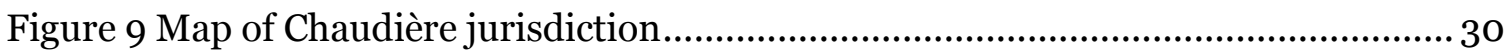

Figure 10 Margaret Atwood, The Ottawa River by Night ............................................ 32

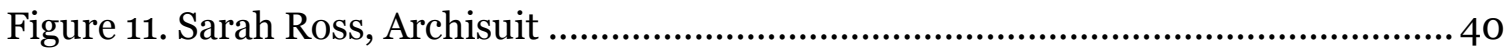

Figure 12 Didier Faustino, Stairway to Heaven........................................................... 41

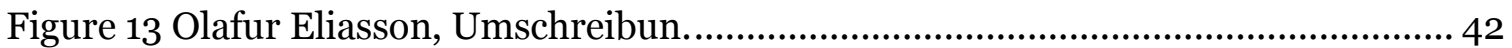

Figure 14 Spatial and historical map of Chaudière and Asinabka................................ 48

Figure 15. Photo sequence along Booth Street Bridge ..............................................50

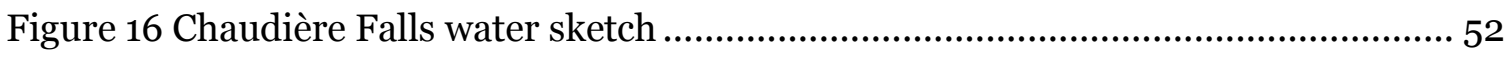

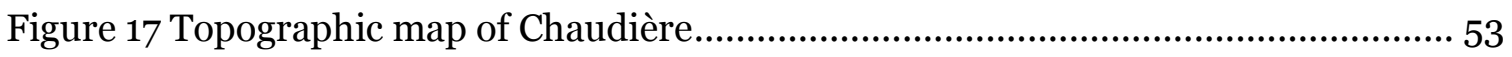

Figure 18 Ring Dam axonometric sketch with Stair to Nowhere .................................. 54

Figure 19 Ring Dam operational, section and structural sketches ............................... 56

Figure 20 Axonometric sketch, Stair to Nowhere .....................................................57

Figure 21 Axonometric of structural connection ....................................................... 58

Figure 22 Axonometric sketch of stair tread and railing ........................................... 59

Figure 23 Layout diagram for cables connecting stair to river..................................... 63

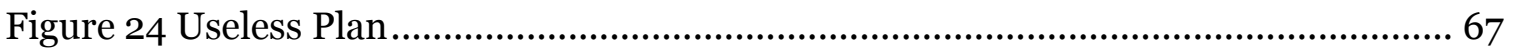

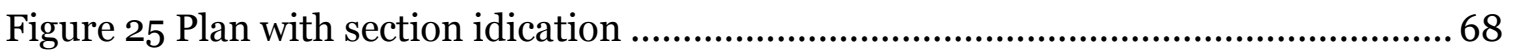

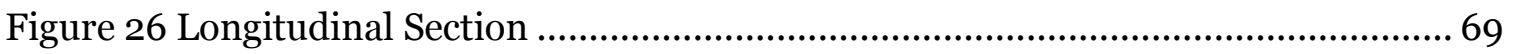

Figure 27 Longitudinal Section.............................................................................. 70

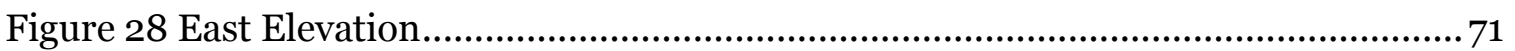

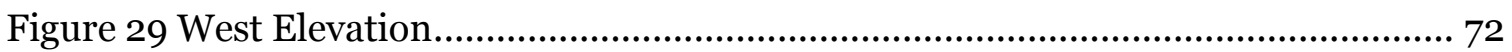

Figure 30 Axonometric with section cut and Ring Dam .......................................... 73

Figure 31 Axonometric Stair detail ....................................................................... 74

Figure 32 View Down River Stair ........................................................................ 75 


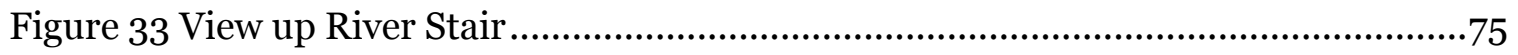

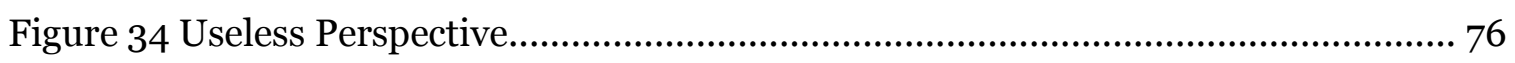

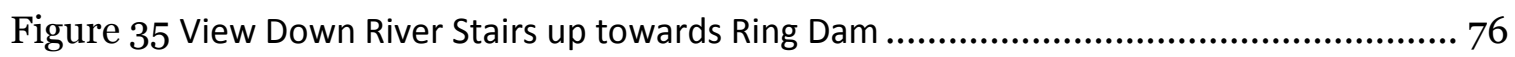

\section{Appendixes}

Useless Concept Mappings ..............................................................................

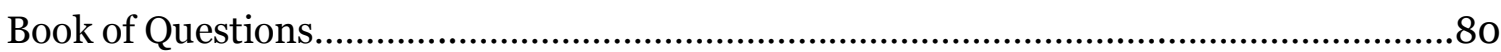

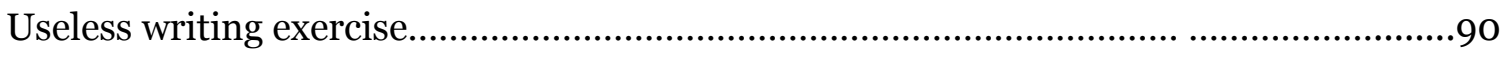

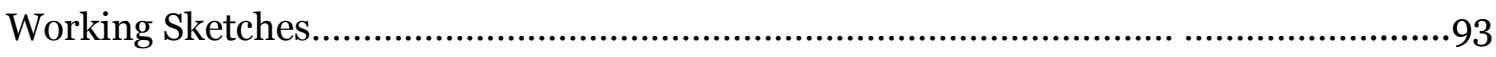

Chaudière Map of proposed publicly accessible waterfront.........................................94 


\section{Introduction}

One might already be asking, but why then 'useless' architecture? What is this subject and does it have any substance, whether weighty or irreverent matter, for if we wished to question this research from the outset we would suggest immediately that this cannot quite be 'serious'. We would then ask the reader to begin again and suspend judgement until consideration has been given to the matter of uselessness in architecture.

What then are we proposing? We are asking the reader to follow in a kind of theatre of the absurd; to ponder a real necessity to understand the relevance of uselessness, and to attempt to re-centre architectural concerns beyond utilitarian functions and economic value. And if we, for a moment, remember that architectural education allows and even indulges our imaginations, through theoretical speculations that are not reduced to mere everyday practice, we can then enter a very serious play, where some of us may indulge our imaginations more than others. It is in this spirit of indulgence that we begin this speculation into the 'useless' in architecture.

This presents one of the essential contradiction of our enquiry into useless architecture. The thinking is embedded in the useful structure of an academic pursuit, striving to be a function of critical thinking and design, however its heart beats to a poetic rhythm. Complex questions begin to reveal themselves. How does one demonstrate the value of useless things without discarding useless ideas? How does one think through useless spaces with useful tools? Is it possible to design 
uselessness, or is it merely a by-product of useful thinking? Or is it even possible that for something to be truly useful it has to contain the seed of uselessness within itself? Can we conceive of light without darkness, or of any concept without understanding its contrary?

\footnotetext{
${ }^{1}$ This document is full of questions because the process of questioning has been an integral part of this design research. Included in Appendix D is an example of a Book of Questions produced during the research as both a free thinking space, but also a restrictive challenge. All entries in the Book of Questions are written as questions, and each page begins with the same question. The example included in this appendix is framed by the question 'What can architecture do?' While this question is not central to the questions driving this specific research, it deeply informs my engagement with architectural research as a whole.
} 


\section{Chapter 1: Towards a useless theory}

This document will attempt to develop a number of maps ${ }^{2}$, however, many of them may be quite useless, and although we will begin in the terrain of utility, the ground may be far from solid. A series of intellectual vignettes will lead us through ideas from Martin Heidegger, Hannah Arendt, Jeremy Bentham and Adam Smith in order to sketch out various perspectives on instrumentality, utilitarianism, utility and use. This may be the first useless map. While it will attempt to outline a coherent critique of utility the result demonstrates that the terrain is far from clear.

\subsection{Instrumentality embedded in the material world}

Martin Heidegger's Question concerning technology puts forward that the essence of technology lies outside the machine itself and in the 'enframing' of reality as a standing reserve. (Heidegger 1977) A dam on a river changes the running water from river to resource. (Heidegger 1977) The essence of technology is how it transforms the earth around us into utility. That is to say, it is defined by its use, by its capacity to be employed for a purpose. Value is no longer intrinsic, it is instead relational, oriented towards ends that are outside of themselves. Everything is a means to an end that is not within itself.

Heidegger's reasoning in the essay pushes beyond the view of technology as a collection of tools and machines that are simply means to ends, suggesting instead that it is a way of thinking that instrumentalizes the world itself. If we wish to resist this thinking, to re-balance our perspective and shift away from the

\footnotetext{
${ }^{2}$ Early sketches of conceptual maps that shaped this chapter are included in Appendix A, B and C.
} 
'enframing' of the world as standing reserve, what relationship do we have to the material products of technological thinking? For instance, in the case offered by Heidegger of the dam and the river, is there a site of this reframing? Is it within the dam? Does it begin in the plans for the dam? The components? Its history? How do we locate it? And if we want to deinstrumentalize the river, how and where do we begin?

\subsection{Utility and meaning}

Political philosopher Hannah Arendt, a student of Heidegger, takes up a similar critique of utility in her chapter on work in The Human Condition. She suggests the theoretical opposition between 'utility' and 'meaningfulness', reflected in language through the phrases 'in order to' and 'for the sake of'. Homo faber, the maker of the world of things we inhabit, is driven by a utilitarianism which prevents them from understanding the difference between these essential concepts.

It is "for the sake of" usefulness in general that homo faber judges and does everything in terms of "in order to." The ideal of usefulness itself, like the ideals of other societies, can no longer be conceived as something needed in order to have something else; it simply defies questioning about its own use. Obviously there is no answer to the question which Lessing once put to the utilitarian philosophers of his time: "And what is the use of use?" The perplexity of utilitarianism is that it gets caught in the unending chain of means and ends without ever arriving at some principle which could justify the category of means and end, that is, of utility itself. (Arendt 2006)

Arendt's concern for the hollow condition of pure utility existing in homo faber is to highlight both its power and its danger. The utility of homo faber is in the essential role of making our world of things; the material that frames our most essential human activities - our capacity to speak and act and appear to each other. 
The "doing of great deeds and the speaking of great words" will leave no trace, no product that might endure after the moment of action and the spoken word has passed. If the animal laborans needs the help of homo faber to ease his labor and remove his pain, and if mortals need his help to erect a home on earth, acting and speaking men need the help of homo faber in his highest capacity, that is, the help of the artist, of poets and historiographers, of monument-builders or writers, because without them the only product of their activity, the story they enact and tell, would not survive at all. In order to be what the world is always meant to be, a home for men during their life on earth, the human artifice must be a place fit for action and speech, for activities not only entirely useless for the necessities of life but of an entirely different nature from the manifold activities of fabrication by which the world itself and all things in it are produced. (Arendt 2006)

For Arendt, action and speech are meaningful and intrinsically valuable. They stand in opposition to utility in the sense that they must be driven by our sense of 'for the sake of' over the 'in order to'. In other words the meaning of action and speech is not grounded in their use, their instrumentalization, but in their uselessness.

Although Arendt offers an opposition of meaning and utility that is somewhat narrower than we are searching for, her contrast of a worldly house for our most useless activities against the basic fabrication of the world is an intriguing proposition. What physical form might distinguish itself significantly from the everyday world of making by homo faber? Is it possible to imagine something material that could stand apart from the 'manifold activities of fabrication'? Can we design an artifice that might match the intrinsic value of speech and action? If we begin, what other human endeavors with such intrinsic value might find a home there? Contemplation? Imagination? This, however, may be a curious paradox. Does the intention to build a house for contemplation or speech require too great a narrowing of purpose? Is it possible for the instrumental to house the intrinsic 
or do we need to orient ourselves towards something more indeterminate? Can we begin to indulge our imaginations in the conception of useless construction? Will this open a more interesting path all together?

\subsection{The unmeasurable value of use}

The critique of utilitarianism presented by Hannah Arendt seems to conflate two overlapping understandings of utility. On one hand we have the moral philosophy of utilitarianism associated most closely with Jeremy Bentham, and on the other, a description of the instrumental function of things. 3 Raymond Williams' describes this complicated terrain in his entry on utilitarian in his study of key critical cultural terms. He identifies traces of the word utility reaching into $14^{\text {th }}$ century English, but "The isolation of utility, as the primary test of the value of anything, belongs principally to $18^{\text {th }}$ century French and English thought." (Williams 1985) This root, which begins with Bentham, and is also found in John Stuart Mill and Henry Sedgewick, is somewhat independent from another root, which is more directly related to the production in the context of the rise of industrial capitalism. Pointing to a description of a tree by a $19^{\text {th }}$ century entomologist, Williams identifies that,

...use, by this period, had been predominantly specialized to the production of things or commodities, so that other uses of the tree needed the specialized romantic or picturesque (both significantly terms of art)... So the

\footnotetext{
${ }^{3}$ The definition of the term instrumental in the Oxford English Dictionary includes "...serving as an instrument or means" and "... serving well for the purpose; serviceable, useful; effective, efficient." (OED Online 2014) In relation to this definition it is important to consider the terms instrument and tool. They hold significantly overlapping definitions, but tool tends to describe simpler devices used intimately by the body, specifically the hand, which gives it a more open application. While the definition of instrument also covers musical territory, which gives it another kind of opening, it overlaps with apparatus and devices for measurement, making it more specific. In this sense instrument and instrumental covers our desired terrain quite closely.
} 
longstanding practice of using things to make other things was specialized by purpose, into one kind, art, and another kind, utility. (Williams 1985)

Conversely, Bentham's philosophy was not directly concerned with the instrumental potential of things, but instead focused on the value of action. He proposed a moral framework that attempted to determine an action as morally correct when it resulted in the most good or most happiness for the most people. (Driver 2009) In Arendt's critique of utilitarianism she suggests that an endless cycle of means and ends results in perpetual meaninglessness, but Bentham's philosophical considerations where still grounded in a time when utility had a broader meaning, which included both happiness and good. Bentham was attempting to create a ground for social change in the society around him, to bring a better quality of life to a larger number of people. He developed a moral philosophy that was significantly different from his contemporaries through its consideration of moral actions in relation to their consequences. One of the legacies of this thinking is the shift from the intrinsic value of moral action to the instrumental value. (Driver 2009) It is perhaps this legacy to which Arendt directs her criticism.

What ties both the object-oriented and moral understandings of utility together is their relationship to the concept of 'instrumental value'. While crossing thinking in disciplines and definitions can be tricky, it may also be interesting to add another consideration of 'instrumental value' from the field of economics. In Raj Patel's book, The Value of Nothing, he highlights a challenge first outlined by Adam Smith in understanding use value, an objects value in use, over exchange value, what an object or your labor is worth in exchange for something else. (Patel 
2009) Patel identifies late $19^{\text {th }}$ century neoclassical economics as a significant shift away from the complexities of use value. He describes the difference as "... not between their explanations of price, but in their concepts of usefulness - Jevons and the neoclassical economists have an abstract and quantitative utility, while Smith has a qualitative idea of value-in-use" (Patel 2009) Patel is suggesting that the dominance of exchange value, as an increasingly complicated system of value, is at least partly based on its capacity to be measured. Let us think through a simple object, such as a shovel, to outline the difficulties in understanding value. Our economic system has difficulty in understanding, or at least accounting for, the value of the shovel in a broad sense. The value it can most easily measure is the value the shovel can be exchanged for, and this is most often described in monetary value. This exchange value has little capacity to measure what you can do with the shovel. We may be able to apply a formula to measure the wear on the shovel, its capacity to produce holes, and even what the exchange value of those holes where, but with all this we would still have no mechanism to measure how we feel about the shovel.

This exploration of use and exchange value helps clarify, or perhaps more accurately demonstrates the difficultly in thinking about uselessness. Smith originally described a complex and qualitative character of use in an economic context, and Patel suggests that its complexity is significant enough, its value somewhat unmeasurable and that the current economic system seems to work around this unpredictable concept. Value then, in the context of economics, has been reduced and focused beyond the simple instrumental capacity of an object, 
or even person, and has become completely relational. This is a very important observation. Our most frequent and everyday transactions exist in a framework dominated by a completely relational system of value. This seems to be a clear echo of Arendt's critique of utility, and the positioning of utility as meaning generating only meaninglessness. While value and meaning are not interchangeable as concepts, the importance lies in the idea that both critiques draw attention to the challenges of understanding the intrinsic and the resulting shift towards the instrumental. This is even more significant in Heidegger's proposition that the essence of technology is the instrumentalization of the world itself. In this terrain, the intrinsic and unmeasurable, or hopefully the poetic and vital, but at least the creative and obscure potential of uselessness begins to emerge. How can uselessness help reassert the unmeasurable qualities of objects? How and where do we begin in order to deinstrumentalize the world? What useless ideas can we contribute to this process? 


\section{Chapter 2: Useless space}

\subsection{Is useless somewhere?}

The previous section attempted to outline a critique of utility, a purposeful thinking that sought to clearly map a political and philosophical terrain, but does this get us anywhere? Or perhaps more importantly where, exactly, are we trying to get to? In thinking through such an indulgent subject do we risk arriving somewhere completely useless? Is this a problem? Experimental composer and musician John Cage offers the following poetic consideration of these questions. As he arrives at the middle of his 1959 Lecture on Nothing, he observes4:

More and more nowhere.

goes on
I have the feeling that we are getting

$$
\text { Slowly }
$$

we are getting nowhere pleasure

It is

only irritating to think one would like to be somewhere else. (Cage,120)

Cage's talk is composed like a piece of music. It moves through time. The text is placed carefully on the page. Useless spaces of various and irregular length evoke an unusual voice, pausing irregularly in its thinking. The words go nowhere at a specific time, but end up somewhere; all the while trying to concentrate on the now. In reading or listening to the talk, its sum effect is neither nowhere nor somewhere, but rather it is in the tension which lies between the two. This tension

\footnotetext{
${ }^{4}$ John Cages' Lecture on Nothing is composed like a piece of music, and so it includes spacing on the page to guide the reader through. The structure on the page not only helps translate Cage's intention, but also emphasizes a spatial aspect of his consideration of nowhere.
} 
is shared with Cage's many explorations of silence, including one of his most wellknown pieces 4"33" which involves an ensemble on stage not playing for four minutes and thirty three seconds. The conceptual motivation behind 4"33" could be interpreted as a presentation of silence. However, through the indeterminate aspects of the sound of spaces around us, the result is an altered experience of listening. Cage's work seems to ask, again and again, this question, how when invoking the impossibility of nothing or silence can we also acknowledge the 'worthwhile'?

Incidentally, George Perec, in Species of Spaces considers a space without use. "For all my efforts, I found it impossible to follow this idea through to the end. Language itself, seemingly, proved unsuited to describing this nothing, this void, as if we could only speak of what is full, useful and functional." (Perec 2008) Perec wrestles with thinking games to try and understand and envision this impossible situation. He lets his mind wander, invokes Escher and Magritte or imagines a vast mansion with an incredible array of rooms all with a single function with the exception of one. He searches his mind in vain to find that room. Throughout these considerations there is a pregnant tension similar to Cage's lecture. Perec relishes in the understanding that the impossibility of the task does not render it fruitless.

The small chapter on a space without use is an exception in Species of Spaces. Beginning from the space of the page and moving outward through our everyday places Perec brings a detailed but unique account of the very real spaces we inhabit. Each entry seems to begin with descriptive task of the material of our 
world, or put differently the material that frames our world, and through the words of Perec a new understanding of the world between and in that existing material is revealed. However, in this section the material does not exist, neither as object or model. If Perec cannot conjure its image, can we search for it? Where will we find it?

\subsection{Not unused, not misused, not yet to be used, but useless}

Can we find useless space in the city? What does that mean? Is it unused space or not yet used? Is it forgotten or discarded or already used up? Turning to the work of artists in the spatial realm may be helpful in gaining perspective on the concept of useless space in the city. In his project Reality Properties: Fake Estates Gordon Matta-Clark engaged with the process of purchasing left over parcels of land in New York City. Matta-Clark identifies and acquires five tiny properties of varying size, commonly called 'gutterspace'. The first component of the work consisted of minimal drawings, the documentation of its purchasing transactions and photo documentation of the land itself. Matta-Clark was exploring the process of property ownership in the city, as well as the notion of what is leftover or what remains. Through this, he discovered that many of the purchasable sites where inaccessible, describing this as “...an interesting quality; something that can be owned but never experienced.” (Lee 2001)

Reality Properties: Fake Estates is an interesting exploration of the tension between the real administrative aspects of property ownership and the futility of the process of purchasing land that one cannot access. Like Cage's nowhere and Perec's useless room, Matta-Clark's inaccessible property opens up our 
imagination and encourages us to reconsider the possibilities of his futile endeavour. What is exciting about Matta-Clark's project is that he is searching for useless space amongst the very useful materials of our world. He draws out new potential of useless space in the city through his engagement with the administrative processes of property ownership. The properties take on new meanings through his work, but that meaning is not clear. Does Matta-Clark want to liberate the properties for return to the public realm? Does he want us to lament what little is left of the city? To draw attention to the useless hidden in the margins of useful real estate? Or is it, as the name implies, to create an imaginary terrain containing a richness unknown to us or simply a fake estate to house unreal desire? 5

\footnotetext{
${ }^{5}$ The work was not fully realized before his pre-mature passing in 1978 at the age of 36, and so even drawing on the artists' suggestion of intention is still short of its realization through their hands. Clark is noted to have considered the sale of Fake Estates as an artwork might have also included the sale of the land itself. (Lee 2001) This raises an interesting question, is the spirit of the artwork undermined by its entrance into a commercial context as an art object? How do its' meaning and value alter once converted into a commodity again?
} 


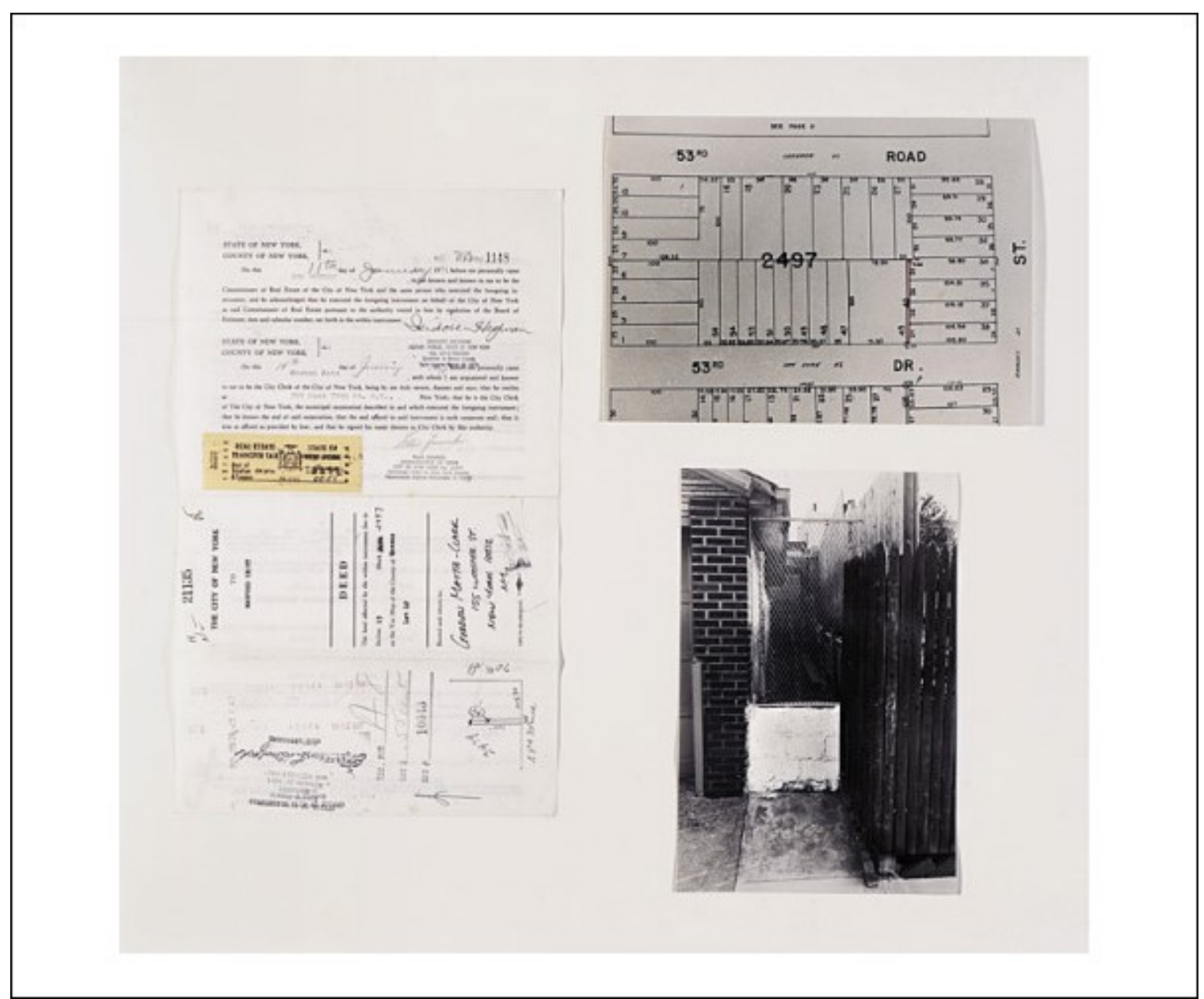

Figure 1 Gordon Matta-Clark, Reality Properties: Fake Estates, Little Alley Block 2497, Lot 42, 1974 (Lee 2001)

Fake Estates brings together the concept of private land and its administration with certain elements of public space via the domain of the art world. At this intersection Fake Estates is exploring the process by which the utility of land ownership might produce useless space, and how this space may become a meaningful work of art through its uselessness. Beyond the notions of uselessness explored in this work, Fake Estates also offers interesting questions about the concept of public space and how the useless is sometimes born in the margins of the useful. How are these margins traced? Are these meaningful or is the spontaneous generation of useless space the hallmark revealing the paradox of 
utility? The material of the work is not formally in public, but Clark blurs the boundary of public and private through his efforts to bring the material into the public view through the art world. There are complicated questions around what makes public space public, and a more elaborate exploration is needed before understanding useless space in the city.

\subsection{Public space}

This elaboration on the understanding of public space is influenced by two significant readings of public space and its value; one may be best exemplified by the writings of Hannah Arendt as outlined in The Human Condition and the other by those of Richard Sennett in his more recent writings and speeches. Political theorist Hannah Arendt describes the place of public space as essential for the maintenance of the 'space of appearance', housed by the 'common world'. Although she defines this space quite ephemerally, meaning the space is created in any place where we are together and speech and action occur, our togetherness is nevertheless of unmeasurable value for our political expression and thus for the expression of our complete humanity. Sociologist and urban theorist, Richard Sennett, a student and friend of Arendt, employs an overlapping view of public space, but suggests a more social and cultural value in public space. For Sennett, it is how we encounter strangers, and most importantly, not only our exposure to difference but how we are skilled to live with the diversity around us.

According to Arendt public “... signifies the world itself, in so far as it is common to all of us and distinguished from our privately owned place in it." (Arendt 2006) For her, the public sphere is composed of two essential elements - 
the space of appearance and the common world. Where the space of appearance is the conceptual space arising between us, the common world is the constructed world of human artifice, both of things and apparatuses. (Arendt 2006) There is a spatial component to the public sphere, but it is not entirely material; the space of appearance is not a physical condition, but it is connected to our togetherness, and although the common world is not exclusively a world of things, "To live together in the world means essentially a world of things is between those who have it in common, as a table is located between those who sit around it; the world, like every in-between, relates and separates men at the same time." (Arendt 2006)

Are we not seduced to see public space as a kind of table? As an artifice that both brings us together and separates us? As a potential platform for human interaction on a more profound level - the physical place that allows for the public sphere to emerge? Its current condition, however, seems conflicted or at least confined. How narrowly can things be defined before we usher in the death of romance? In the administrative language of the city, urban planning, master plans and design documents, how does one describe the need for our material world to allow for togetherness for the sake of togetherness? If there is no goal outside of itself; if there is no metric to return a quantified value, how can it be included? What precarious position does this produce? If public space has lost intrinsic value, superseded by its utilitarian value, be it for circulation, commerce or other instrumental uses, what have we lost? If our togetherness becomes a function of something else what is left of its' potential as a space of appearance?

It is, of course, an over-simplification to suggest that the antidote to the 
instrumentalized city is useless space. However, if what is at stake is the political potential of public places, and our togetherness, not as a mass but in an ideal of humanity, both together and connected but also individual and expressive, then useless space seems not only poetic but necessary.

While Arendt places a high value on the realization of the political self and the role of public space to attain this, Richard Sennett has a complementary concern for its capacity to shape who we are, or perhaps more specifically how we are with each other. This description is taken from a recent speech given on the public realm as part of his research into openness in the urban environment.

The most important fact about the public realm is what happens in it. Gathering together strangers enables certain kinds of activities which cannot happen, or do not happen as well, in the intimate private realm. In public, people can access unfamiliar knowledge, expanding the horizons of their information... In public, people can discuss and debate with people who may not share the same assumptions or the same interests... The public realm offers people a chance to lighten the pressures for conformity, of fitting into a fixed role in the social order; anonymity and impersonality provide a milieu for more individual development. (Sennett n.d.)

It is important to consider here not only what can be expressed for the individual in the public realm, but how individuals learn to experience others. The simultaneous expression and experience of difference that helps create common ground. This basic description can help us consider the subtle differences between being in public space and simply being together with strangers. How public is a shopping centre or concert hall? Are these essentially privately-owned places of mass gathering operating largely as mono-functional consumer centers? What remains of our publically-owned spaces? How 'public' are those empty places under our collective ownership? 
The overlapping terrain between these two authors reveals different perspectives on a key concept for this exploration of the useless. For Arendt it seems that the role of public space is to house our intrinsically valuable speech and action. This focus on their inherent value opens up a space for the useless, or at the least the indeterminate, in that the instrumental value or purpose is secondary. Sennett's perspective on the value of public space seems expressly focused on its indeterminate qualities as a place of cultural development. The ideal of openness central to his notion creates a diversity of lived or at least exposed experience, and while it may be tempting to propose a purpose, this diversity may be best valued for its intrinsic qualities. The lived experience of diversity has the potential to skill us to live better together, but doesn't it reduce the value of that diversity if it is primarily understood as an instrument of public life rather than a quality?

\subsection{Narrowing of purpose and the instrumentalization of space}

The empty places in the city can be the spatial component of this public ideal. The square, the park, the sidewalk and street should contain the greatest potential for the realization of a public space. They can be a space of appearance where we can come together in our best (and sometimes darkest) moments. It is here where we can be together for the sake of being together, to declare our presence to each other, and some of the most recent political movements in North America attempt to maximize this potential. The Occupy Wall Street movement, for instance, was a not a specifically instrumental protest, at its heart it sought to assemble and make present those struggling in an increasingly stratified society. This is captured in its simple slogan "We are the 99\%" which references the 
concentration of wealth into a smaller and smaller percentage of the population ${ }^{6}$. There is no demand in this simple statement, no objection, only a declaration of presence. GLBT7 Pride parades around the world attempt a similar, although usually more colorful declaration. One of the early slogans of the Queer Movement, "We're here! We're queer!" captures the same tone of declaration as the Occupy Movement, and the elaborate and beautiful parades still contain this celebratory and non-instrumental political action.

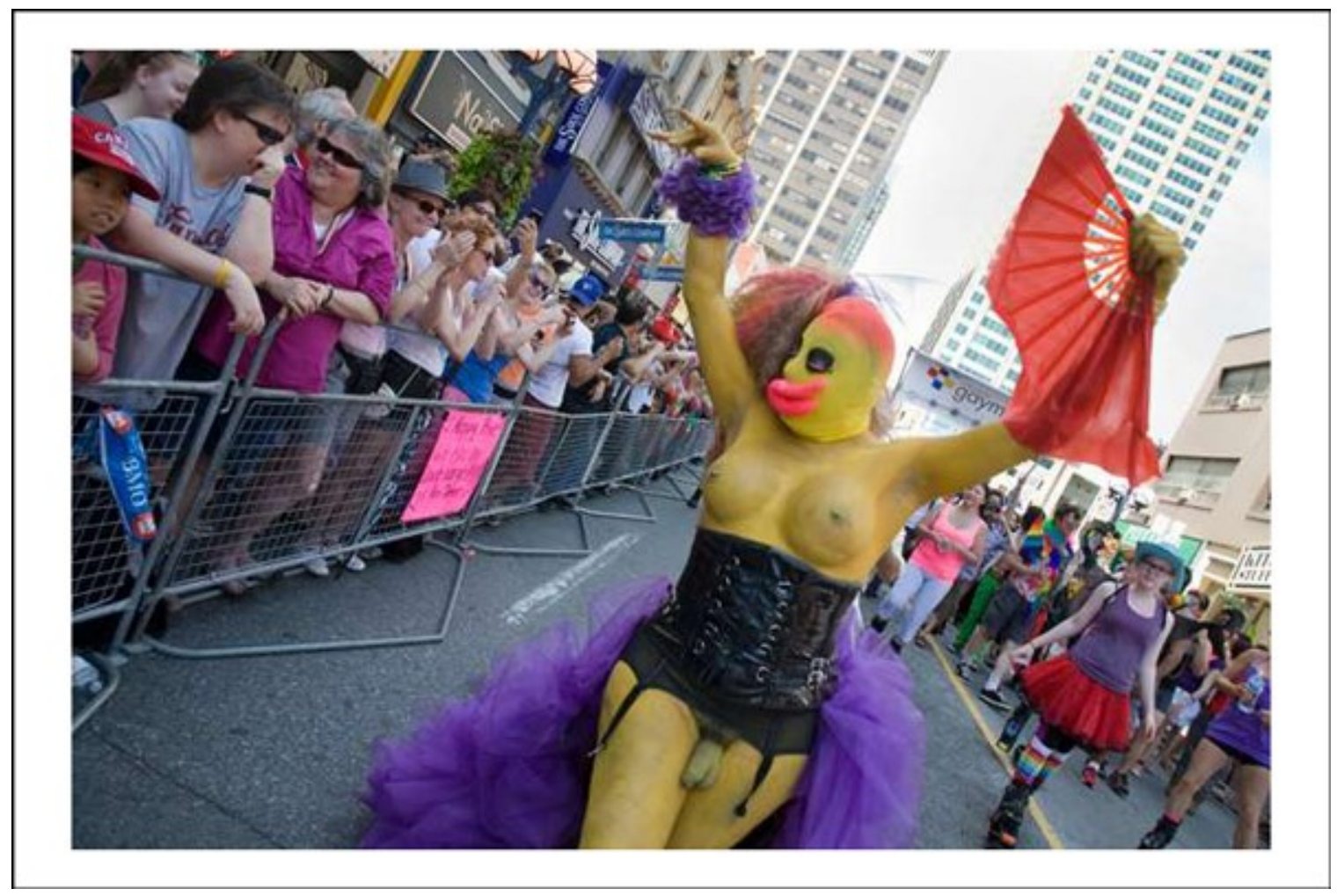

Figure 2. Ethan Eisenberg, Toronto Pride Parade. (Now Magazine 2013)

\footnotetext{
6 "We are the 99\%" is an excellent slogan that captures the spirit of this fascinating movement. In an article for the Huffington Post economist Jigar Bhatt outlines the rise of the slogan back through the Occupy Movement to a US Senator and to the research of Thomas Piketty and Emmanuel Saez. (Bhatt 2012) While the actual statistics on income inequality may be complicated, let alone the nuanced differences of class and culture, this simple message declares at the same time that it invites you to participate and be represented.

${ }^{7}$ Various organizations delineate different levels of acronyms in attempts to be as inclusive as possible. Gay, Lesbian, Bi-Sexual and Transgender is commonly represented in this abbreviation, but also may include a $Q$ for Queer or Questioning, I for Intersex or A for Ally.
} 
Is it this potential, brought to realization in these congregations of citizens, which increasingly brings public space so sharply into the sights of both private and public powers? The empty spaces of the city seem targeted, narrowed in on, closed off, and controlled. In nineteen-ninety-four geographer Steven Flusty's studied the increasing proliferation of these spatial tactics of control throughout Los Angeles. His research pamphlet, titled Building Paranoia: The Proliferation of Interdictory Space and the Erosion of Spatial Justice, categorizes five tactics that describe his 'post-public' world:

Stealthy Space is space that cannot be found, camouflaged or more commonly obscured by such view impediments as intervening objects or grade changes....Slippery Space is space that cannot be reach, due to contorted, protracted or missing paths of approach... Crusty Space is space that cannot be accessed, due to obstructions such as walls, gates and check points...Prickly space is space that cannot be comfortably occupied... Jittery space is space that cannot be utilized unobserved, due to active monitoring by roving patrols and/or remote technologies feeding to security stations. (Flusty 1994)

It may seem that this is the conversion of space into useless places, but perhaps it is the opposite that is true. Flusty proposes that the developments of these spatial tactics are a result of the increase in private control and commercial interest over open spaces combined with significant urban fear growing within the public. ${ }^{8}$ (Flusty 1994) From this perspective space is not only instrumentalized as response to fear in the city, but it risks becoming a machine for control through a narrowing

\footnotetext{
${ }^{8}$ An article from the New York Times in 1993 (around the same time as Flusty's research) highlights the reactions both anecdotally and statistically to the issues of crime. Generally, growth of fear surpasses the growth in crime rates, but interestingly the article highlights increased exposure to details of violence through an expanded media presence in their lives. The media landscape of the early 1990s would have included a significant expansion in cable television including the growing place of 24 hour news networks. (Meier 1993)
} 
of purpose; a machine in that it closes down into a specific design for a specific task? Is this another material embodiment of Heidegger's critique of the machine? In the example given in The Question Concerning Technology, Heidegger discusses the river and the dam, and the transformation of the natural world into a resource for our use. Considering space from this perspective the concern becomes not simply an individual instance of architecture becoming a machine for control, but that this thinking transforms all space into a standing reserve of control. If technological thinking is increasingly influencing our understanding of space, then how can the indeterminate, openness and diversity develop within this instrumentalized landscape?

As outlined in the thinking of Hannah Arendt and Richard Sennett, public space plays a key role in shaping our world, and both theorists embrace openeness and plurality as necessary conditions of an indeterminate public space. While neither describes a specific material vision for an ideal public space, their clear value on accessibility and diversity directly challenge an instrumental view of public space in the city. In his consideration of the material of public spaces Steven Flusty uses the phrase 'post-public world' to highlight what this instrumentalization puts at risk, proposing that the side effect of these machines of spatial control is the loss of the 'public' from the open spaces in the city. If we value the possibilities of the public world suggested by Sennett and Arendt, we must ask if there is any wiggle room remaining in our current spaces of hyperbolic usefulness? But this also raises the question of how fruitful it is to think through to an indeterminate and pluralistic public space from the perspective of utility? Is it 
an uncomfortable contradiction to consider the instrumentalization of public space as a tactic of resistance against this narrowing of purpose? How can we broaden our considerations? Is it reasonable (or at least delightfully unreasonable) to also consider the opposite - what is the potential for useless space?

\subsection{Looking for the useless with very useful tools}

How can we open the terrain of the enquiry? What tools do we have at hand to play the open potential of useless space against the use of space as a machine? How can we approach this reconsideration of a map of the useless with the useful tools of existing maps and data? Maybe if we layer the maps together? If we put them in the way of themselves will they reveal something interesting? Is this an essential part of considering the useless, to stand in the way of utility? 


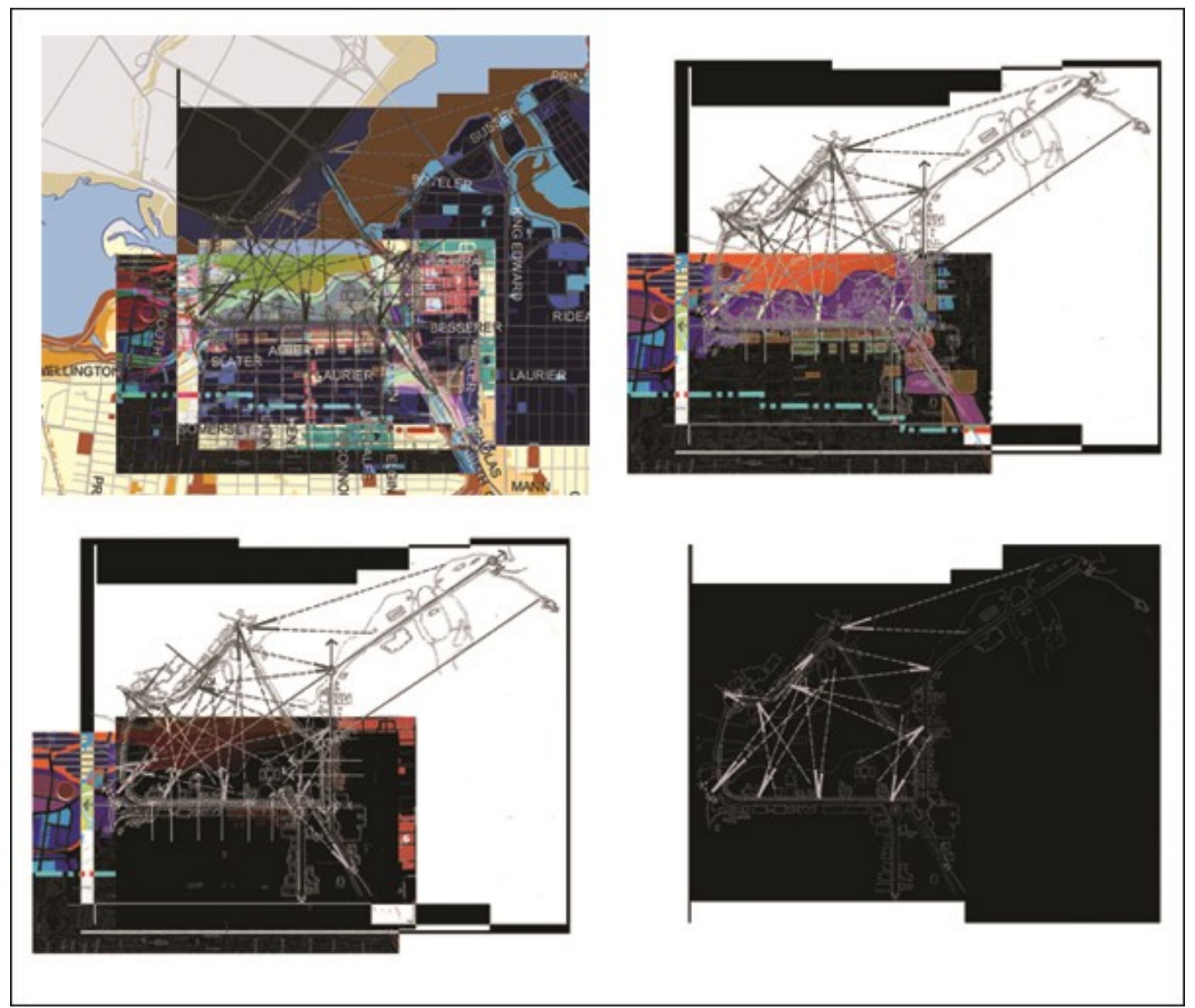

Figure 3 Maps of the center of Ottawa getting in the way of each other

Artists are always standing in the way of utility. Take Terry Atkinson and Michael Baldwin's Map To Not Indicate...9 ${ }^{9}$ This succinct work includes only two abstracted geo-political forms (the states of Iowa and Kentucky) and a list of all which has been erased from the map. Ontario, James Bay, St-Lawrence River,

\footnotetext{
${ }^{9}$ The full title of this map is Map to not indicate: CANADA, JAMES BAY, ONTARIO, QUEBEC, ST. LAWRENCE RIVER, NEW BRUNSWICK, MANITOBA, AKIMISKI ISLAND, LAKE WINNIPEG, LAKE OF THE WOODS, LAKE NIPIGON, LAKE SUPERIOR, LAKE HURON, LAKE MICHIGAN, LAKE ONTARIO, LAKE ERIE, MAINE, NEW HAMPSHIRE, MASSACHUSETTS, VERMONT, CONNECTICUT, RHODE ISLAND, NEW YORK, NEW JERSEY, PENNSYLVANIA, DELAWARE, MARYLAND, WEST VIRGINIA, VIRGINIA, OHIO, MICHIGAN, WISCONSIN, MINNESOTA, EASTERN BORDERS OF NORTH DAKOTA, SOUTH DAKOTA, NEBRASKA, KANSAS, OKLAHOMA, TEXAS, MISSOURI, ILLINOIS, INDIANA, TENNESSEE, ARKANSAS, LOUISIANA, MISSISSIPPI, ALABAMA, GEORGIA, NORTH CAROLINA, SOUTH CAROLINA, FLORIDA, CUBA, BAHAMAS, ATLANTIC OCEAN, ANDROS ISLANDS, GULF OF MEXICO, STRAITS OF FLORIDA and is loosely connected to two others titled Map of itself and Map of a thirty-six square mile surface area of the Pacific Ocean west of Oahu. (Wood 2006)
} 
Quebec, New Brunswick, Manitoba and so the list goes on of that which is not indicated. Or consider the Bellman's Map from Lewis Carol's non-sense poem Hunting of the Snark, as the crew praises the perfection found in its absence of information we reflect on the meaning of such useless representation. (Caroll 1995) What world are they trying to describe? What journey do we embark on with these navigational aids?

Neither of these maps will help you find what you are looking for. Unless what you are looking for is nothing in particular. In the case of the Map To Not Indicate... there is a sense of purpose working against utility, an attempt to express something about the abstraction necessary for cartography, but Carol's map comes from almost pure poetic nonsense. From this position it is perhaps better said that the map will help you get nowhere. And so we find ourselves again with John Cage, "... as the talk goes on we are getting nowhere and it is a pleasure. It is not irritating to be where one is. It is only irritating to think one would like to be somewhere else.” (Cage 2011) 


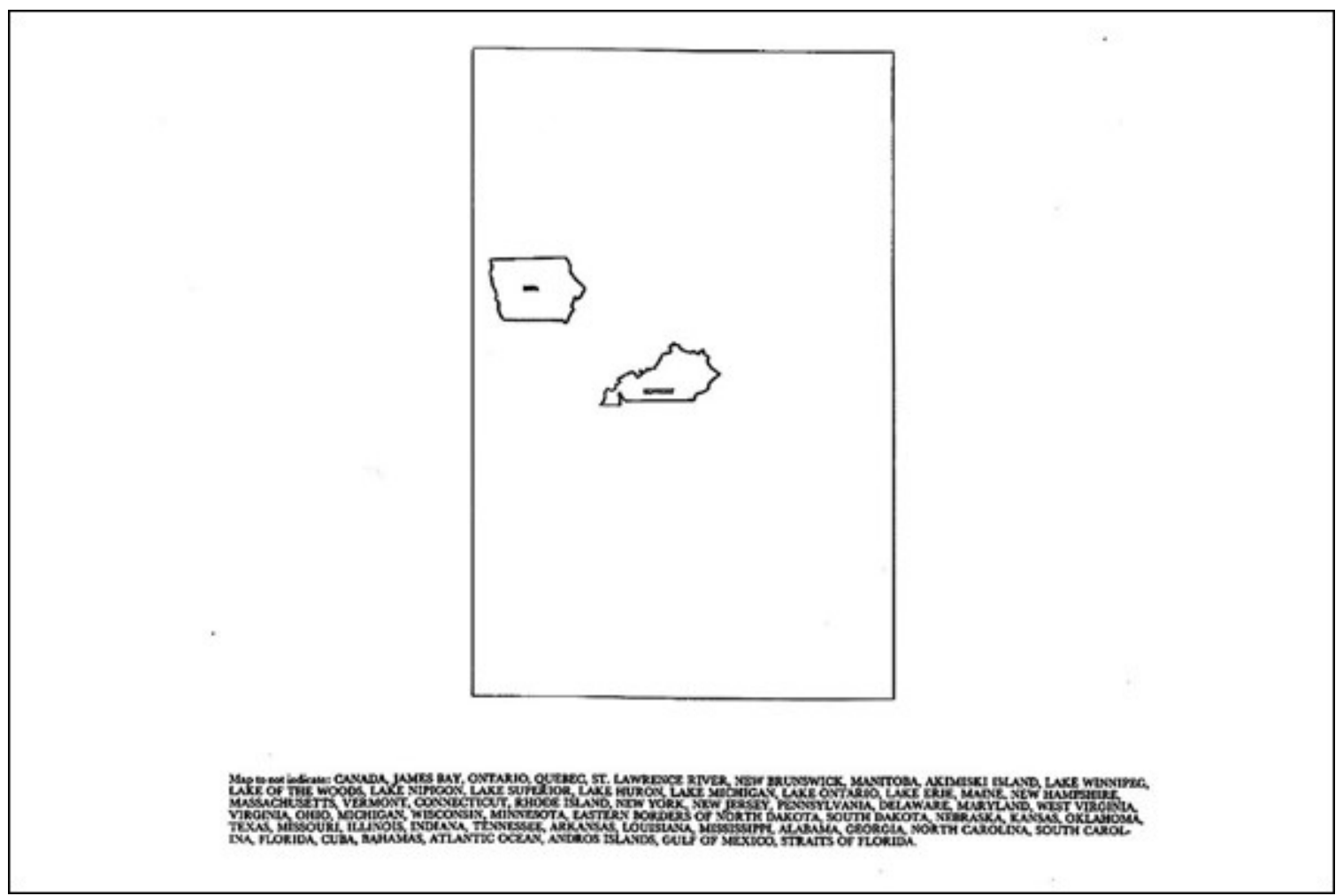

Figure 4 Terry Atkinson and Michael Baldwin, Map To Not Indicate...

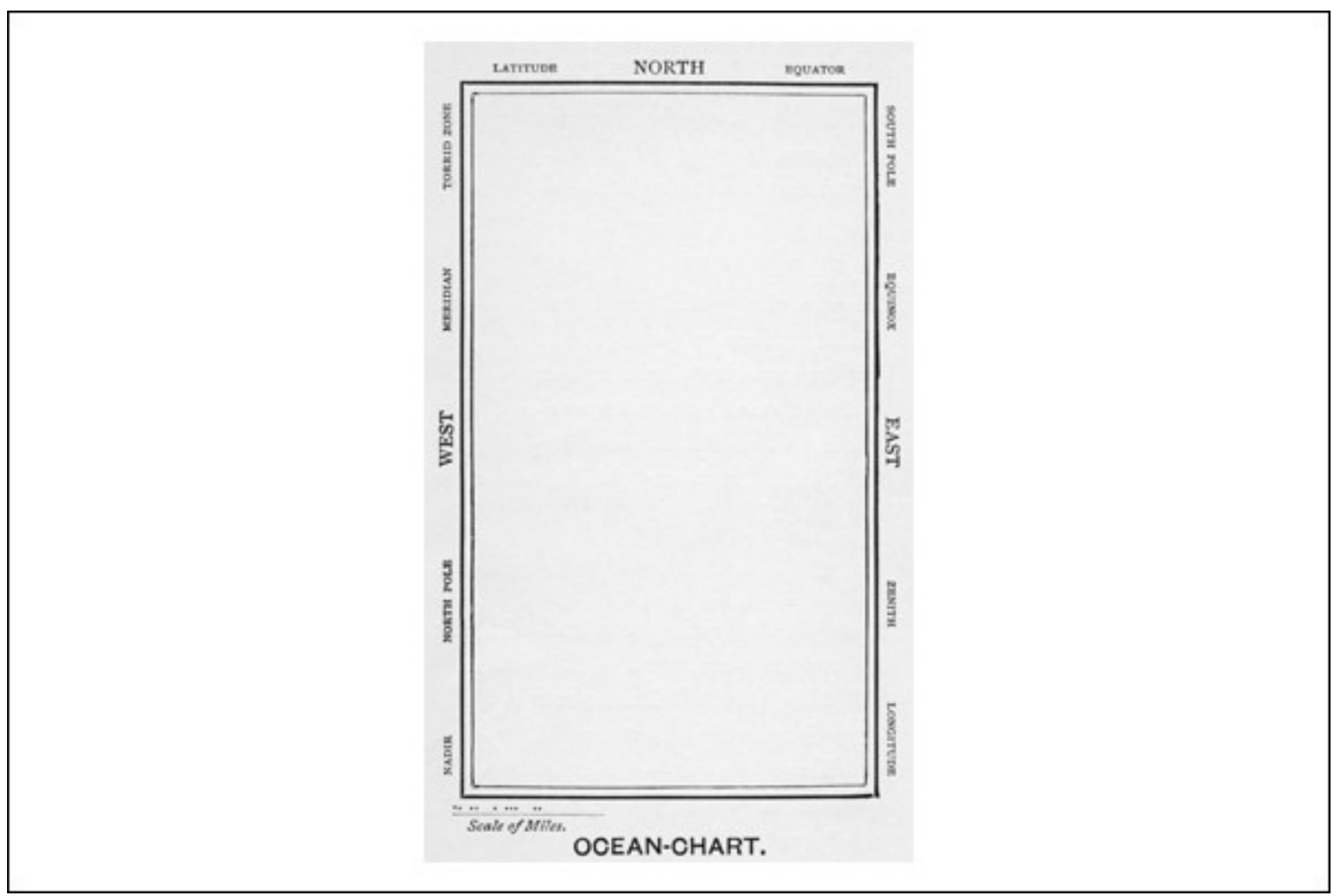

Figure 5 Lewis Carroll, Ocean Chart, The Hunting of the Snark 


\subsection{Mapping the unmeasurable}

The exploration of useless territory may require new tools. Ones that attempt to translate the unmeasurable qualities of the city, and open up new perspectives on the landscape. This research into mapping began in a design studio in collaboration with Jessie Fyfe-Loose. The focus of the studio was the Chaudière Falls area of Ottawa, and we attempted to interpret the site with a consideration of both experience and time that manifested in what we called a Sensation Map. This map included four types of representation, each containing a highly subjective interpretation or unmeasurable quality of the territory. The categories are as follows: 1) Lived - an awareness of time before the present 2) Lived/Living awareness of time before the present combined with an awareness of being in the present 3) Visual - physiological and aesthetic experience of the visual and 4) Sonic - combined physical and auditory experience of sound. We deepened the obscurity of this map by expanding its object qualities into a model. The experimental sensation map was pushed into the realm of complete uselessness and opened up to new interpretations as a site for architecture. 


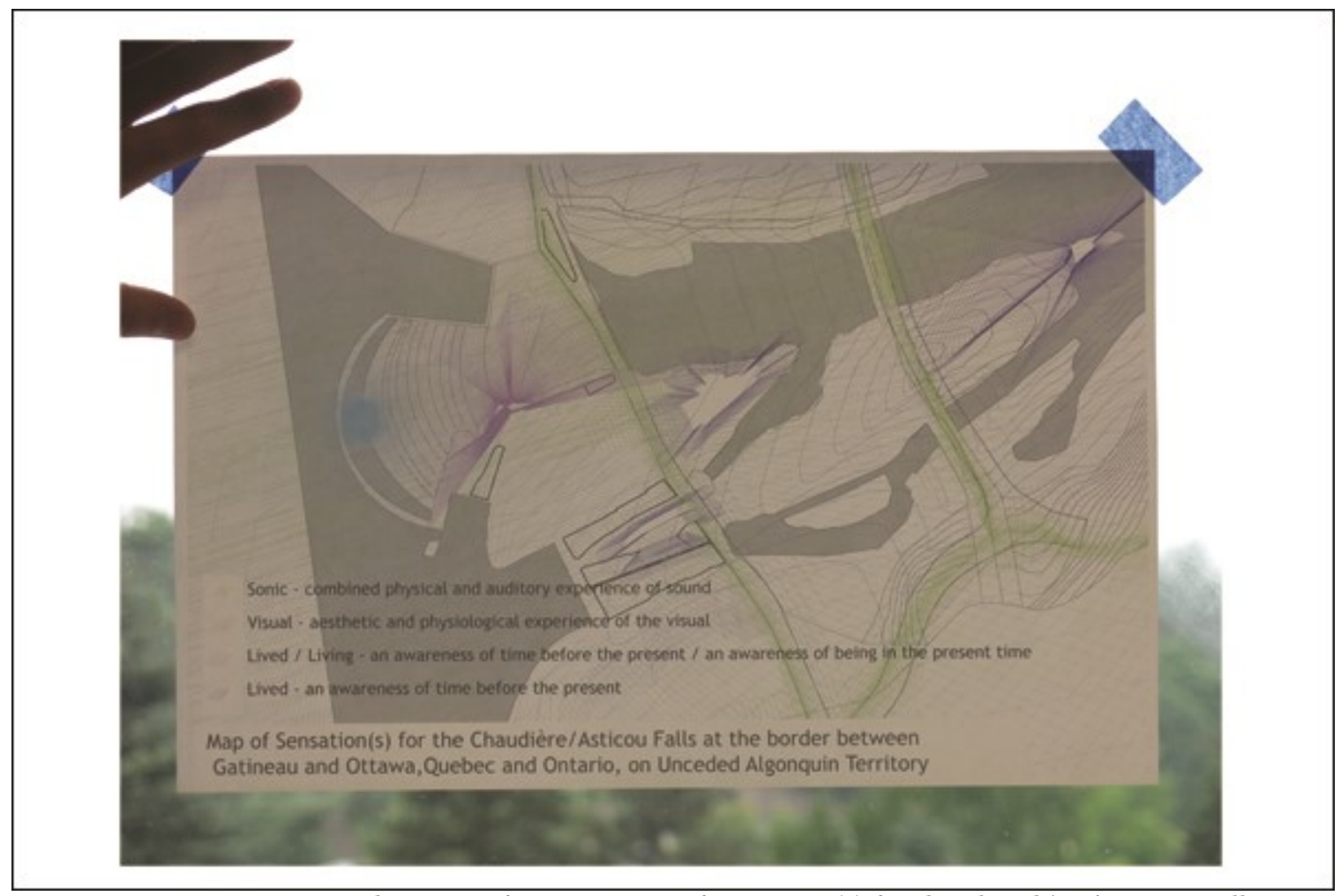

Figure 6 Ryan Stec and Jessie Fyfe-Loose, Map of Sensation(s) for the Chaudière/Asticou Falls

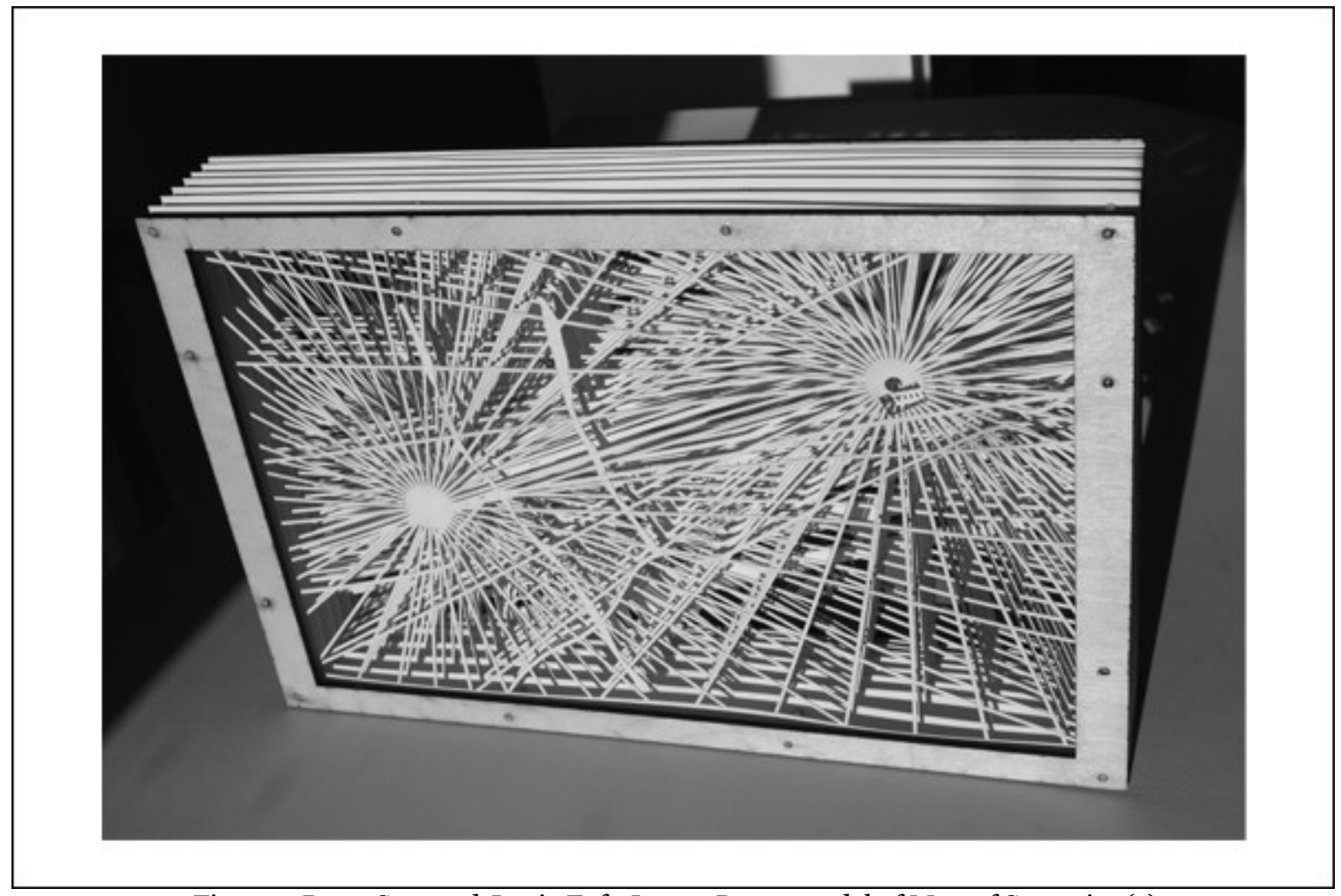

Figure 7 Ryan Stec and Jessie Fyfe-Loose, Paper model of Map of Sensation(s) 
For this research I have returned to the Chaudière Falls area, drawn to its rich complexity. Its cultural, political and economic significance is difficult to describe in its entirety, but most significantly for me, lying at the heart of the area, is the challenging collision between the instrumental and intrinsic value of this ten meter drop in the Ottawa river as it moves along its path towards the St-Lawrence River and into the Atlantic Ocean.

The Chaudière Ring Dam circles the top edge of the Chaudière Falls in order to divert water into several hydroelectric stations on the river. The Chaudière Ring Dam is very useful architecture. Its purpose is to transform the river into a resource and to use this resource for the production of electricity.

The Chaudière Falls, before the Ring Dam, were described in journals and stories of all kinds as a singularly beautiful experience to behold. ${ }^{10}$ We can understand the falls through the ecological role it plays in the life of fish or even their economic potential as a tourist destination, but I put forward that the falls are at their best, and perhaps most meaningful, when understood as essentially useless. Their greatest value is not at the service of some use or purpose outside of themselves, but instead their intrinsic value.

\subsection{A useless understanding of the Chaudière site}

If useful maps proved ineffectual in identifying useless space, what maps should I develop for a more useless understanding of the site? What tools could

\footnotetext{
${ }^{10}$ The Heritage Study of the Ottawa River contains various early description of the river and the falls as well as a selection of poetry including The Ottawa River by Wilfred Campbell of 1900, (QuebecLabrador Foundation 2005) and in an open letter published in the Ottawa Citizen Lindsay Lambert points us to the description found in the 1894 book America's Wonderlands claiming "... a more entrancing sight can hardly been found in any part of North America." (Lambert 2014)
} 
help describe the collision of the very useful architecture of the Chaudière Ring Dam and the Chaudière Falls? I offer three tools for alternative construction of the site; the first is a mapping that seeks to expand the understanding of the river as the site; the second is a map of the jurisdictions governing the site, and the third is a poem by Margaret Atwood.

The map of the river attempts to capture the incomprehensible scale of the river basin as the site for the dam. If the river is in constant movement than the question arises: How do we define the boundary of the flowing water? If the site is the flowing river at Chaudière then I propose that this drawing is the river and thus the site of the architecture as it is understood in this project.

This second map describes the multiple jurisdictions governing the site. It is a rough attempt to represent the invisible boundaries of the political and legal apparatus that control the Chaudière Falls. The goal is not to clarify the jurisdiction, but instead to spatialize it and represent its complexity. It is, in many ways, useless. 


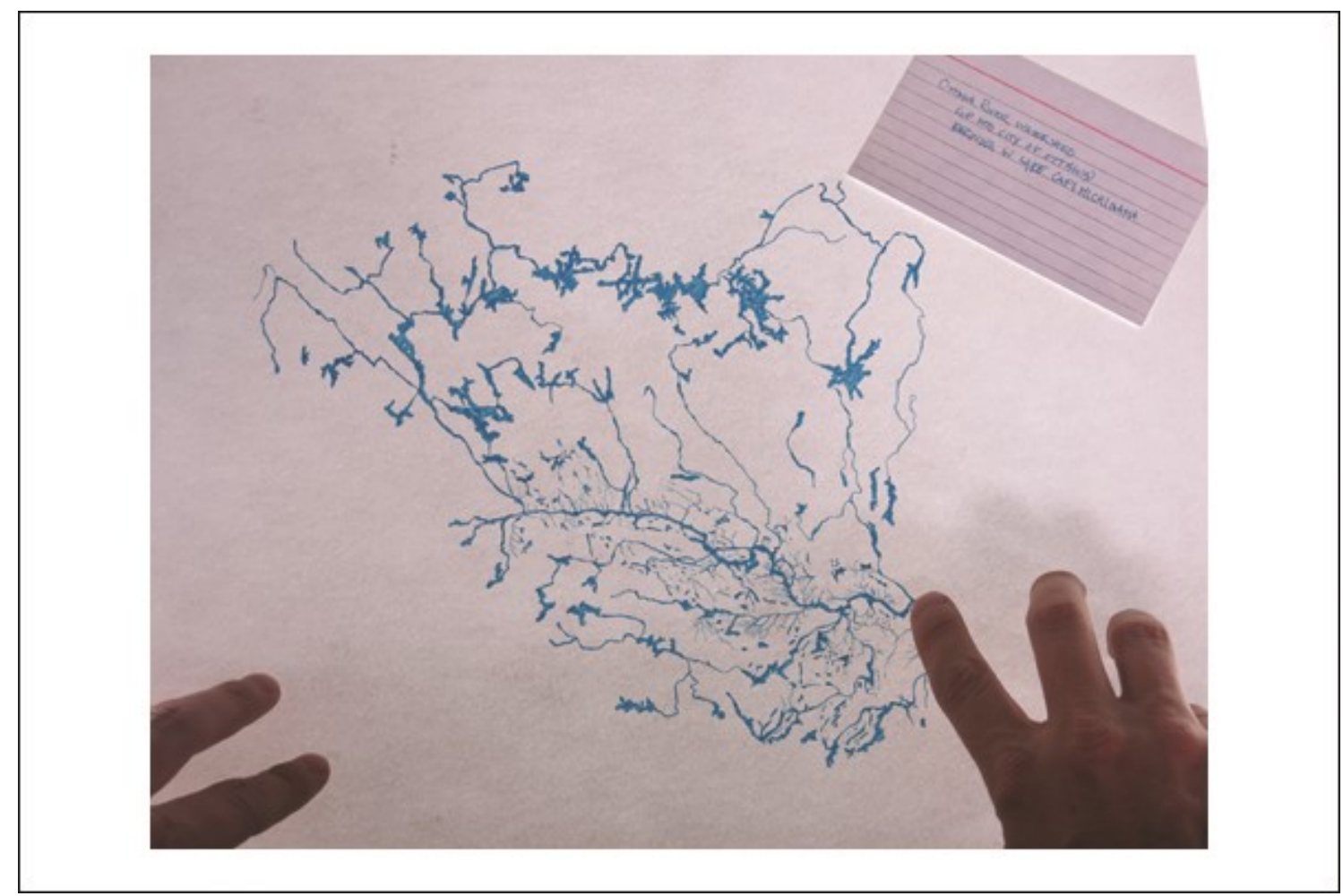

Figure 8 Expanded site map of the flowing river

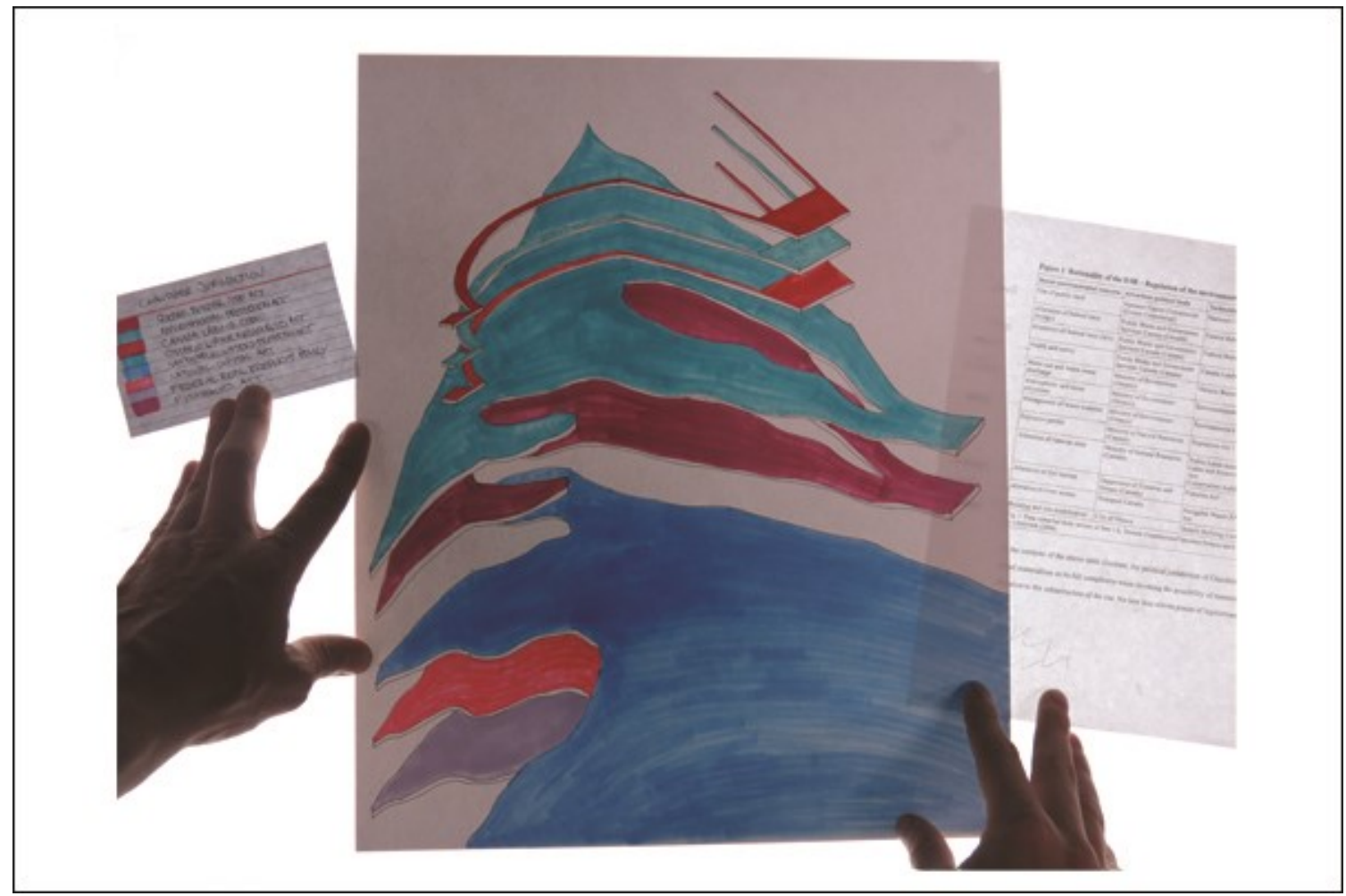

Figure 9 Map of Chaudière jurisdiction 
This jurisdictional understanding is derived from the research of Eric L. Smith. (Smith 2011) The description of the jurisdiction is also accompanied by the "technology of governance" associated with each instance. Smith was attempting to describe the regulation of the environment at Chaudière with the specific goal of revealing the most significant absence - the Algonquin peoples. This absence is both administrative and physical. Not only have the people long displaced from this space, their voice and their capacity to act within these relationships is removed on this key cultural site. Beyond this, if these original peoples could be included once again in this process what would that look like? How do you incorporate a completely different world view, one that cannot measure the value of Chaudière in legal or economic terms, into the now dominant social and political structures of the place? This study cannot draw a new map of engagement, and it certainly cannot speak for any peoples, but if it can open up any paths towards inclusion perhaps we can call this some measure of success.

The third interpretation is not a map of any recognizable kind, but rather a poem by Margaret Atwood entitled The Ottawa River at Night. Including the poem for consideration is not a call for picturesque praise of the river, but rather to highlight the capacity of language to illuminate a specific and emotional experience. This is not necessarily in opposition to the abstract utility of your average cartography, but about an overlapping experience of place. The poem can be understood as a map towards an indeterminate location across an imaginary terrain. 
THE OTIAWA RIVER BY NIGHT

In the full moon you dream more.

I know where I arm the Ottawa River

far up, where the dam gors across.

Once, midstorm, in the wide cold water

upatream, two long canoes full

of children tipped, and they all held hands

and sang till the chill reached their hearts.

I suppose in oar waking lives that's the best

we can hope for, if you think of that moment

stretched out for years.

Once, my father

along a lake neas here

at nighe, with the trees like a pelt of dark

hackles, and the waves handly moving.

In the moonlight the way ahead was clear

and obscure both. I was twenty

and impatient to get there, thinking

such a thing existed.

None of this

is in the dream, of course. Just the thick square-

edped shape of the dam, and eastwart

the halls of sawdust from the mill, gleaming as white

tos

as dunes. To the left, stillness; to the right,

the swirling foam of rapids

over sharp rocks and snags; and below that, my father,

moring away downstream

in his boat, so skilfully

although dead, I remember now; but no longer as old.

He wears his grey hat, and evidently

he can see again. There now,

he's around the corner. He's heading eventually

to the sea. Not the real one, with its sick whales

and oil slicks, but the other sea, where there can still be

safe artivals.

Only a dream, I think, waking

the sound of nothing

Not nothing. I heard: it was a beach, or shore,

and someone far off, walking.

It ahways takes a long time

to decipher where joure

Figure 10 Margaret Atwood, The Ottawa River by Night (Atwood 1995) 
These three 'maps' describe the collision of different understandings of the site. One is a useful map of a different understanding of the river that is both expansive and holistic. The second, an essentially useless depiction of the complexities of the legal and administrative control of the site, and the third offers the question, can we understand a poem as a map? Is it successful at being simultaneously human and abstract? Can we consider this a useless but meaningful map? An architectural proposal for this site will attempt to confront this space where the useless and utility encounter each other. 


\section{Chapter 3: Useless architecture}

\subsection{Architectural instruments}

Jeremy Bentham creates a fascinating intersection between philosophy and architecture. A key figure in the definition of utilitarianism in the late eighteen century, he also conceived of the Panopticon prison concept as an embodiment of his moral position. He was not the first or only of his contemporaries to deeply consider an instrumentalization of architecture, particularly in the realm of prison reform, as they explored the potent possibilities of what architecture could do. (Bergdoll 2000) In the context of his peers in psychology Bentham saw the human self as a tabular rasa that could be continually remolded. (Baird 1995) The Panopticon was guided by early concepts of behavioural modification derived rather than corporal punishment, and was guided by this core belief in the malleability of a person. As an architectural manifestation of his philosophy his complete confidence in the design is perhaps best considered through his own words.

Morals reformed - health preserved - industry invigorated - instruction diffused - public burdens lightened - economy seated, as it were, upon a rock - the Gordian know of the Poor Laws not cut but untied - all by a simple idea in Architecture! (Baird 1995)

In his discussion of the Panopticon in his book, The Space of Appearance, an examination of modern architectural theory framed through the ideas of Hannah Arendt, George Baird suggests there are very few statements that demonstrate such a dramatic and total belief in the instrumental capacity of architecture. (Baird, 174) Baird places him in the company of pioneer Frederick Taylor and his "radical instrumental conception of the labor process" (Baird 1995) Despite the eloquent disgust for what the Panopticon represented in architecture expressed by 
the likes of Augustus Pugin and Samuel Coleridge, or the more general and passionate challenges to the industrial revolution by those like John Ruskin and William Morris, Baird suggests that,

...the instrumentalization, both of things and of men, that had been so powerfully launched in the late years of the eighteenth century continued to hold sway over the dominant evolution of ideas in the western world well into the middle of the twentieth. (Baird 1995)

Baird goes on to outline what he see as the principal challenges facing architecture at the closing end of the twentieth century, "to formulate a conception of architecture that is indeed deinstrumentalized, yet also appropriately reinstituted." (Baird 1995) He further elaborates on what he sees are the possibility for new technological developments to be part of this process of deinstrumentalization. It is outside the scope of this research to explore the relationship between technological developments and instrumentalization, or challenge Baird's cautious optimism. However, the theoretical framework developed in Chapter 1 questioned technological thinking as a process of instrumentalizing the world around us. While Baird challenge for architecture is an important one, this research will also continue to follow Heidegger direction, and search for ideas to balance against the effects of technological thinking.

In this research, considering what it might mean to find an architecture that is deinstrumentalized, different questions emerged. How can a project be open and invite multiple readings? How can architecture open itself up while at the same time position itself as a kind of resistance? If a project is not instrumentalized what is it? Clear answers are rare in the work of John Hejduk, but his approach to architecture seems to offer clues on how to think differently about these questions. 
Hejduks projects feel like architectural fiction constructing character buildings, spirits, people and questionable machines. In the 1993 project, Soundings, and as in most of Hejduk's work, it draws on and draws out a world of architecture as what could be argued to be a useless but profound tale. Alongside the drawn lines in Hejduk's world, language, and most specifically poetry, play a key to role in the unfolding of its story. The first pages of Soundings begin with this:

\author{
She replied, \\ "Architect keep your \\ hard-edge geometry \\ I will keep my softness. \\ My breasts are \\ more beautiful \\ than church spires." \\ "Feel my body architect \\ so your plans will not be so rigid \\ listen to the sound \\ of my voice \\ so you will know \\ what volume is \\ my soul is made \\ of no substance \\ your space might be the same \\ I am made for birth \\ and you?" \\ (Hejduk 1993)
}

The Soundings project is a rather expansive document, but this position at the beginning of the journey is significant. An opposition between rationality and romance draws us into the story and challenges us with an open-ended question. What are we made for? What kind of instrument are we? She has presented her terrain, both immaterial and yielding, and so how do we present ours? Do we stand 
in opposition and claim the material and the hard? Do we blend or dance or find a place within the immaterial and the softness? Can we be comfortable in this unmeasurable terrain?

John Hejduk had published Soundings only a few years before Baird's book, Space of Appearance. Although it seems unlikely that Hejduk's work was unknown to Baird, and while it seems almost undeniably non-instrumental, is it perhaps the challenge of 'reinstitution' that excludes Hejduk's name from Baird's recounting of the later part of $20^{\text {th }}$ century architectural history? If we consider Baird's question can we conceive of something radically deinstrumentalized that could nonetheless achieve the goal of reinstitution? Does Hejduk's work rise to the challenge? Where else might we find useless ideas to help us house the unmeasurable?

\subsection{Against function: art, monuments and ruins}

There is a necessary but perhaps simple leap of thought to understand space as useless, or at least intrinsically valuable. This is particularly simple in the case of natural beauty and areas like the once grand Chaudière Falls. However, what kind of imagination is required to further understand useless architecture? Looking at Hejduks work to consider its desinstrumentalized qualities begins to open up this terrain. Can we broaden the terrain and consider the concept of the ruin, the monument and the work of art as architectural positions against utility? If their value is somehow inextricable from their non-functionality what do these useless things offer architecture?

The path to shedding the weight of functionality is unique for the ruin. In a perpetual state of loss, the architecture dissolves bit by bit and an incredible 
tension is drawn between the reminders of the past and its inevitable drift into future and further decay. Rose McAulay has explored this tension deeply in her book The Pleasure of the Ruin. In her consideration of the new ruin, architecture that stands on the emerging edge of its dissolution, she describes the drama unfolding in a house recently touched by fire,

But often the ruin has put on, in its catastrophic tipsy chaos, a bizarre new charm. What was last week a drab little house has become a steep flight of stairs winding up in the open between gaily-coloured walls, tiled lavatories, interiors bright and intimate like a Dutch picture or a stage set; the stairway climbs up and up, undaunted, to the roofless summit where it meets the sky. The house has put on melodrama... (McAulay 1966)

The house has made its first steps into ruin. Accelerated into uselessness through catastrophe, it begins to cultivate mystery in its collapsing structure. The old ruin has long distanced itself from its particular crisis. It sits at a safer distance in time to the source of its collapse, but the material decay nonetheless contains both the mystery of its past and the instability of its present. In this way the ruin invites a more imaginative but also more dangerous passage to nowhere. One could lose their footing in the shifting decay. The risks of true discovery could be felt in the body.

If the nowhere of the ruin is dangerously open, then the nowhere of the monument is questionably closed. Take, for example, Washington D.C. and its concentration of colossal monuments, not its monumental buildings but those buildings that are in fact exclusively monuments. The Lincoln Memorial is an astounding example with its overwhelmingly excessive steps, its room for a single speech and its symbolic 38 columns for each of the states of the union at the time of Lincoln's presidency. Here, architectural theorist, Robert Harbison has this to 
say of the columns, "A more truthful monument would have found a way of representing architecturally the determined effort by eleven of these to leave the building. Like many others this monument represents an interesting conflict as stasis." (Harbison 1991) This is an essential element of the monument which reveals an interesting reading of the useless. The monument attempts to fix time, to stop it and orient your perspective somewhere specific. For you to contemplate that moment in time which has been solidified for your consideration.

However, such incredible colossus cannot be built without cracks in the container, and in Harbison's book The Built, The Unbuilt and the Unbuildable: In Pursuit of Architectural Meaning, he questions the prescribed perspective attempted by the most formidable monuments of the world - the Lincoln Memorial, the Statue of Liberty, Monument to the Russian Peoples at Stalingrad and others. In the cases of these colossal monuments the architecture seems to open up other readings not always available when uninhabited. For instance, where do we think we are going when uselessly ascending Liberty Enlightening the World? Is it towards the light? What do we see when we get there? While the monument may be remarkably successful in defining how we see it, how much more difficult it is to control what we might see when we look out from its peak.

Artists work against functionality in yet another way, often facing it directly with a spirit of creative interference. Montreal artist Sarah Ross, for instance, considered the spatial tactics of uncomfortable benches (or prickly space in Flusty's typology) and proposes an absurd, but somewhat adorable, suit with excessive padding in the back to allow the wearer to stretch out fully on a prickly 
bench (figure 11). Ross's project is tension between use and useless, intended as 'functional' solution to a very specific problem, its excessive specificity focuses attention on the spatial position of an increasingly ubiquitous design object - the new public bench. While the Archisuit is in reaction to an object in the urban fabric and through that disruption attempts to create new perception of the environment, there are other useless objects we can identify that offer something to architecture.

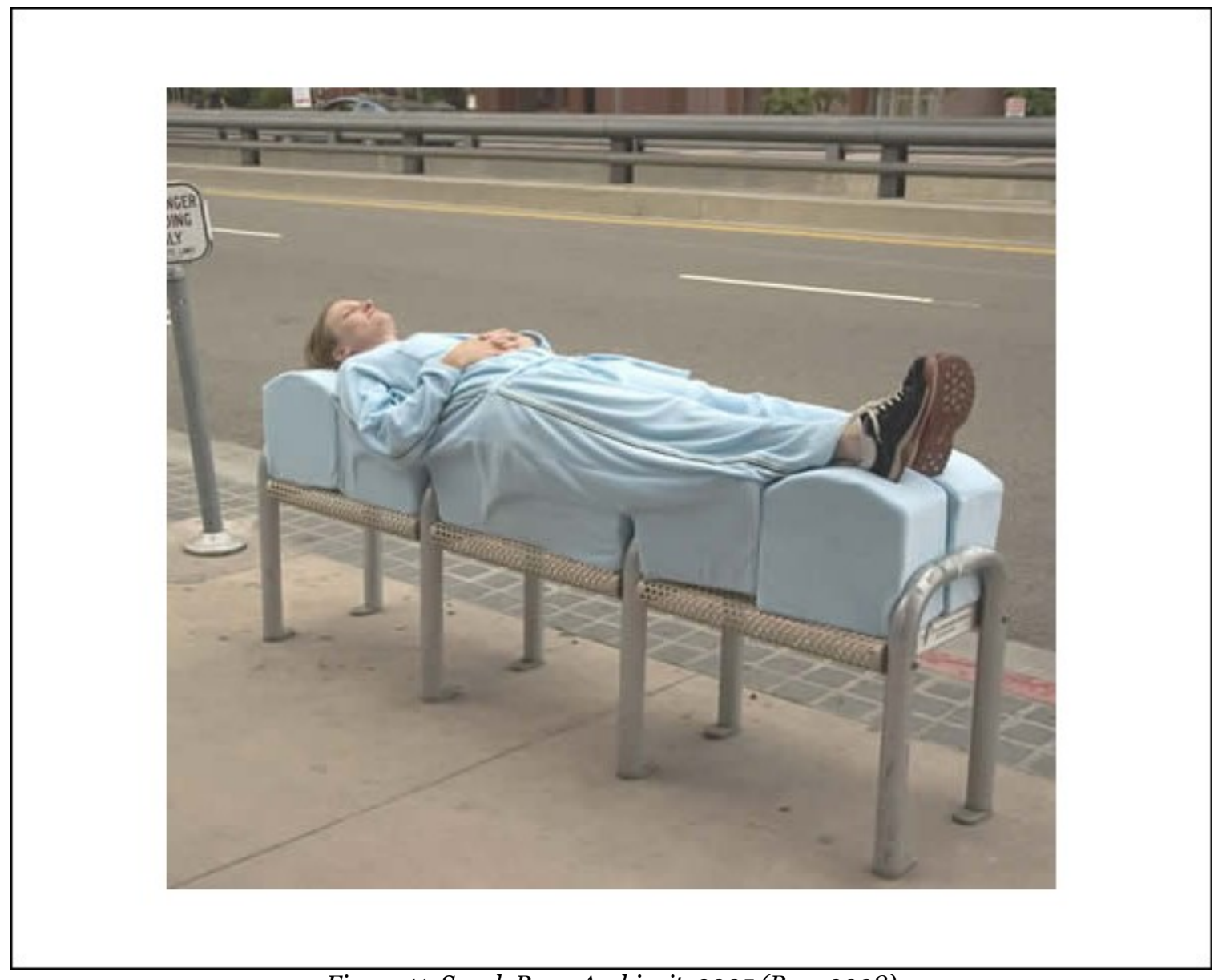

Figure 11. Sarah Ross, Archisuit. 2005 (Ross 2008)

Didier Faustino operates between a space of architecture and art, and his work often oscillates, or perhaps vibrates and collides, between functionality and uselessness. In his work Stairway to Heaven (figure 12) Faustino presents a single concrete stair ending in a caged platform. This stair to nowhere engages the utility 
stair, drawing on the typology of the fire stair that in this instance is exposed for us to consider, and repositions its instrumental role leaving only the act of ascent and descent for us. The passage of the stair has been limited leaving only Faustino's suggestion of heaven as a destination, an exit stair to an eternal nowhere. The juxtaposition of the idea of heaven and such a contained destination can be read as a cynical position on the nature of belief, but equally as an optimistic gesture in which the body remains still but the imagination escapes beyond the contained edge.

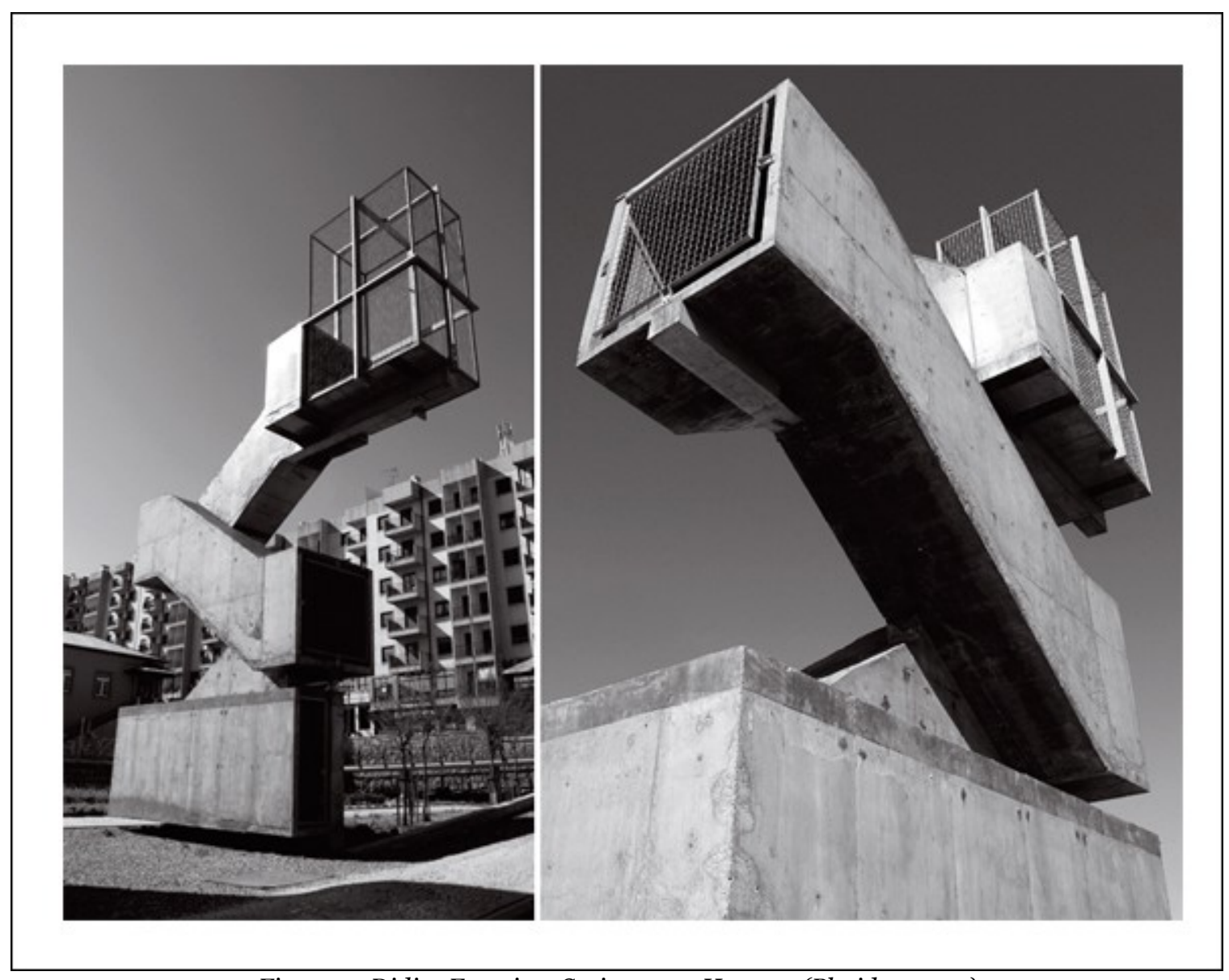

Figure 12 Didier Faustino, Stairway to Heaven. (Phaidon 2010) 
Danish artist, Olafur Eilasson offers another material consideration of uselessness in his Infinite Staircase (figure 13). The stairs leave and return from a single point, grounded on earth, as Eliasson offers a Mobius strip of nonfunctionality, relieving the stairs of their responsibility. Lighter in tone and materiality than Faustino's stairs, Eilasson's piece is less concerned with the tension Faustino accentuates between ascent and descent, between heaven and ground, between the spirit and the body. The Infinite Staircase rises and falls with more playful curves, and we are welcomed into the possibility of an unending and irrelevant movement.

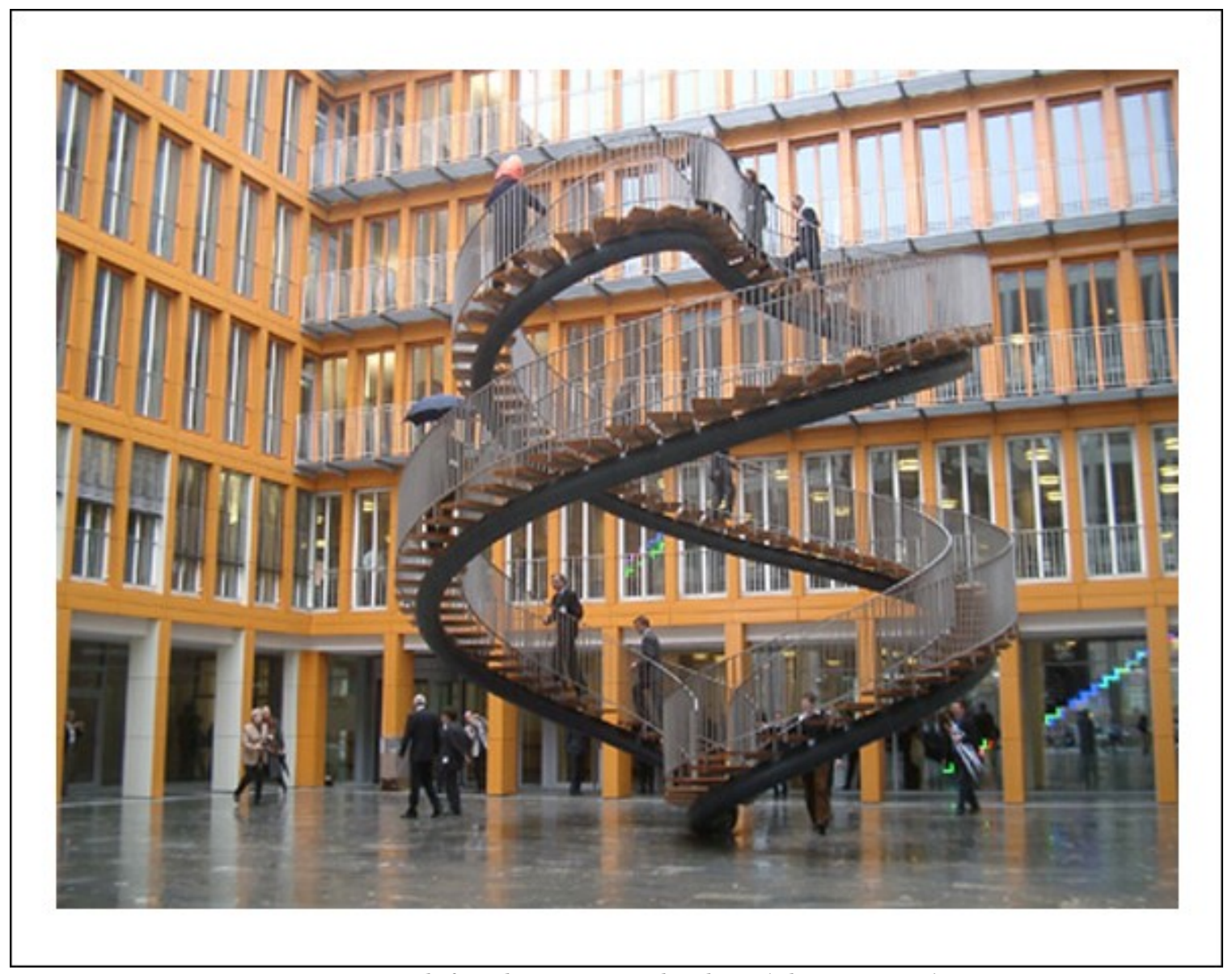

Figure 13 Olafur Eliasson, Umschreibun. (Eliasson 2004) 


\subsection{Utility interrupted}

Here we have arrived at stairs to nowhere. As we see with Eliasson and Faustino, as well as the monument and the ruin, that nowhere is not always the same place, and different stairs arrive by different paths.

Can we learn from the ruin, the monument and the artistic project? Can we learn to make something undefined that we still understand as architecture? Not a faux ruin or a mock chaos, but truly indeterminate. Not making space, but leaving room for anyone to place themselves. Not a mixed-use or multi-purpose space but one of complete purposelessness. Not a happen-stance of construction or an architecture without architects, but designed uselessness.

Does the possibility of going nowhere open up a world between us? ${ }^{11}$ Can this uselessness interrupt our attention just long enough to discover something unexpected in ourselves? In each other? Can architecture discover something for the city it was not asked to find?

\footnotetext{
11 The concept of the stair to nowhere began to evolve into an interesting architectural consideration, and as an exercise in exploration of the concept in linguistic terms Federica Goffi suggested a writing exercise where you cannot use the terms you are trying to explain. I have included one of these exercises in Appendix $C$ which explores the ideas of uselessness through the act of going up stairs. This is also influenced by the writing of Georges Perec and his focus on the experience and meaning of the everyday. This passage, and the end of this chapter in general, was significantly influenced by these writing exercises.
} 


\section{Chapter 4: A useless project}

\subsection{Un-mapping}

I have tried to assemble a kit of useless tools to explore the terrain of this project. This list so far includes: a mindful position towards a balance of the intrinsic and the instrumental; belief in the fruitful possibilities of futile endeavours; an openness to the unpredictable possibilities of useless space; the role of obscurity in finding your way; elements of danger gathered from the ruins; the irrelevant movement possible inside colossal monuments; the utter uselessness of art and an incessant list of questions.

Where on this terrain should we begin? After such a detailed effort in unmapping, perhaps it is important to remind ourselves of the absurdity of this endeavour. I suggest, then, to restate the nonsense of Lewis Carroll's fictional sea farers $^{12}$ :

"What's the good of Mercator's

North Poles and Equators, Tropics, Zones, and Meridian Lines?" so the Bellman would cry, and the crew would reply:

"They are merely conventional signs!"

"Other maps are such shapes, with their islands and capes!

But we've got our brave Captain to thank,"

(so the crew would protest)

"that he's bought us the best -

a perfect and absolute blank!"

(Caroll 1995)

\footnotetext{
${ }^{12}$ The map described here appearing in Chapter 2 (figure 5) is a beautiful bit of non-sense mapping accompanying a beautiful non-sense poem. I have come across the map in a number of places during my research including the opening pages of Species of Spaces (Perec 2008)and in David Turnbulls wonderful little book Maps are Territories. (Turnbull 1989)
} 
With this nonsense in mind, let us consider the delicate and difficult balance I must strike here, as I attempt to embed this embrace of the useless into the reasonable structure of an academic pursuit. If I falter at this entrance into the project, I will likely fail at both the poetic and pragmatic. This is an important threshold.

In Chapter 2, I began to develop a useless understanding of the site that contrasts the impossibility of scale at work in a flowing river (figure 7), the invisible constructions of jurisdiction (figure 8) and the verbal maps of memory and poetry (figure 9). This obscure outline will serve as our threshold, but we will require more useless details to better define the terrain.

The work of John Hejduk is a significant influence on the development of this research, and his approach to the description of a project will provide further guidance to the passage through this important threshold. ${ }^{13}$ For Hejduk, it seems the site exists between the space of the paper and the world. In Soundings (Hejduk 1993) the projects appears as collections of objects and characters (including objects as characters) separate from what we might normally understand as ground or site. However, they also seem to open up an imaginative territory with a more emotional and open reading of place and history. In the fourth section of Soundings, entitled Berlin Night, Hejduk presents an extensive list of characters, their built component in both title and shifting representation ${ }^{14}$, and an obtuse or anecdotal text for each character. The general history that grounds Berlin Night is

\footnotetext{
${ }^{13}$ Beyond the study of Hejduk's published work I also visited the Canadian Center for Architecture, which houses a significant portion of his archive, to view his sketch books for Berlin Night in the hopes of gaining further insight into his interpretation of the site and the construction of the project. ${ }^{14}$ Each of the numbered drawings in the overall map is not the same representation as listed in the following pages. It is a very curious position to present shifting iconography for the description of the characters.
} 
not transparent or accessible, but something else is in its place. Components such as "The Architecture for the Amplification of Lost Sound" invokes the inconceivable loss of voices through the Holocaust. The project's poetic depth supports and expands the concrete details of this dark history, and Hejduk seems to be asking what role the architectural imagination may play in healing complicated wounds.

\subsection{A story about Chaudière}

Depending on what character you choose to identify with in the story of Chaudière one could also describe it as a complicated wound. In the spirit of Hejduk, I would like to consider how he might understand the site of Chaudière. There are many characters, both living and object, but also the invisible elements comprised of jurisdictions, bureaucracies and histories.

I propose to begin with a grand arc; a lineage that outlines the territory in both time and space. Beginning with the Chaudière/Asticou Falls ${ }^{15}$ born of the meeting of Rock and River. Rock and River are perhaps the head of all lineage here. Rock, under the soil, grounds the trees and the life they support. River runs through everything eventually, and without it there is nothing that lives.

The water has many images. The Spiritual Falls brought many original people to this place. The Productive River brought another layer of people to settle.

\footnotetext{
${ }^{15}$ The Heritage Study of the Ottawa River cites missionary J.A. Cuoq, who suggests that the Algonquin name for the falls Asticou is possibly a misprint given that the Algonquin word for boiler is Akikok. Further in the document it is also suggested that the name Algonquin is also an erroneous label whose origin is not clear. Samuel de Champlain, the Recollets and Jesuit missionaries used the name to refer to a number of different anishnabe-speaking people living near the Ottawa River. (Quebec-Labrador Foundation 2005)
} 
Original and Settler, this is an interesting and important opposition. While a settler may be a question of perspective, for Rock even the Great White Pine was a settler, we know that some settle differently than others.

The presence of the Productive River grew until the voice of the Spiritual Falls was stilled. The trees left and set sail for other waters. The Rock held up the Ring Dam. The Settlers flowed towards the setting sun. The Original People were moved. The buildings of settlers settled. The material of a working town became the material of a city. The Immaterial City grows on top of the material one. This Immaterial City now houses the centre of the immaterial country, a complex collection of jurisdictions, rights, regulations, processes, procedures, laws and of course ceremony. The weight of the Invisible Country bears down on this place. The Original Peoples seek to recover the Spiritual Falls and with that the children of the river, the eel amongst them, while a new group of Settlers propose new settlements, imported from other territories. 


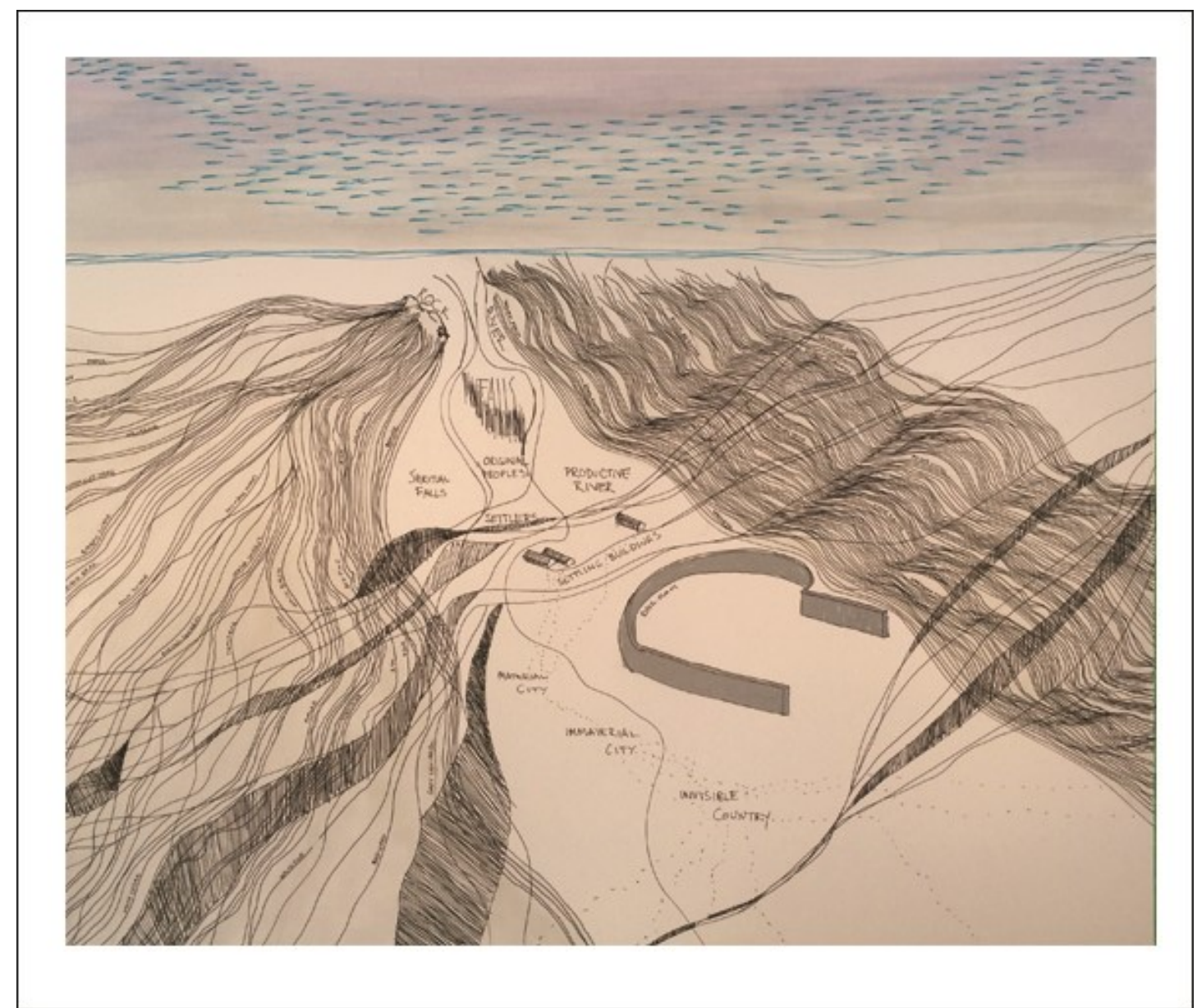

Figure 14 Spatial and historical map of Chaudière and Asinabka

\section{The Spatial and historical map of Chaudière and Asinabka ${ }^{16}$ (Figure 14)}

attempts to provide an alternate description of the site. It seeks to represent important aspects of the project missing from other maps. ${ }^{17}$ Through a reading of

\footnotetext{
${ }^{16}$ The term Asinabka is an Anishabe term that refers to the general area including the falls, Chaudière, Victoria and the many smaller islands, but also the shores. The term is used in the materials from the Circle of All Nations, an Indigenous group founded by Elder William Commanda of the Kitigan Zibi Anishinabeg, who have as part of their vision for the area to free the falls from the constraints of the dam and other industrial presence in the area. (Smith 2011)

${ }^{17}$ Included in Appendix E is one of the many maps produced by Windmill Developments for the Domtar Lands Redevelopment which is to be a large mixed-use development project over much of the Chaudière area. (Windmill Developments 2014) The map included in the appendix is an outline of the potential renewed public access to waterfront in the Chaudière/Asinabka Area as a result of their proposed developments. While not wishing to reduce the intentions of Windmill Developments into a one dimensional commercial venture, it is not an overstatement to categorize their maps as instrumental. Each map in their master plan is designed to provide a fairly specific perspective to help reinforce their development goals. It is worth restating in different terms that the maps offered here are not provided to influence the discussion in a specific direction, but instead to offer a less clear map in the hopes of opening up a more interesting dialogue.
} 
the entirety of the Ottawa River Basin as the site this map includes the representation of 300 bird species, dashed across the sky, the 53 lines of mammals, 33 species of reptiles and amphibians, and 85 species of fish all flowing from Rock and River. (Quebec-Labrador Foundation 2005) The binary opposition between the Original and Settling people remains in name, but the interplay in their lines of representation attempts to grapple with the real complexity of both our lineage and our occupation of any land.

\subsection{Ring Dam}

The Ring Dam at Chaudière and Asinabka stands as an interesting object. The very useful architecture of this dam will serve as rich terrain for a consideration of the poetic potential of useless architecture. The dam seems to be the embodiment of utility, and, as outlined in Chapter 1, Heidegger suggests that a dam on a river brings forth a fundamental shift in our perception, transforming a river into a resource. In the case of these falls, this conversion seems even more profound. With the area under lease to the private interests of various industries the falls have been mostly inaccessible to the public for close to a century. (QuebecLabrador Foundation 2005) The falls now exist primarily as an idea constructed from the past or a physical thing that is viewed from afar, and almost impossible to experience with any intimacy. The photo sequence in figure 15 is taken while moving across the Booth Street Bridge on bicycle. This is one of the closest vantage points for the falls or dam unless one gains special permissions. The pedestrian portion of the Booth Street Bridge, where one could pause or linger, is on the opposite side and so one must look through both the bridge and its heavy traffic to see the falls or the dam. 

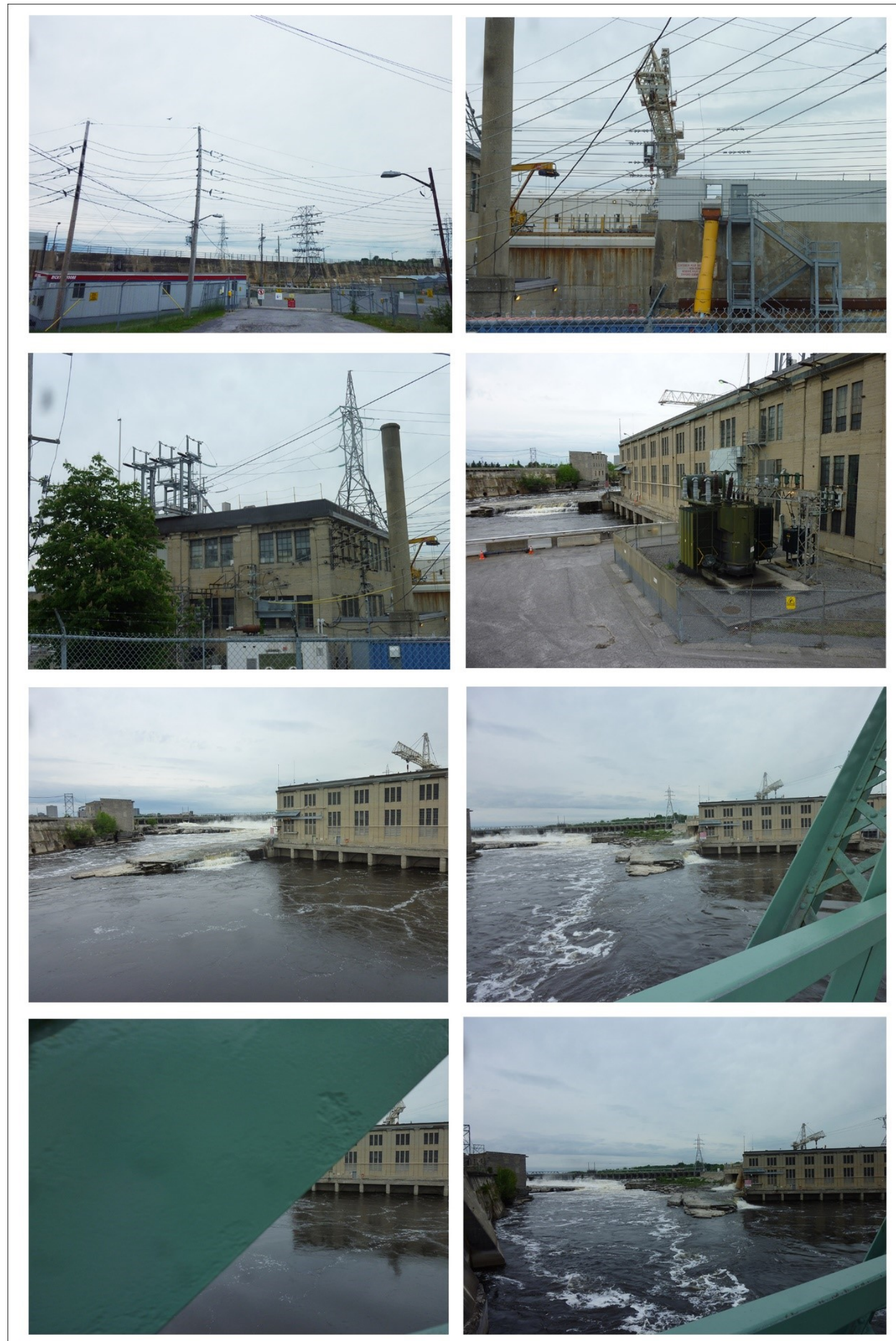

Figure 15. Photo sequence along Booth Street Bridge 
Following this there are two more considerations of the site of the dam and falls. The first (figure 16 ) is a drawing that looks at the dynamic aspects of the river water positioning the dam itself as an absence, not directly in the spirit of the efforts to free the falls ${ }^{18}$, but to understand its interaction with the water. The second (figure 17) is a map of a very useful kind - a topography map with changes in elevation indicated every meter. This map seems exceptional however, and in its narrow specificity of the abstraction of the territory a fairly confusing image is presented. Any attempts to match the ground depicted with other maps or photographs always leaves some element obscure. This map is almost undoubtedly an accurate representation of the landscape, but here it seems wholly inadequate to describe even the physical terrain. These two maps present different abstractions of the terrain. They offer more layers of obscurity of the physical site in consideration of how these representations may push against the spatial historical map.

\footnotetext{
${ }_{18}$ There are several recommendations, or movements, to free the falls. These include the work began by Elder William Commanda and The Circle of Nations group, which has developed a plan for Indigenous Meeting Center in collaboration with Douglas Cardinal (Smith 2011), the Ottawa River Heritage Designation Committee (Quebec-Labrador Foundation 2005), a petition on Change.org (Stockdale 2014), and even at one point in 1998 the Ottawa Mayor Bob Chiarelli. (Lambert 2014)
} 


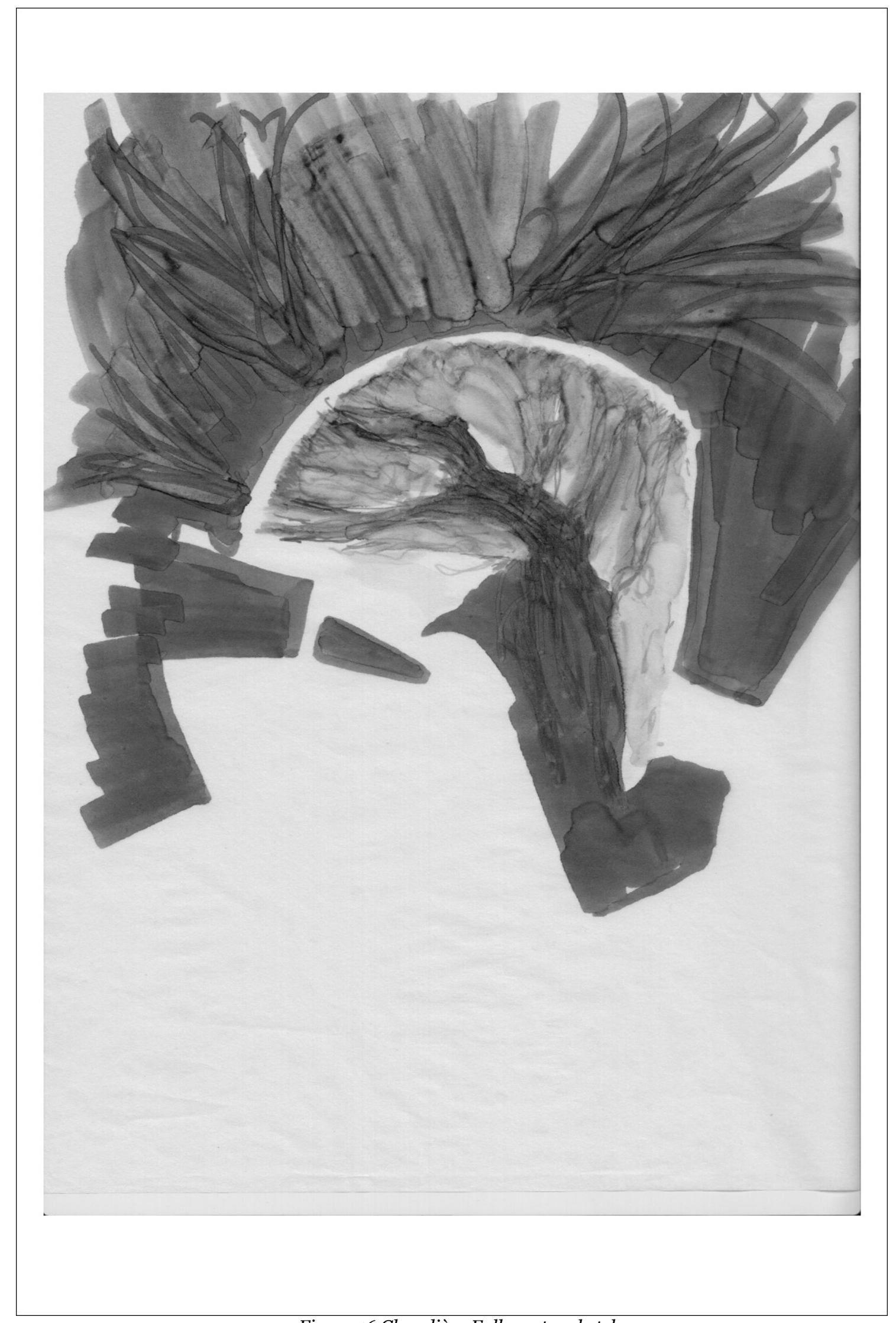

Figure 16 Chaudière Falls water sketch 


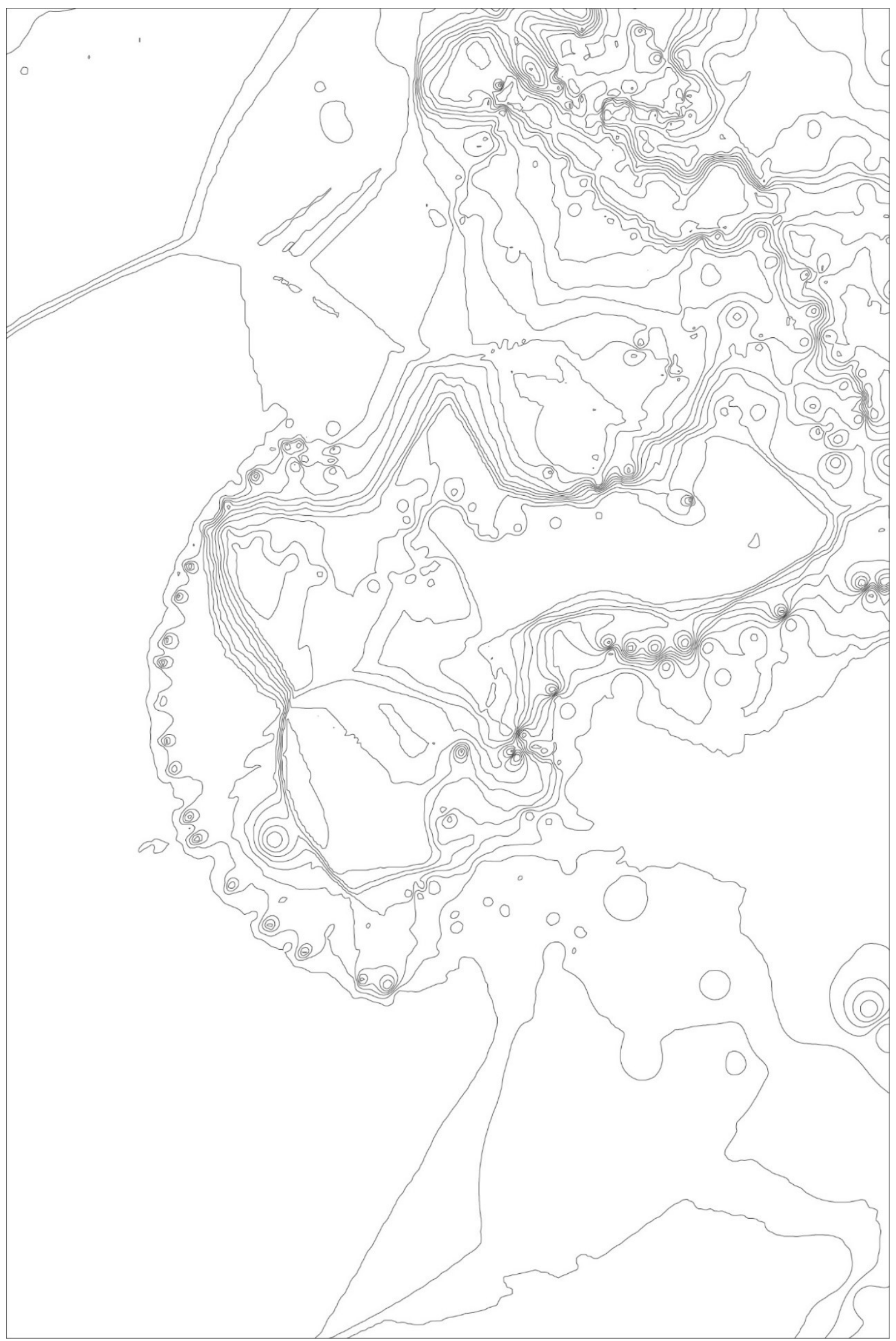

Figure 17 Topographic map of Chaudière 


\subsection{A Stair to Nowhere}

Amongst these collisions of representation, the characters of Rock, River, The Spiritual Falls, The Ring Dam, Original Peoples and those settling, amongst this complex physical and invisible terrain, I propose a simple and useless addition to the dam - a staircase straddling the very useful architecture and going nowhere. On each side of the dam the useless stairs descend towards the river. Upstream, towards the west, the descent brings you close to the water held above the falls, and downstream, towards the east, the descent is towards the falls. The water level of one will be the inverse of the other. When the sluice is open the falls finds its voice and the water level above the falls is reduced. When the barriers are in, the water rises to meet the upriver stair, and downriver the falls are quiet.

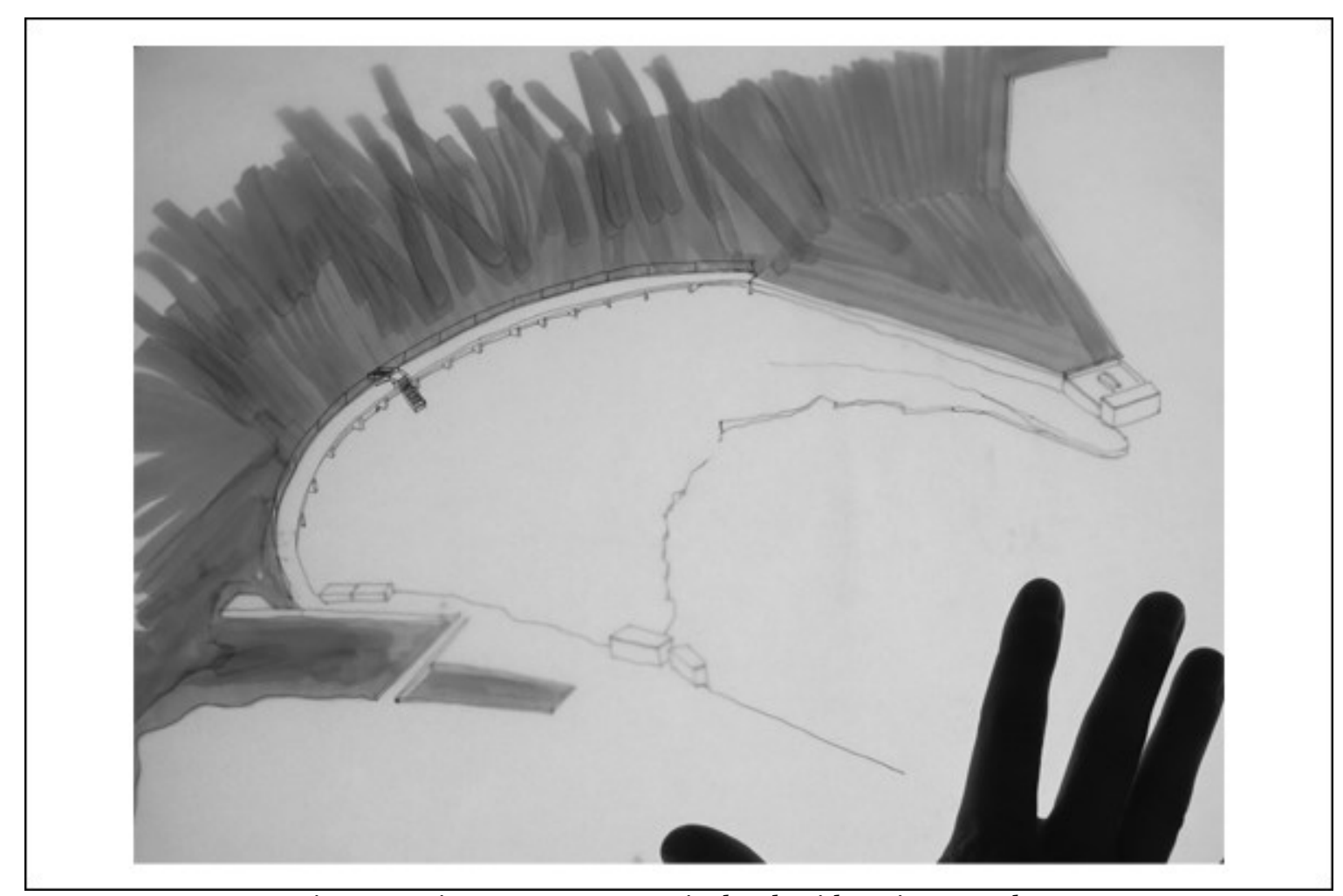

Figure 18 Ring Dam axonometric sketch with Stair to Nowhere 
This pairing of stairs is placed at the center of the Ring Dam and descends 20 steps on each side. The treads are large and the descent is slow and easy, but the stairs are wide, spanning the entire six meter sluice in the dam, giving them an open and precarious feeling. Unwilling to bear further on the rock itself the stair is conceived of as an addition, an appendage if you will, to the dam. The principal structural elements are on steel braces attached to the concrete structure of the dam. The upriver component suspends the bottom ten stairs from steel supports projecting above the stairs. This stair hovers above the river. The downriver stair reaches deeper into the sluice for its support with perhaps unnecessary complexity, while a string of cables create a physical and sonic connection with the running river. 


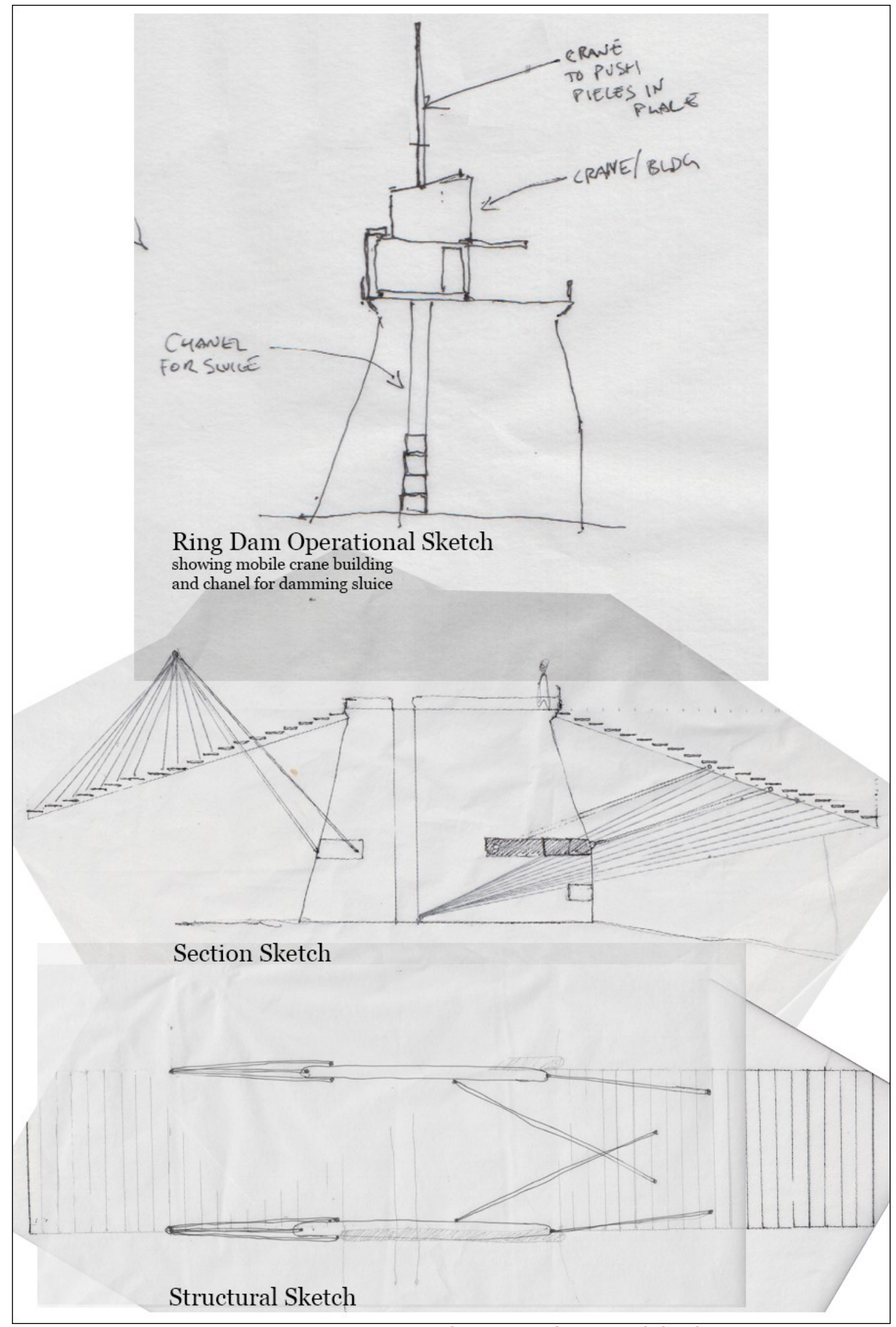

Figure 19 Ring Dam operational, section and structural sketches 


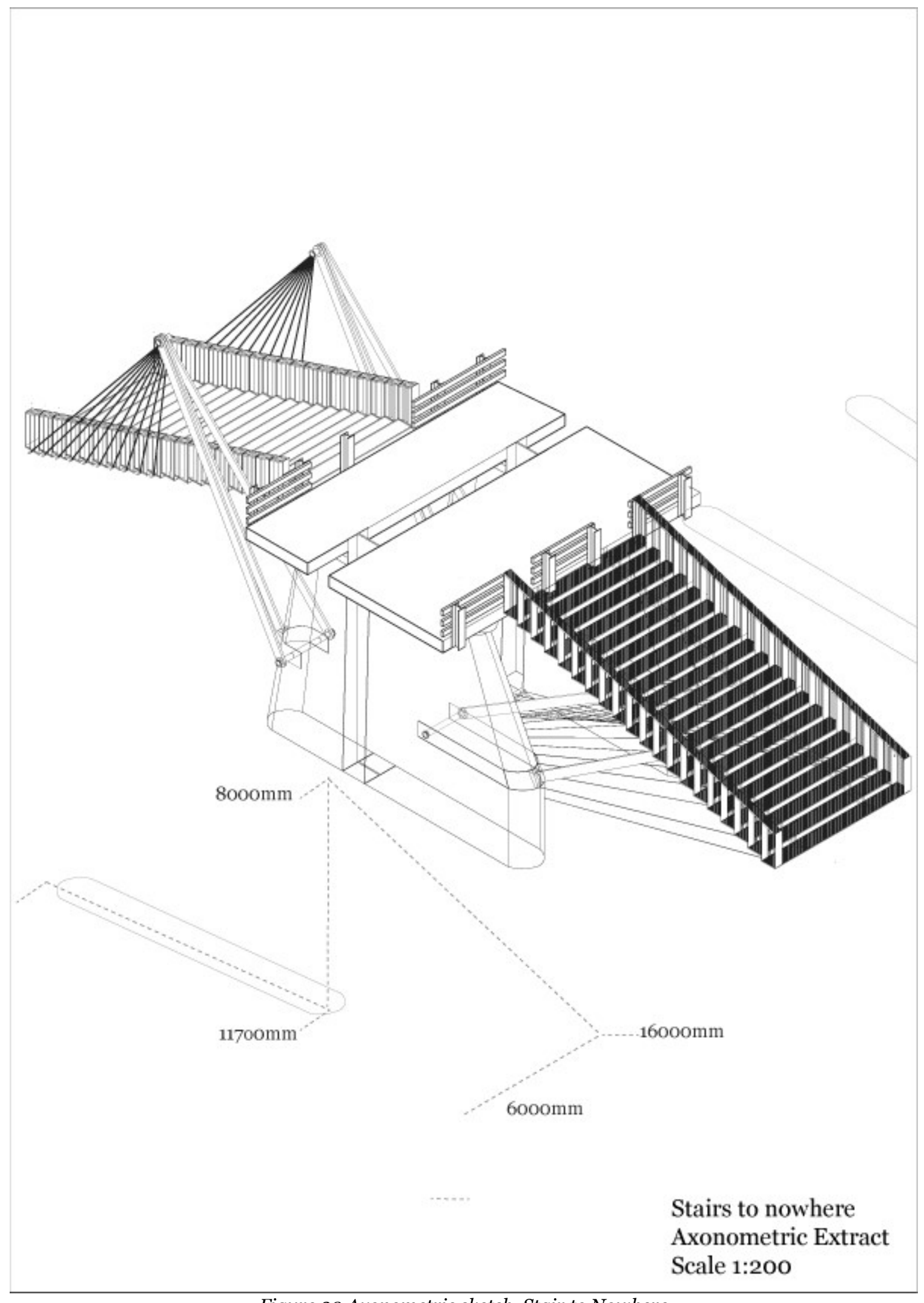

Figure 20 Axonometric sketch, Stair to Nowhere 


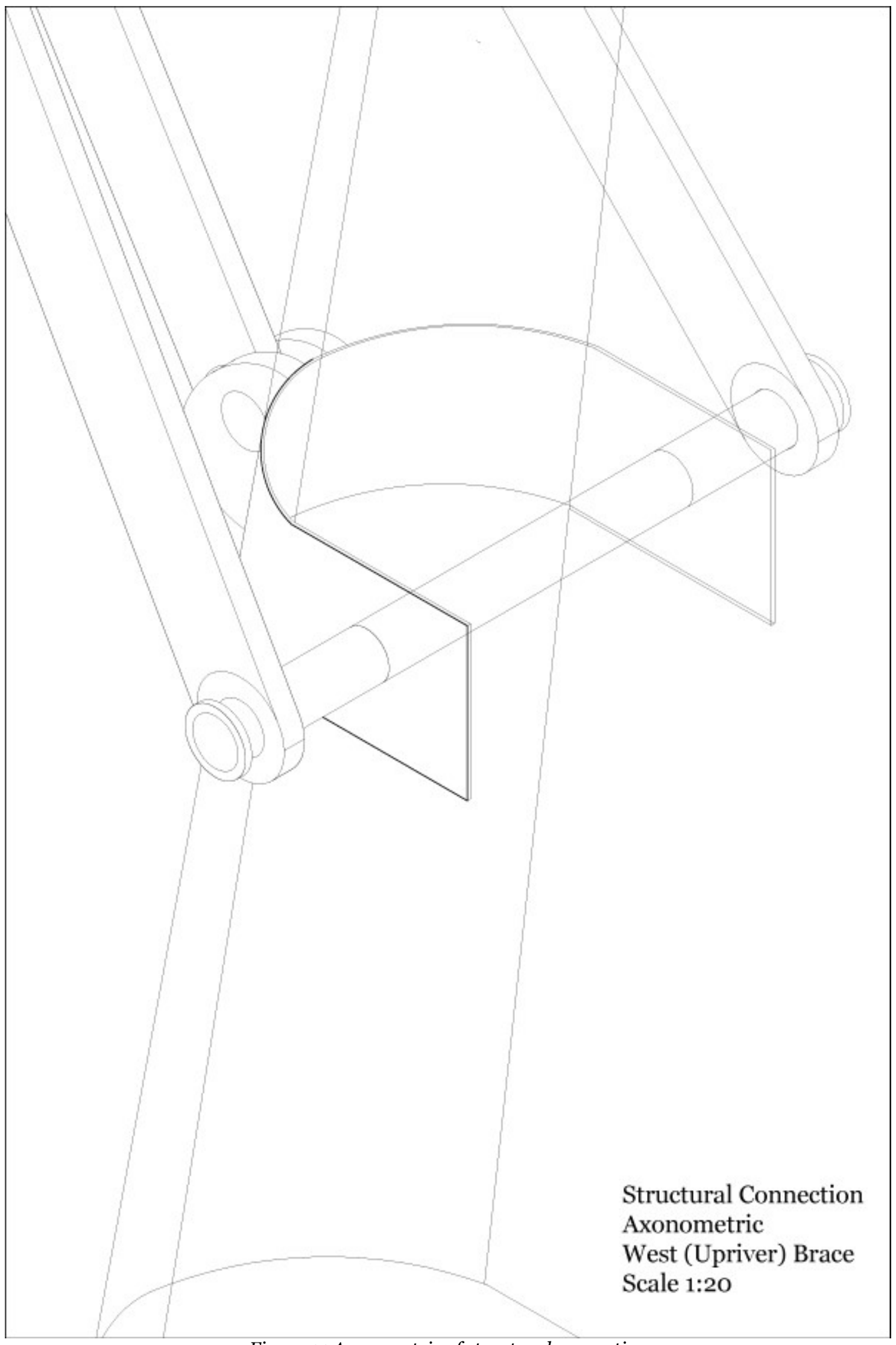

Figure 21 Axonometric of structural connection 


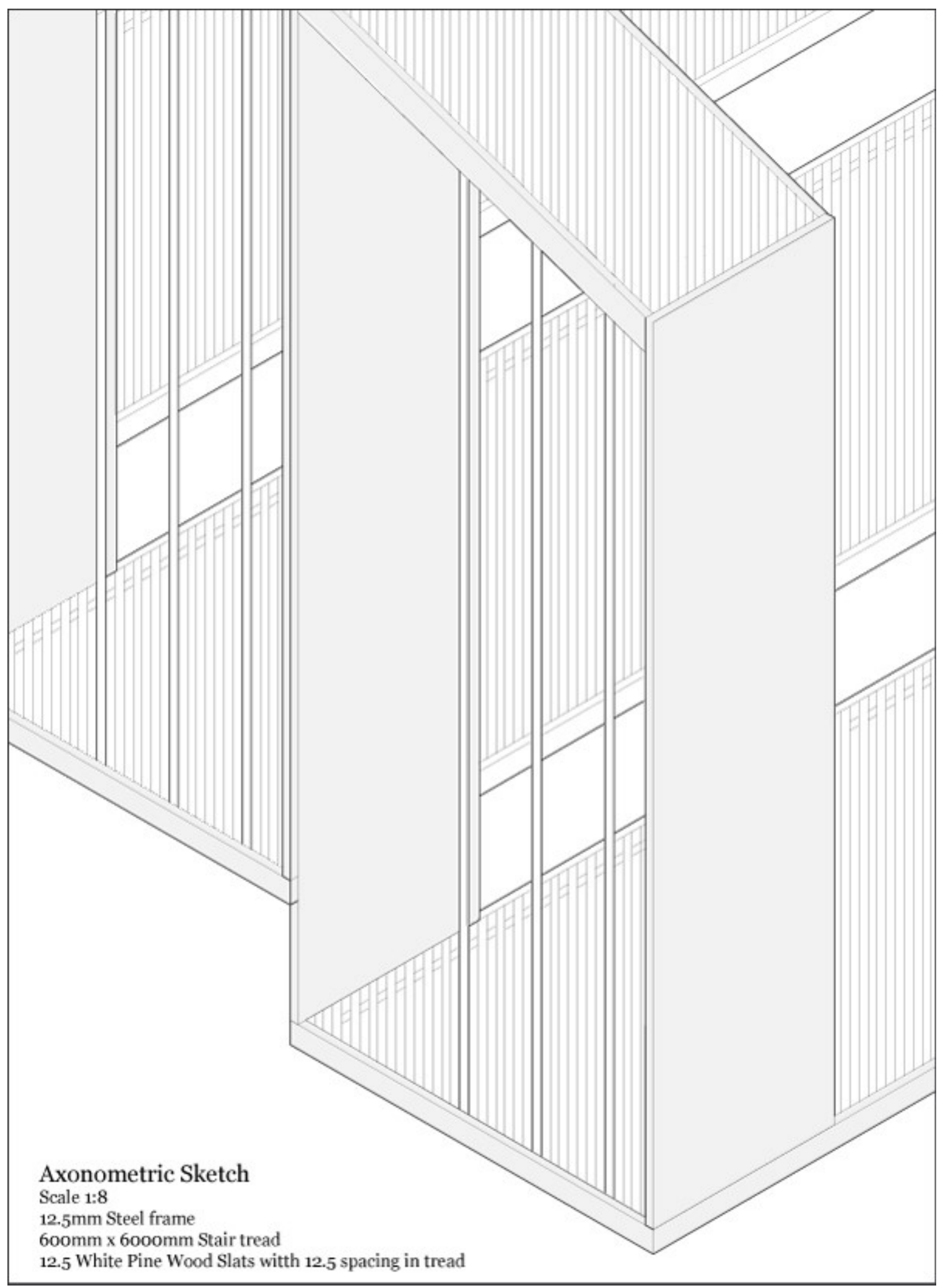

Figure 22 Axonometric sketch of stair tread and railing 


\subsection{Purposeless steps}

What has proceeded is useful information about these stairs to nowhere. I have attempted to generally outline their material and structural design to make them tangible, but how do we translate the experience of the stairs without narrowing their possibilities they offer? How can they be a house for the many versions of the world that we carry with us? The proposal I am offering attempts to exist a state I might describe as challenging generosity or seductive confrontation. The tread of the stair is wide, descending like the easy steps of a public plaza, but this width, this freedom, leaves one exposed more precariously in such proximity to the river. The treads are framed reassuringly in steel, and filled with slats of White Pine remnants ${ }^{19}$, a familiar wood that seems almost innocent or at least disarming. However, there are gaps, and through the gaps your feet can sense the more dangerous world of the river below. The hand rails are also wide, referencing an older type, perhaps of limestone like those in front of the Parliament buildings. The material is, again, wood, warm and friendly to the touch, but the wide rails make for an uncomfortable grip, and you may raise questions about whether the stair has your safety in mind. Each of these moments is intended to draw you into the architecture, to encourage you to consider what you are doing not in the rhetorical sense, but to focus on the specific steps you will take. Through

\footnotetext{
${ }^{19}$ Great stands of White Pine once dominated the Ottawa Valley, and it is these trees that ushered in the lumber boom which felled nearly all of the old growth forests of the region. (Quebec-Labrador Foundation 2005) The notion of remnants here would be to collect the useless bits of timber not fit for other purposes, but also to make reference to the idea of what was here and what remains here in the region.
} 
this attention to action, the stairs ask you to be present in this place and to contemplate what is here.

The experience of the stair is connected to the world you perceive while on it. Downriver you descend to an impossible location, suspended above the heart of the falls, tranquil or tumultuous, you are flanked by the dam and the useful structures it feeds. The river extends seaward. The bridges cross. What new landscape you will construct from here will only be drawn once your imagination has arrived here. As you turn back up towards the dam you see through the precarious stair. You see the useless cables connecting you to the river below. You see the structure reaching through the sluice, and with every step you see yourself coming into line with the river above you. The more barriers that fill the sluice the more steps it takes to bring your head above water. You see through the dam and into the west in the impossible position of a river looking back on itself.

Westward the descent is different. The embellished basin above the falls is flat with anticipation of its departure down the river. Before the arrival of the Ring Dam the river here looked different. Less water would wait for the Falls. More water would run. Now a large basin sits, and while the stair downriver brings you towards the fluctuating heart of the falls, upriver the stair descends to the harnessed resource, occupying a space once more accessible to us. Although the waters appear still, they are far from stagnant and they fluctuate with the opening and closing of the sluice. It is however, the calmer and more contained descent. The structure components suspend the stair above the river and it stands apart. This expression of structure is more reassuring than the downriver descent, and 
from these steps I imagine the feeling towards the water is different. Is it contained? Tamed? Controlled? Calmed? The stairs will have some answers, feet on the steps will have others, as will those looking up the river. Hopefully all will have more questions.

While I am willing to attempt a description of the experience of the stairs, what remains to be outlined is what we might call 'the urban context' of the stair. The research has elaborated on a very poetic re-reading of both the historical and its current spatial context, but has not described the site in clear and direct language. The current context of the dam and falls is that they are generally inaccessible, but this proposal does not include a detailed idea on how to progress towards accessibility. Instead, I suggest an inversion of the process, that the useless stair be implemented before the specific planning of the dam and falls' new, more integrated urban life begins.

\subsection{Useless cables}

The down river side of the stairs is tied to the run of the river. Cables running in rising symmetrical formation are grounded into a line just inside the structure for the manual infill of the sluice. This cabling is inspired by the work of sound and sculpture artist Gordon Monahan, whose work is concerned with the material of sound production as well as the physical properties of sound itself. Monahan has constructed both Aeolian and Aquaeolian instruments that interact with natural forces to create elegant sound experiences. (Monahan 2011) Here, the concept will be applied for its sonic properties, but also a more significant physical interaction with the river itself. As the design of the stair conceives of them as an appendage 
to the existing structure, these cables are the principal and direct interaction with the river. As water passes through the sluice the cables will vibrate. The more active the river the greater the vibration as a new voice emerging from the falls. The tone of the voice will be underscored by the physical effect on the stair. As the river rages the stairs will share its emotion. We should feel the danger in the stair, thinking perhaps of future ruins. 


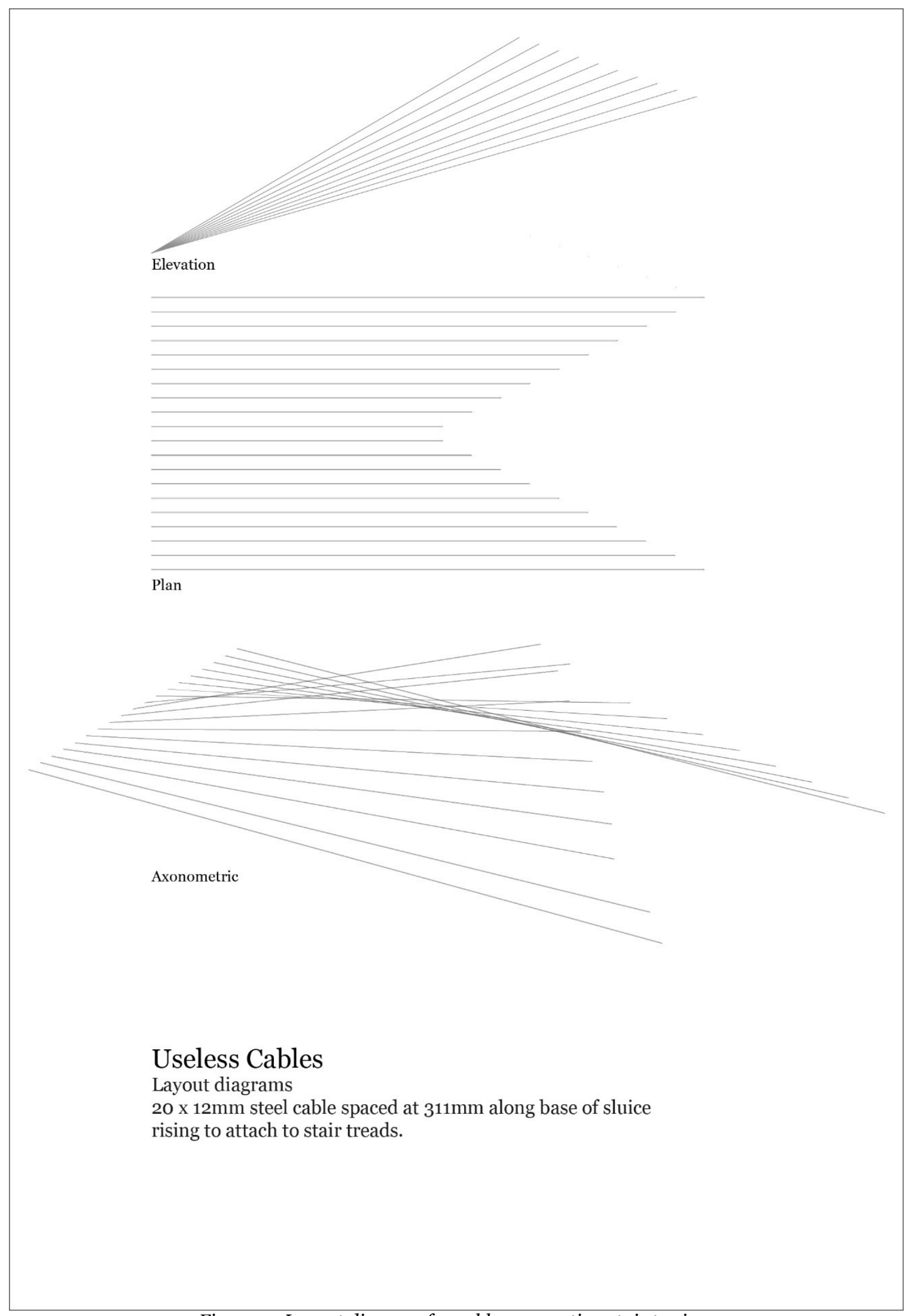

Figure 23 Layout diagram for cables connecting stair to river 


\subsection{Invisible Falls}

A final element of the project remains focused on the sonic heart of the falls - the creation of a localized FM radio station continuously broadcasting the sound of the falls. The sound of the falls would be captured through a simple high quality microphone, and broadcast over an FM station. Ideally, a localized transmission would attempted to match the distance the falls could once be heard from. ${ }^{20}$ The radio station attempts to renew and amplify the sonic heart of the falls, and reimagine as a heart of the city. A running of water that anyone can tune into.

Using Very Low Frequency (VLF) FM transmission it is possible to broadcast using 1Watt of power from a device approved by Industry Canada that can operate without a Canadian Radio and Telecommunications Commission (CRTC) ${ }^{21}$. (CRTC 2008) The transmitter would be located under the bridge and the antenna connected to the existing power infrastructure used by the moving cranes. However, as is the case with sound, radio frequencies have physical properties and are effected by the terrain. In other words the form of the cities on both sides of the falls will affect the path of the broadcast and the access we have to its heart.

\footnotetext{
${ }^{20}$ Samuel de Champlain writes in his journal that the great falls could be heard from a distance of two leagues, which could measure between six and ten kilometers. (Champlain 1906)

${ }^{21}$ There are provisions within the act for certain approved devices to work on low power for uses that include broadcasting within movie theaters, concert halls and industrial sites. There are also special provisions for tourist oriented information broadcasting which may provide another interesting avenue for broadcasting within the existing legal framework.
} 


\section{Conclusion}

If we return to my drawn map of Chaudière and Asinabka, how does this new appendage to the dam fit in? What is the nature of this architectural character? Given the complications of the area there is unlikely to be any simple solution for the problems affecting its heart. A solution is precisely what I am trying to avoid proposing. I am proposing instead something intentionally difficult to define, and like all good characters it attempts to avoid a one dimensional reading. It is a monument to the dam. It is a memorial for the falls. It is space for contemplation. It is a dangerous ruin. It is a useless piece of art. It is an act of architectural resistance. It is preposterous. In its attempts to be these things it hopes to resist all of them.

This is how the Stair to Nowhere will join the stage of Chaudière and Asinabka, a useless character that is instrumental to no one or no thing. I can only hope that its obscurity may offer a new perspective on the path forward. Not at the service of Rock or River or Dam or Settler, but in conversation with them. 


\section{Post Script: Project Drawings}

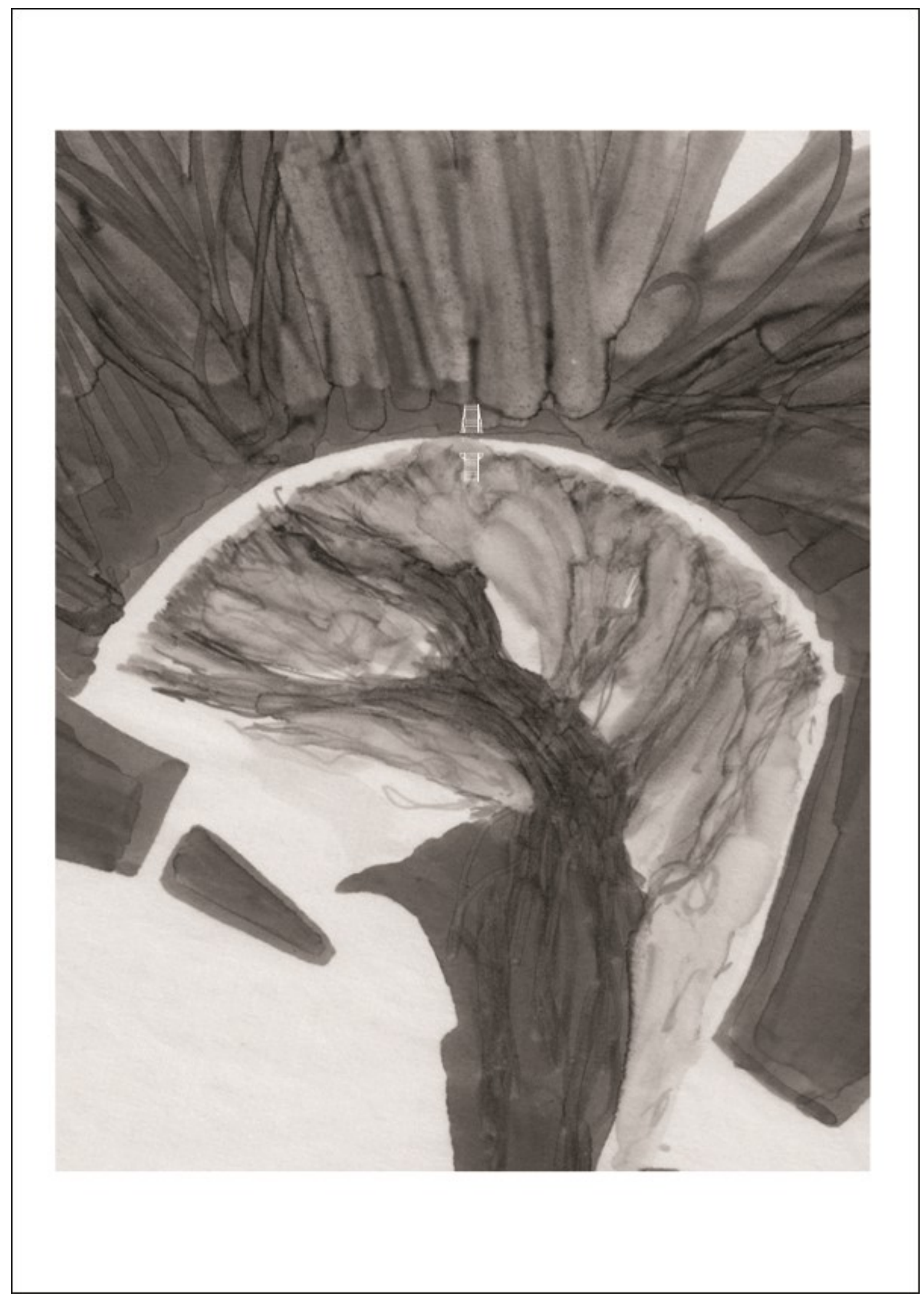

Figure 24 Useless Plan 


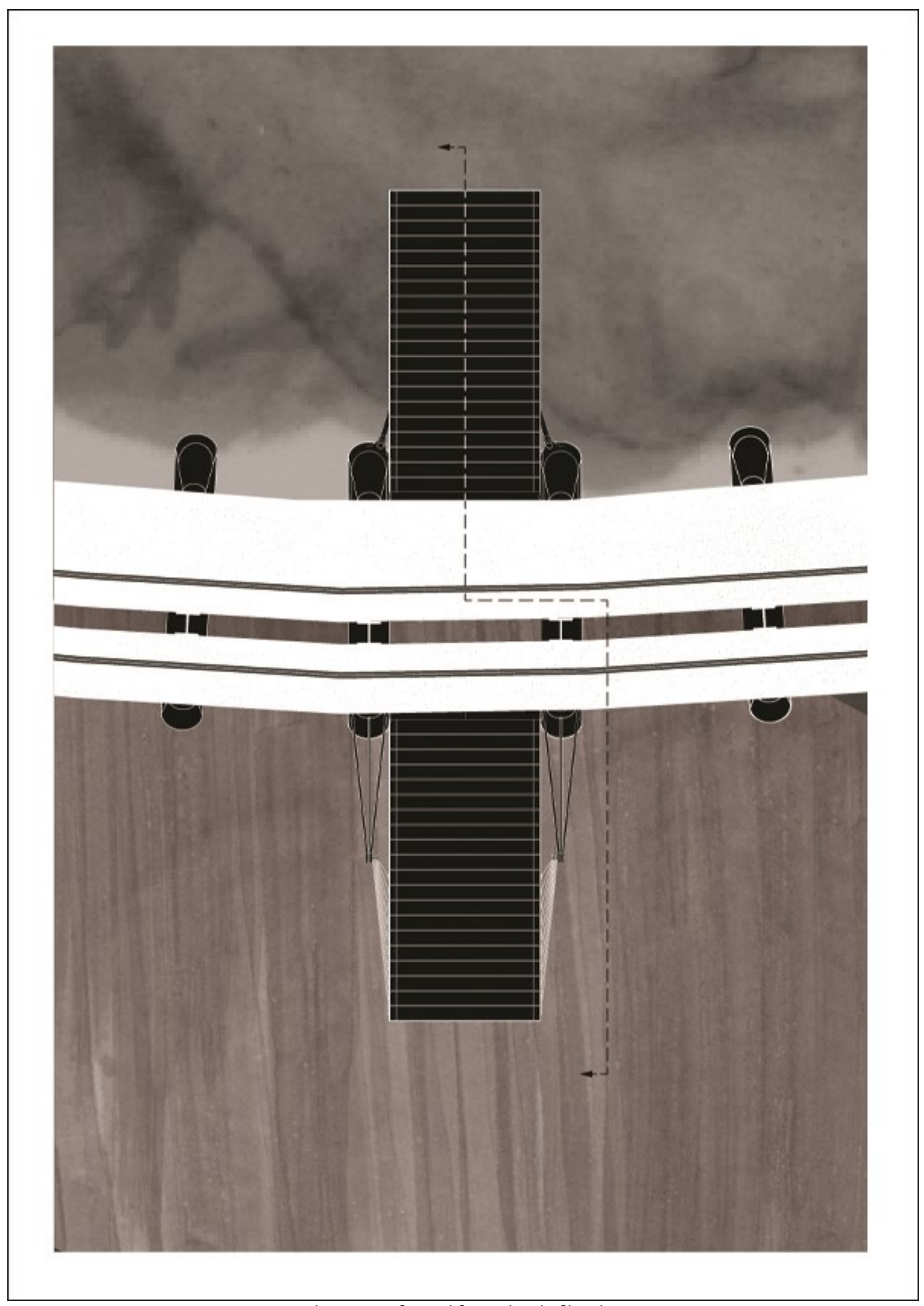

Figure 25 Plan with section indication 


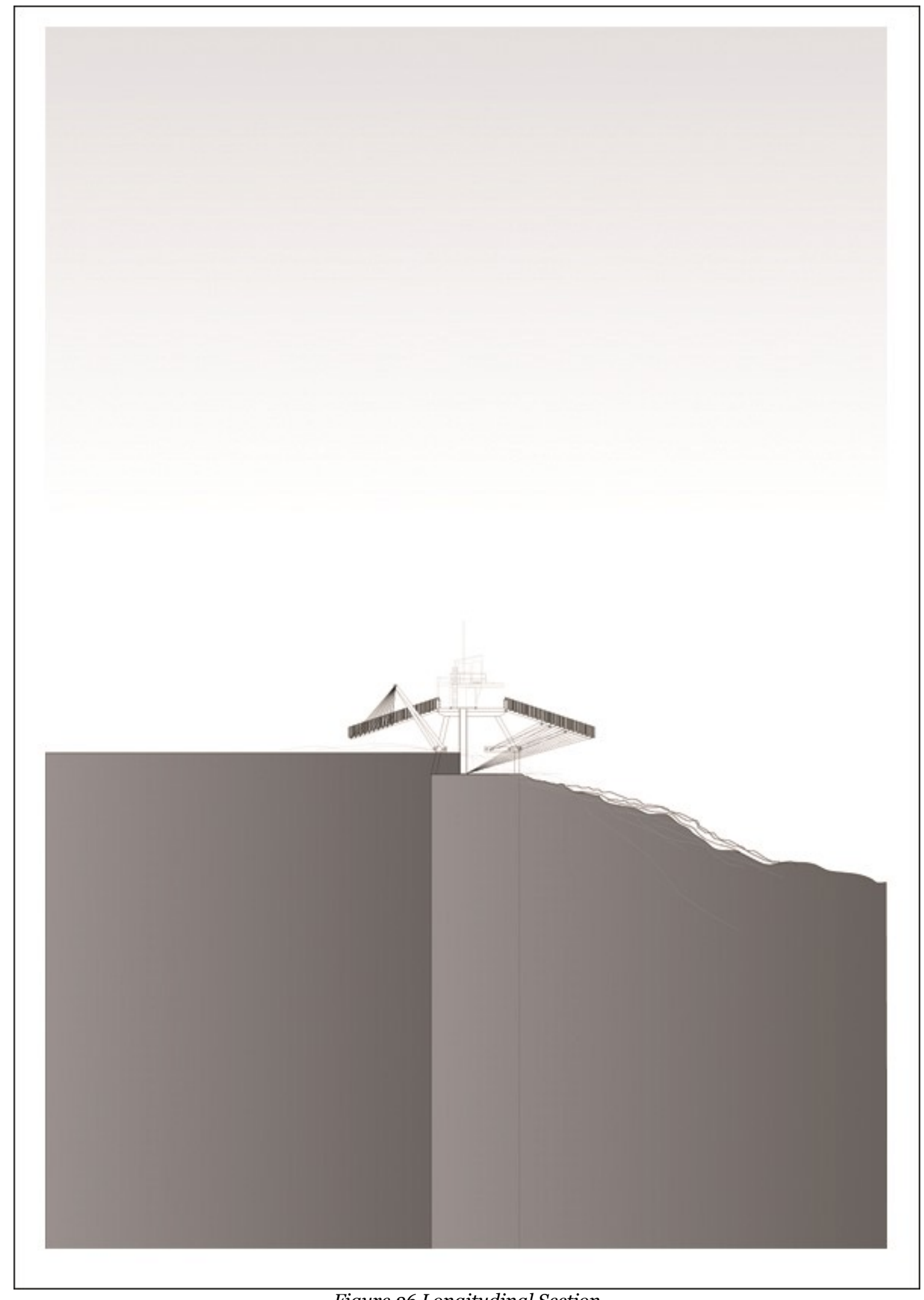

Figure 26 Longitudinal Section 


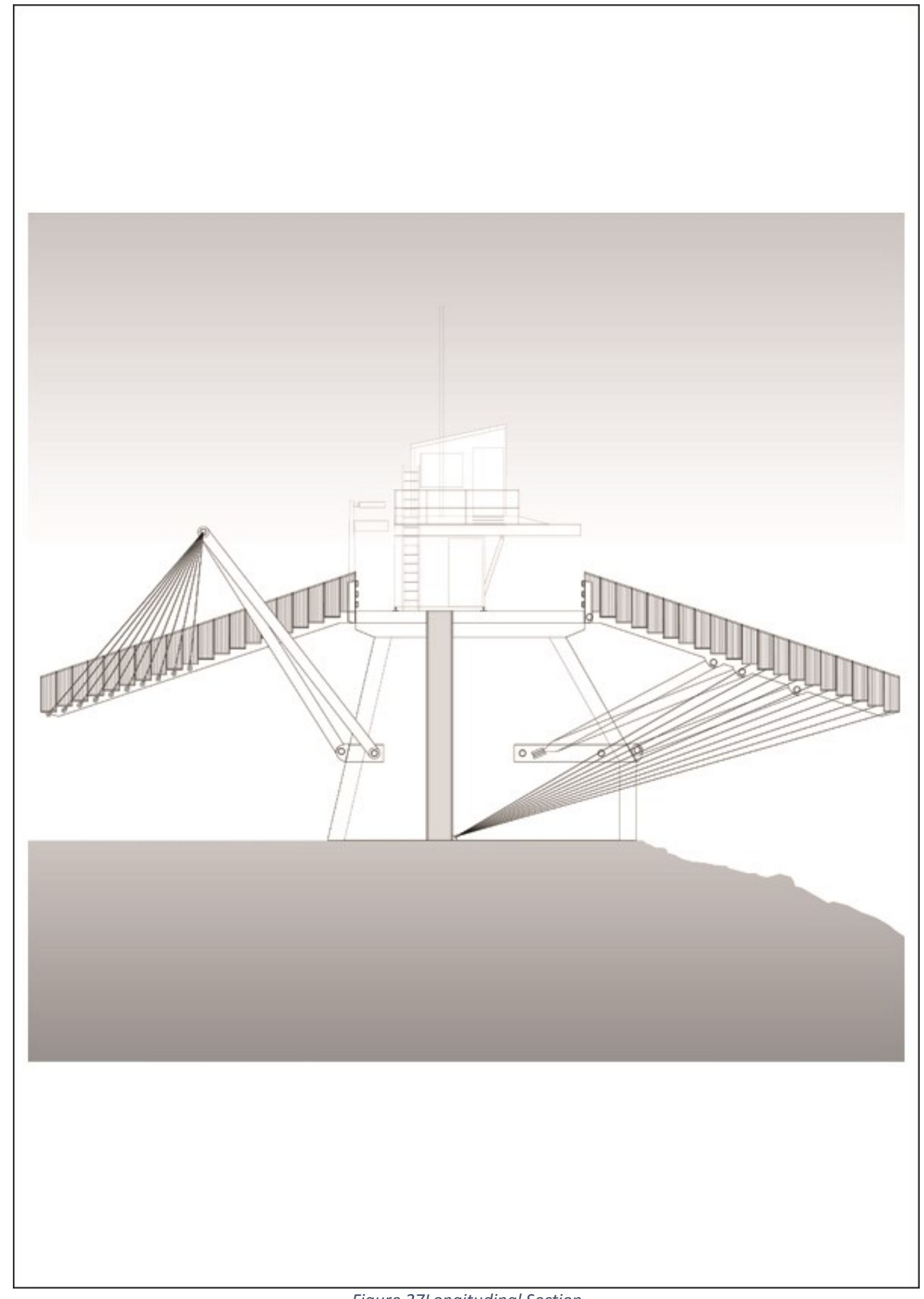

Figure 27Longitudinal Section 


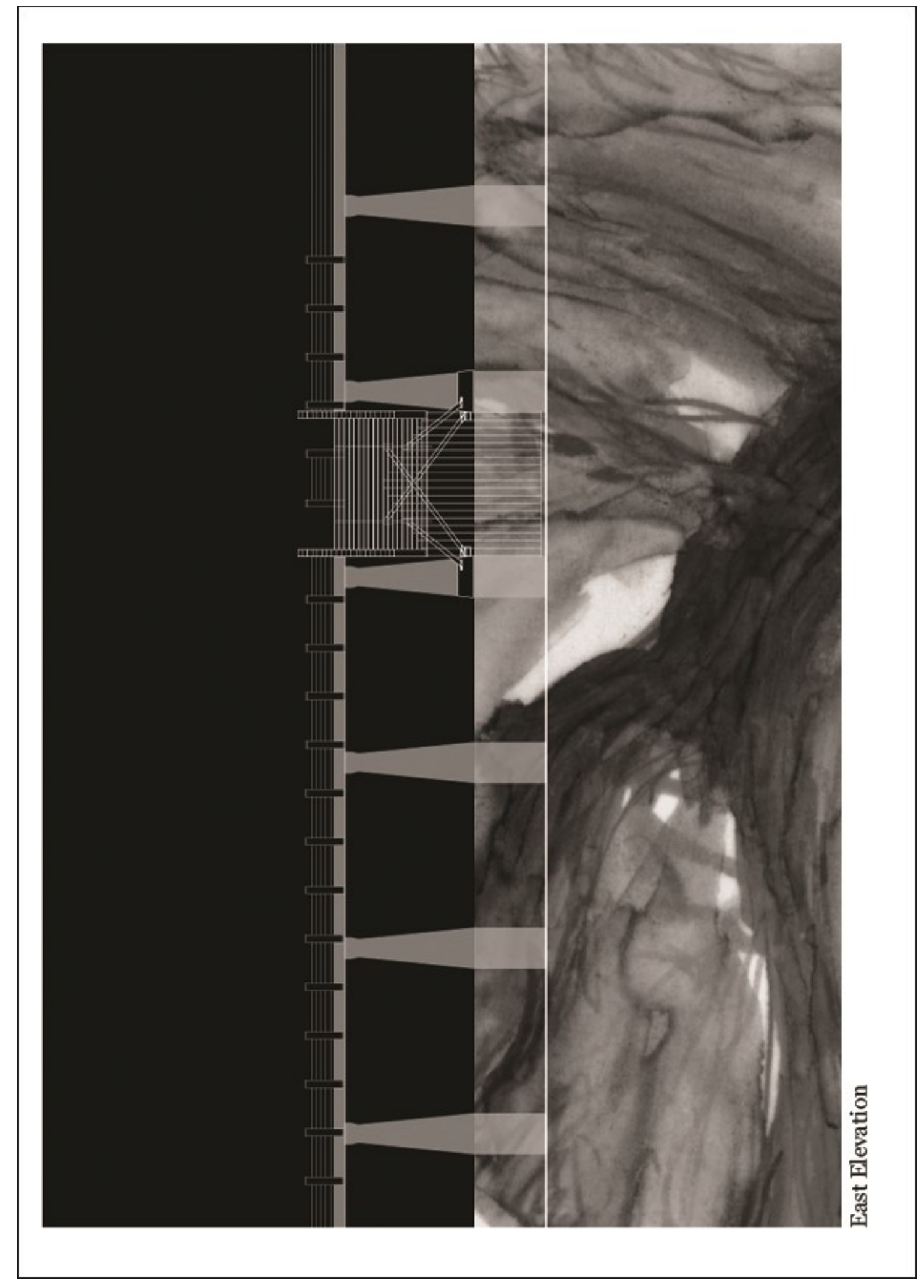

Figure 28 


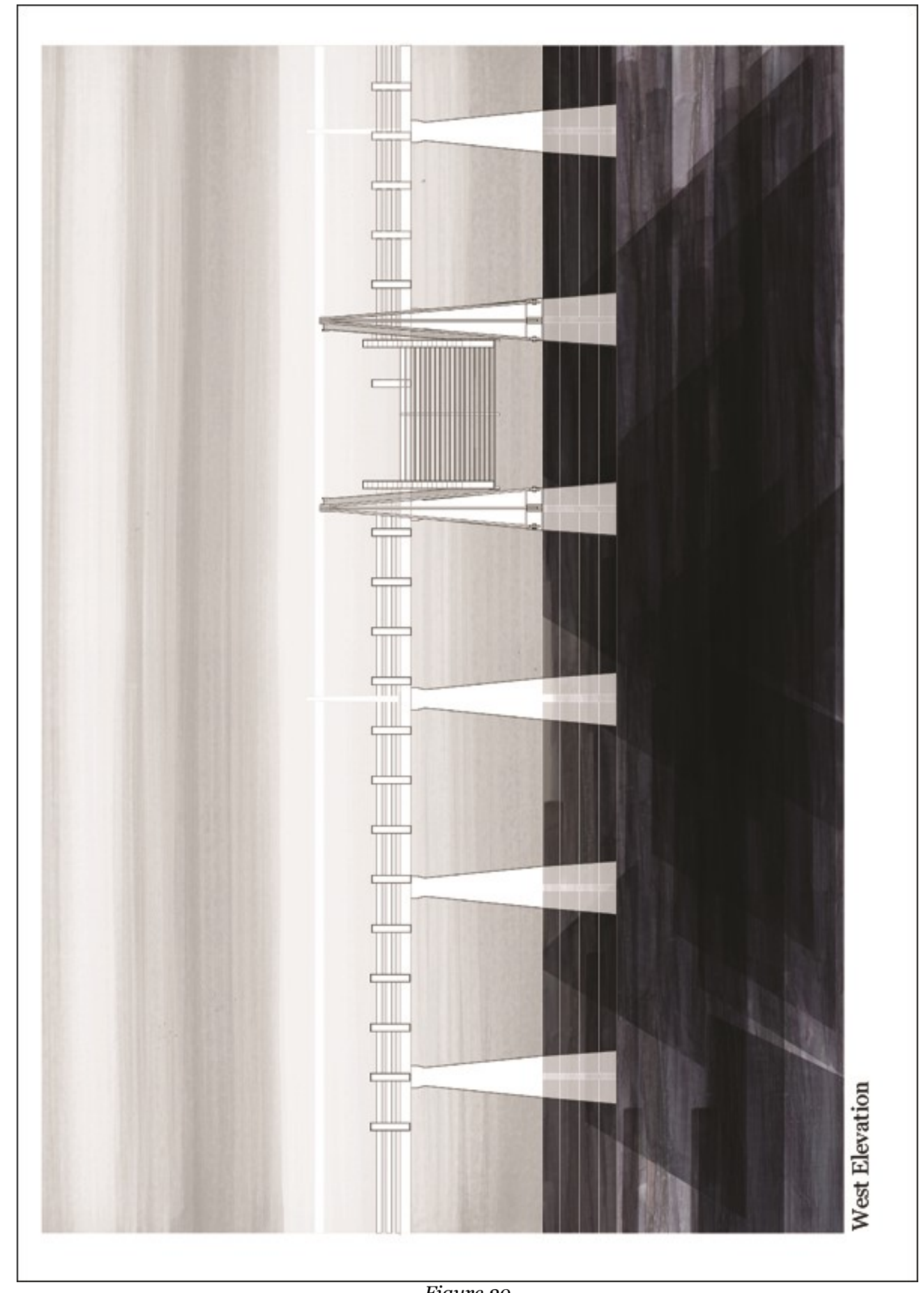

Figure 29 


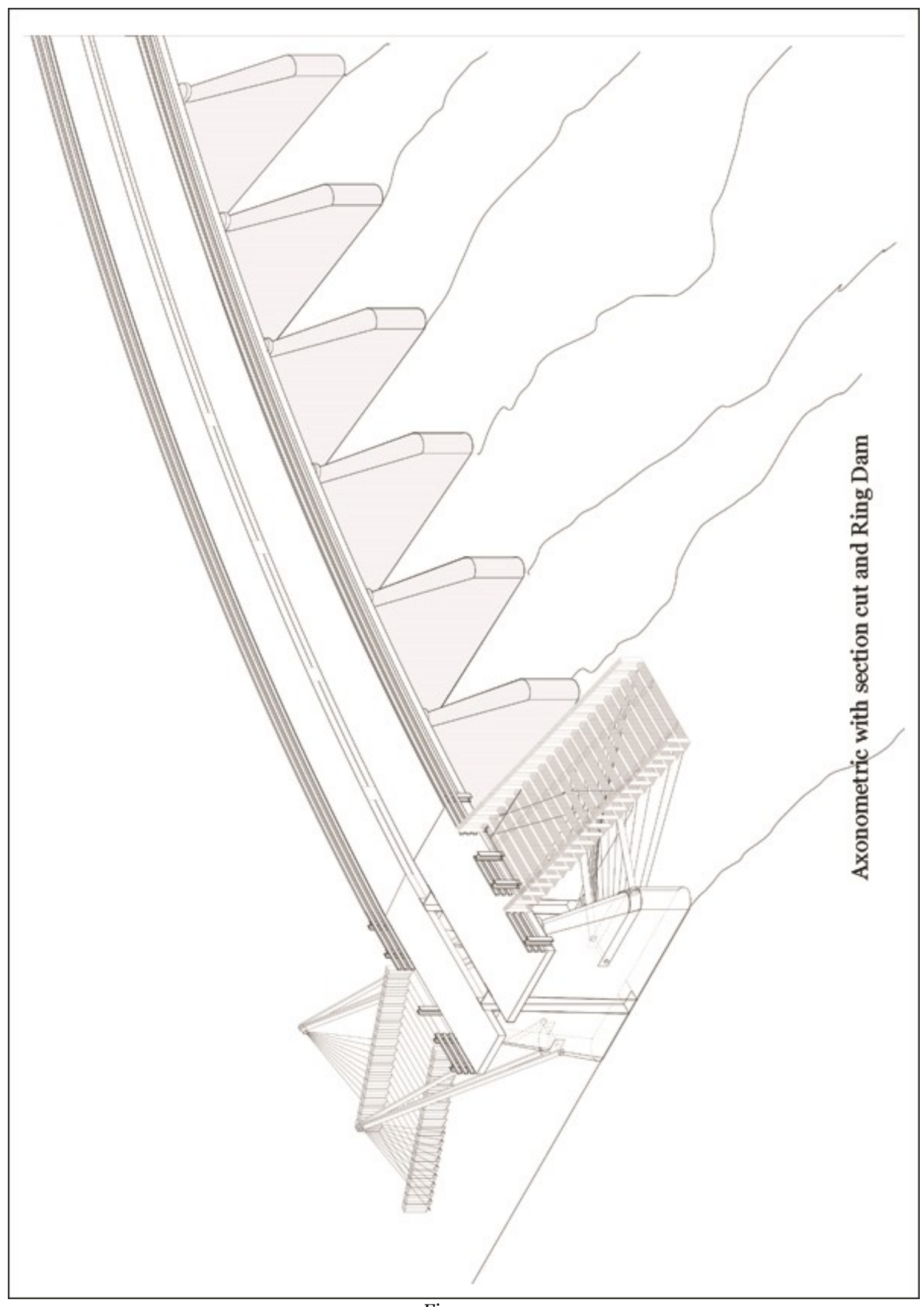

Figure 30 


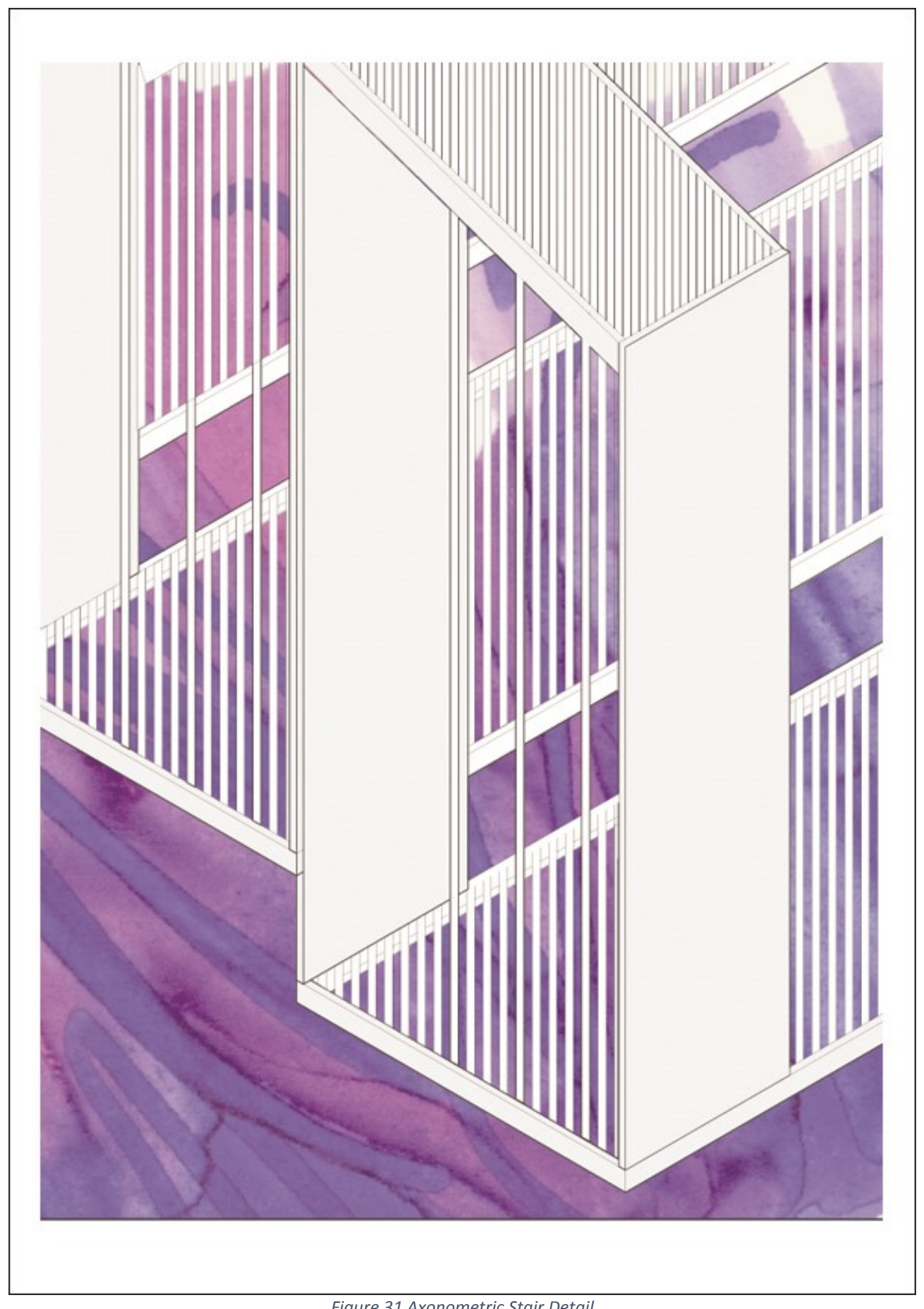

Figure 31 Axonometric Stair Detail 


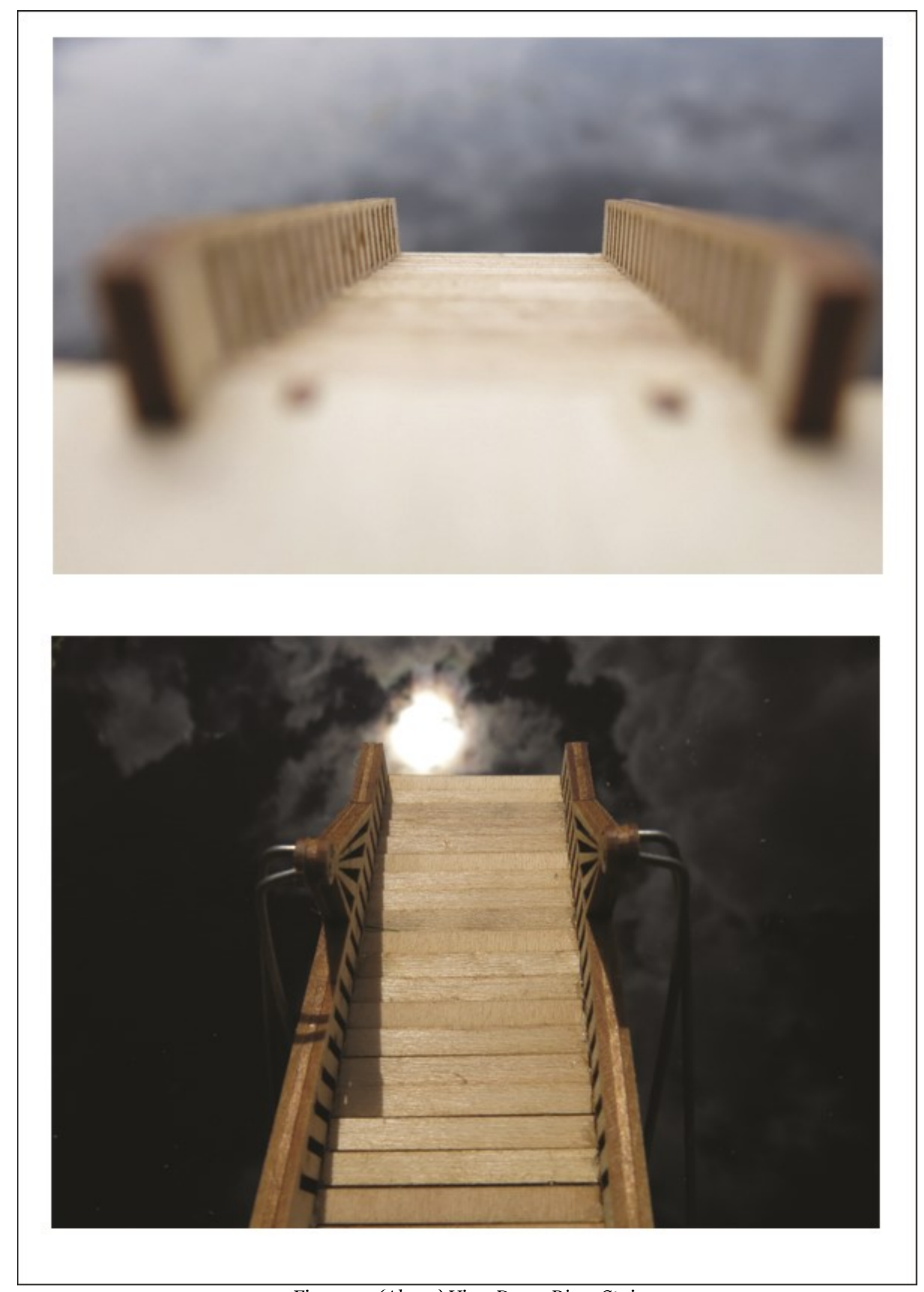

Figure 32 (Above) View Down River Stair Figure 33 (Below) View Up River Stair 


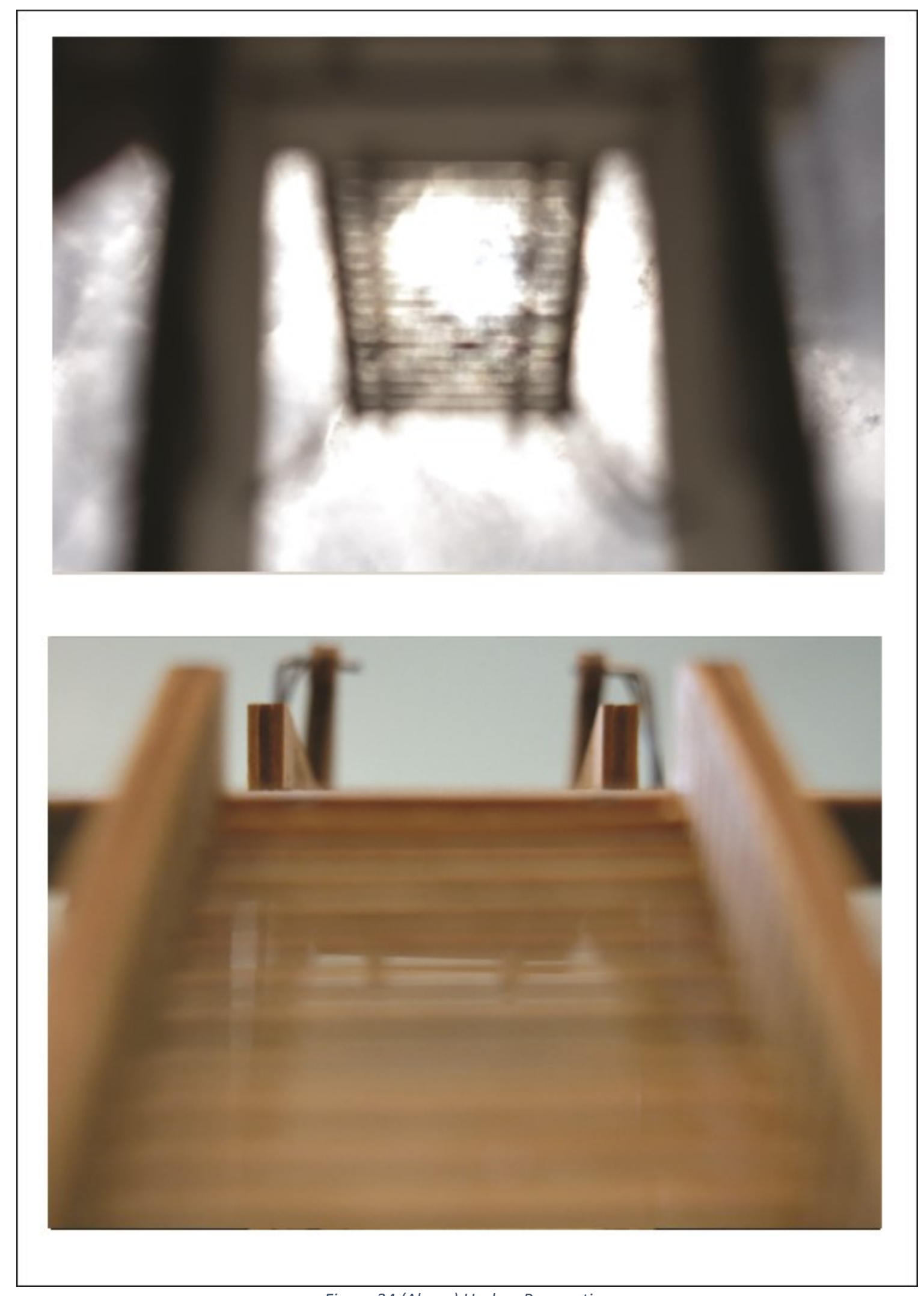

Figure 34 (Above) Useless Perspective

Figure 35 (Below) View Down River Stairs up towards Ring Dam 


\section{Appendix A}

Useless Concept Map 1

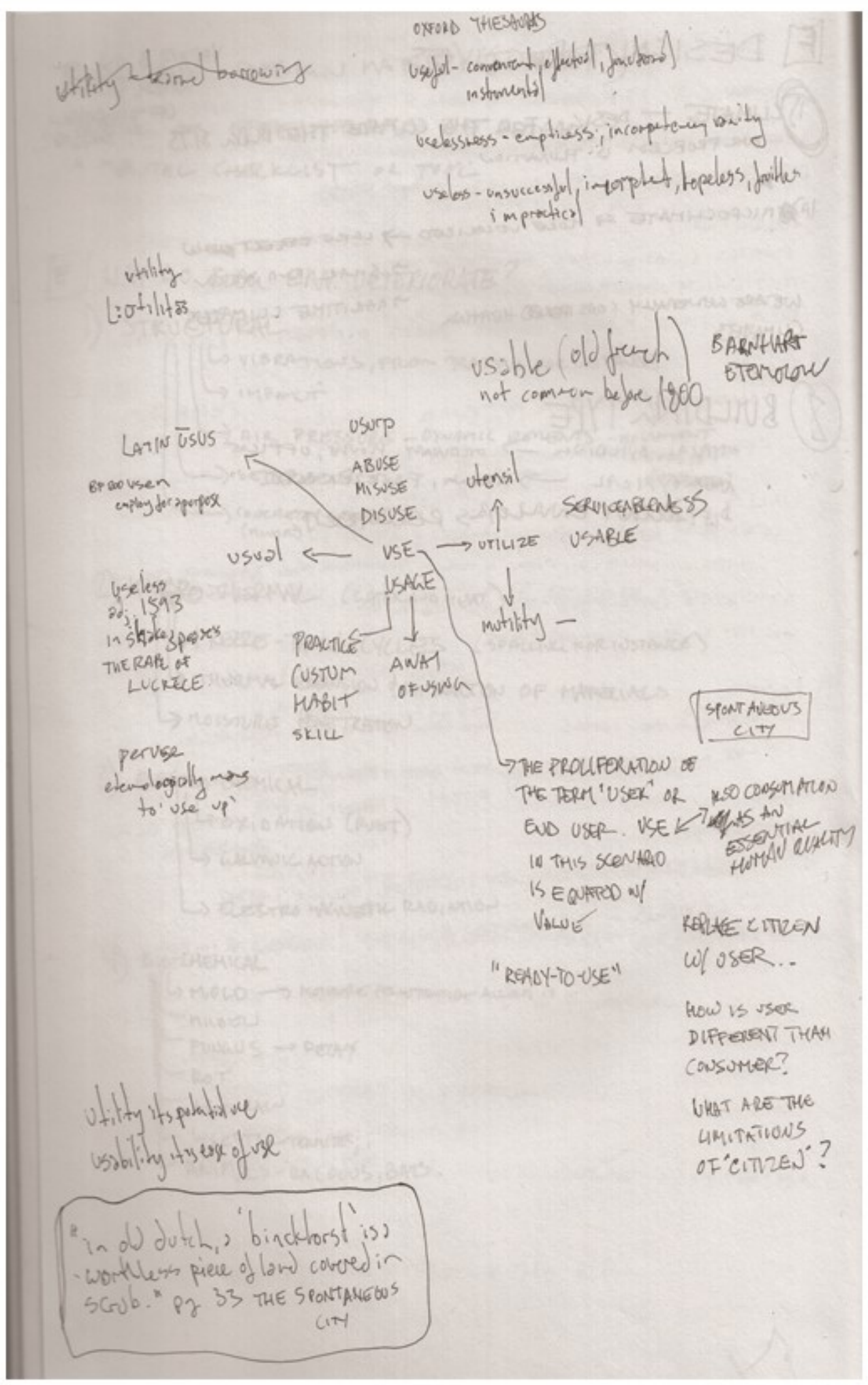




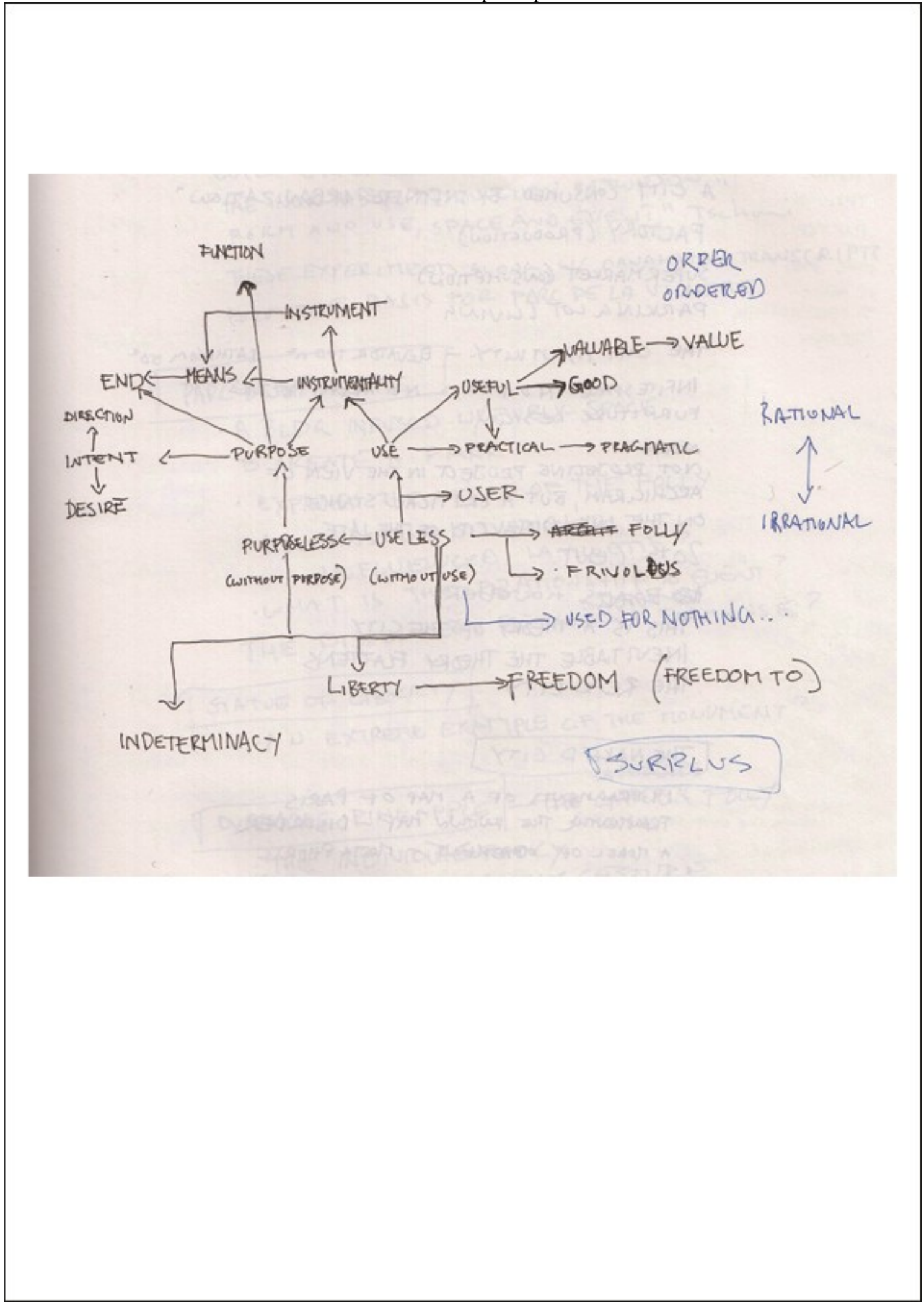


THINK THS INPEA ORDINAFY

THE CONDITIN OF ARCHITECTURE

THE CONAITIONINA OP AR-CHITECTURE

FIKWERT: THENECESS ITY OF ANTIFICE..

HPWNA STIEFEL VIANNA PLAZA PROJECT.

CITY SEAPES

WALK-SCKeOS

poune scapes
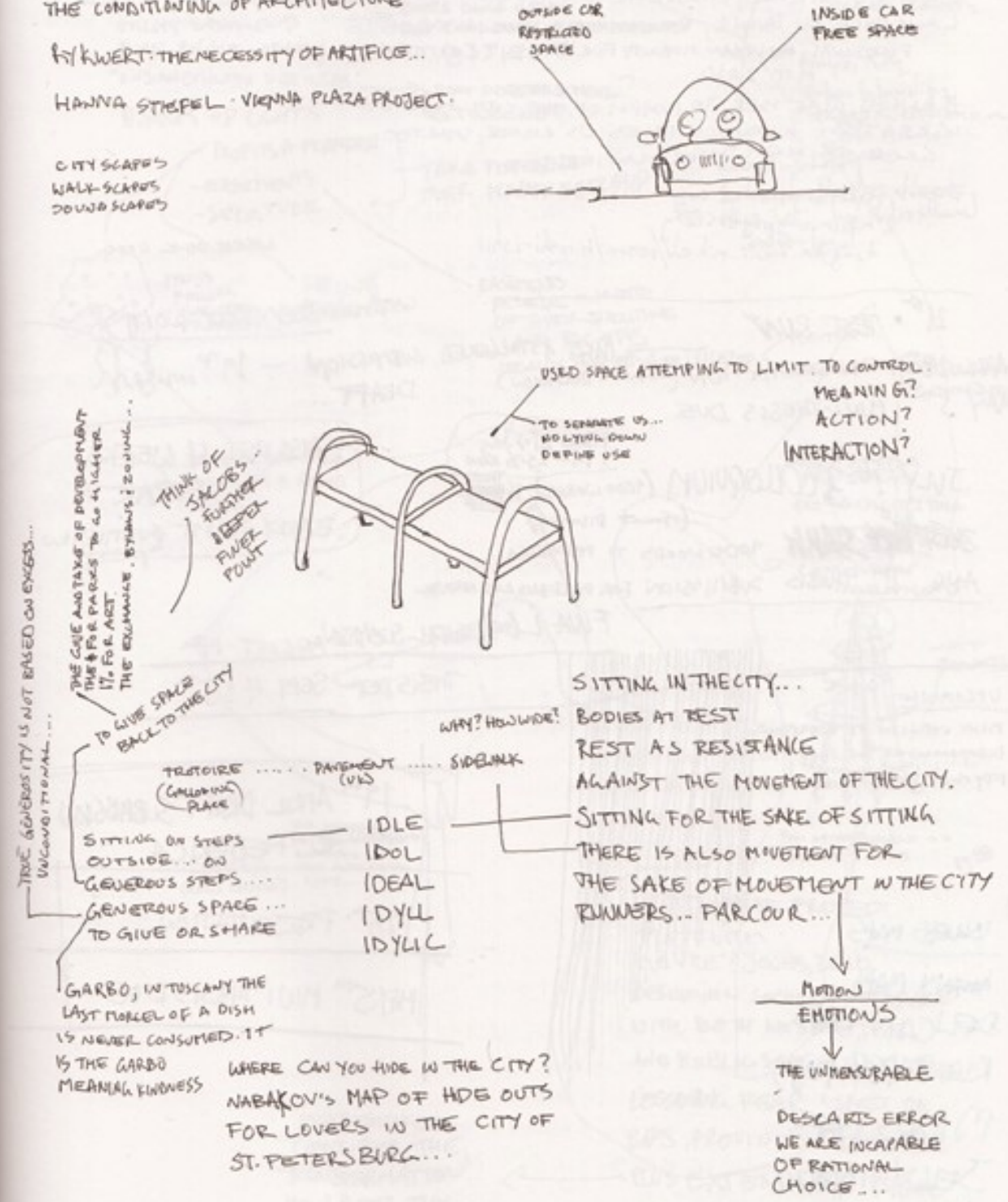


\section{Appendix B}

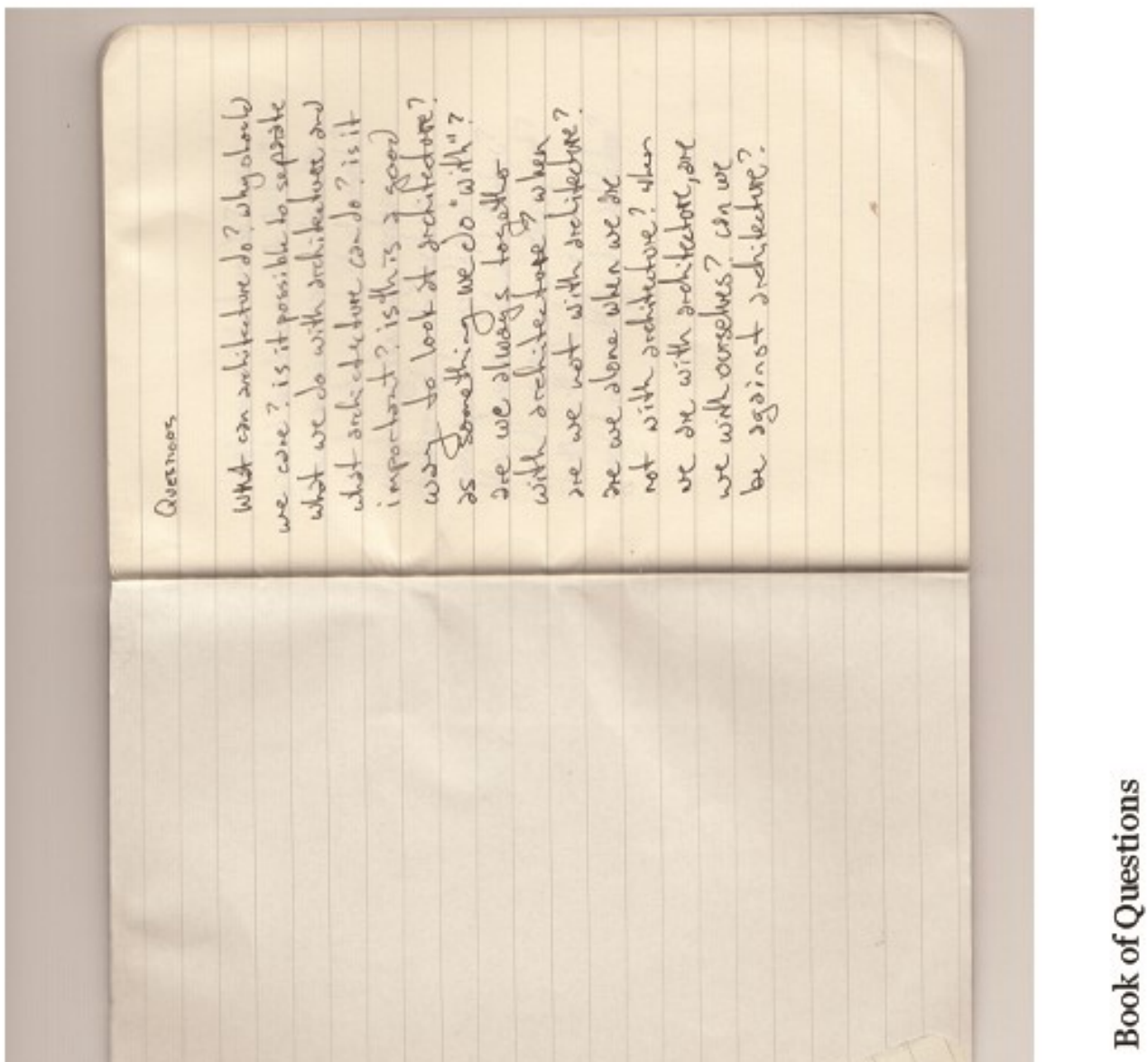



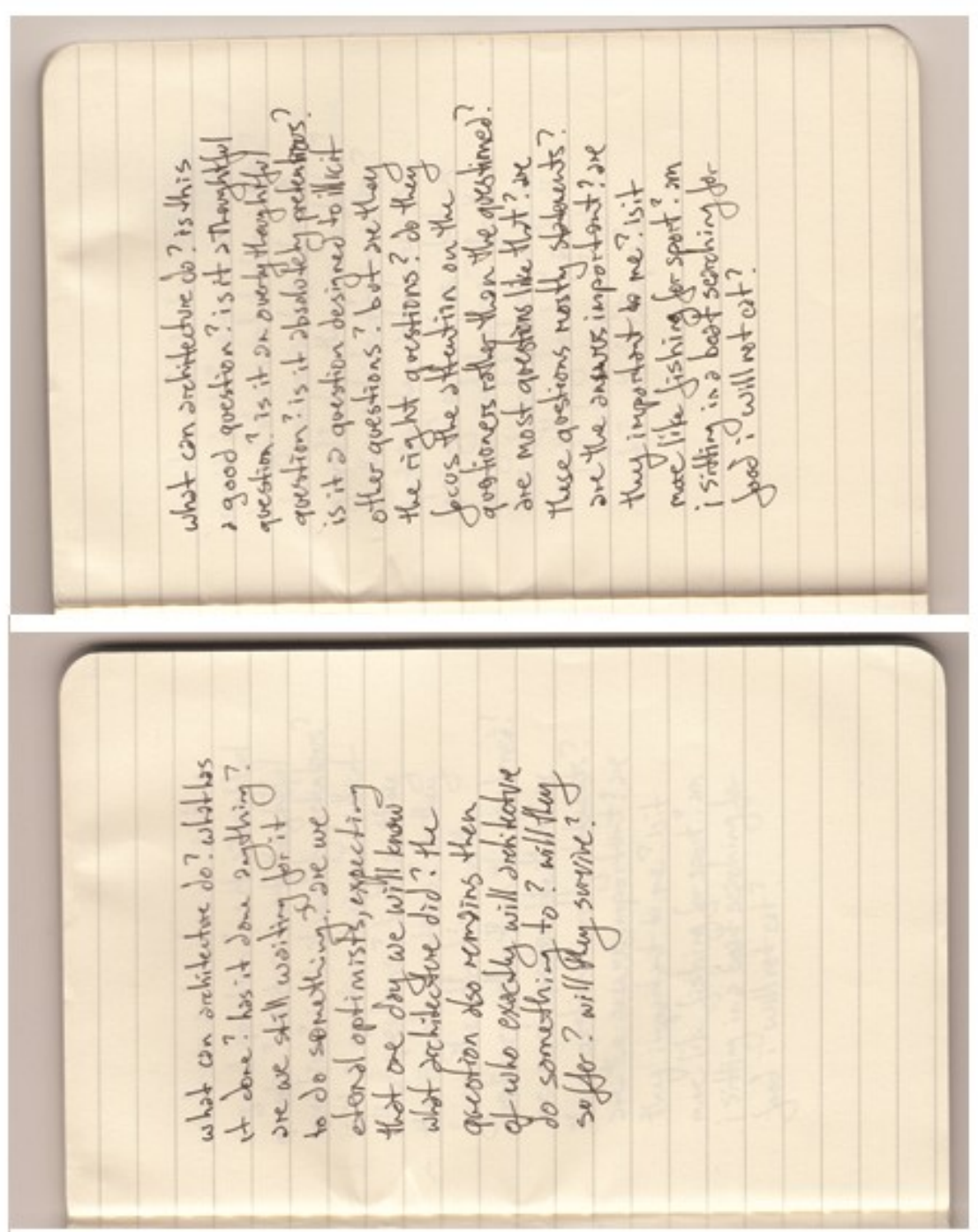

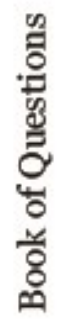

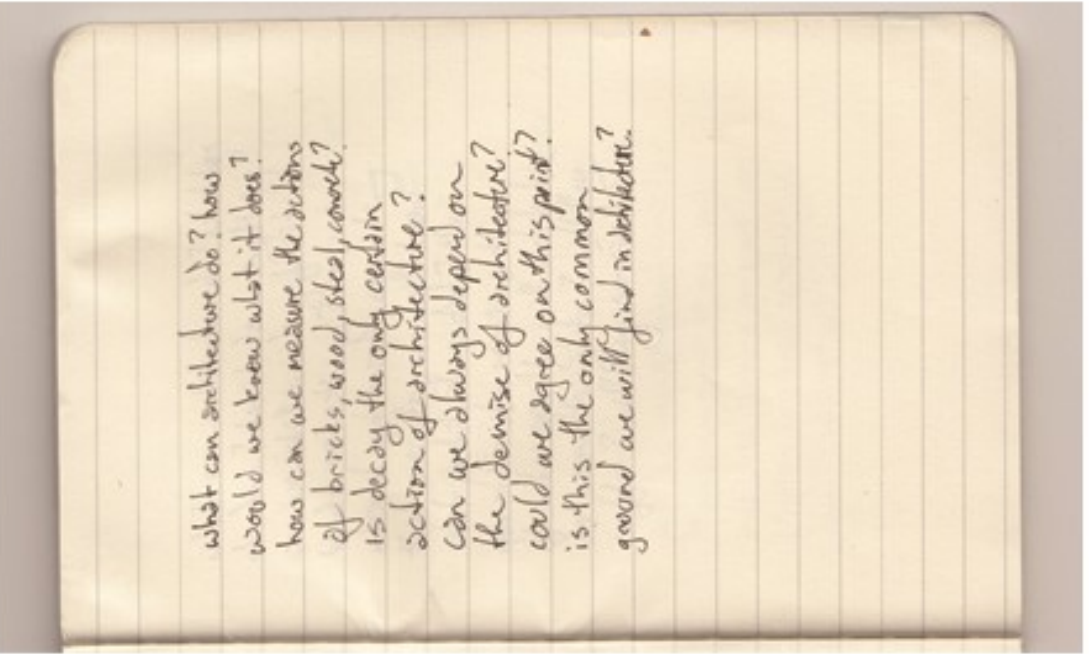



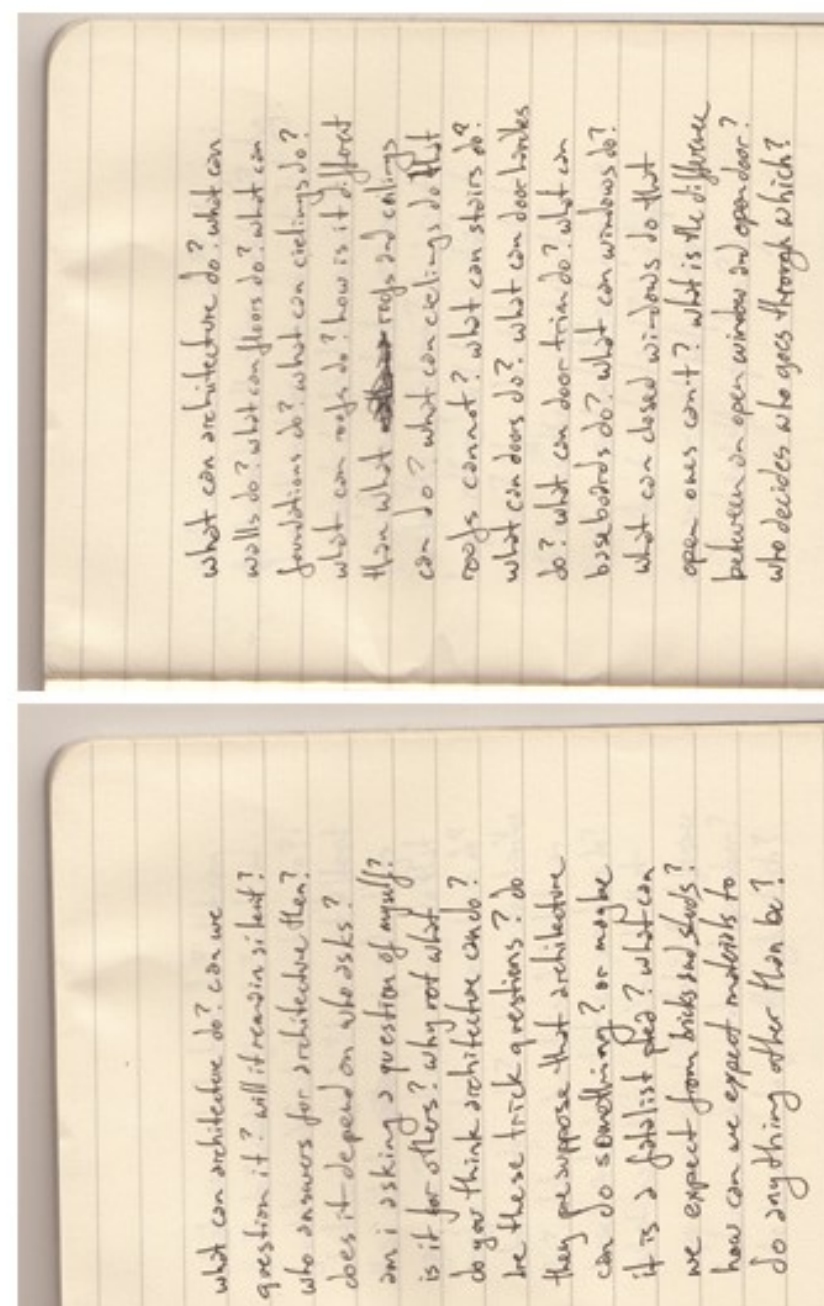

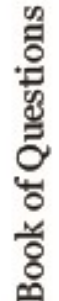

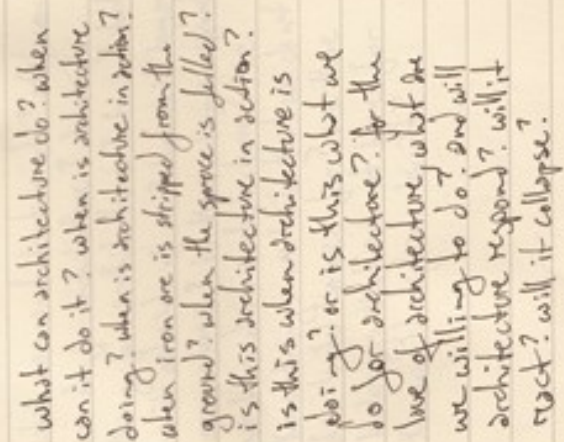



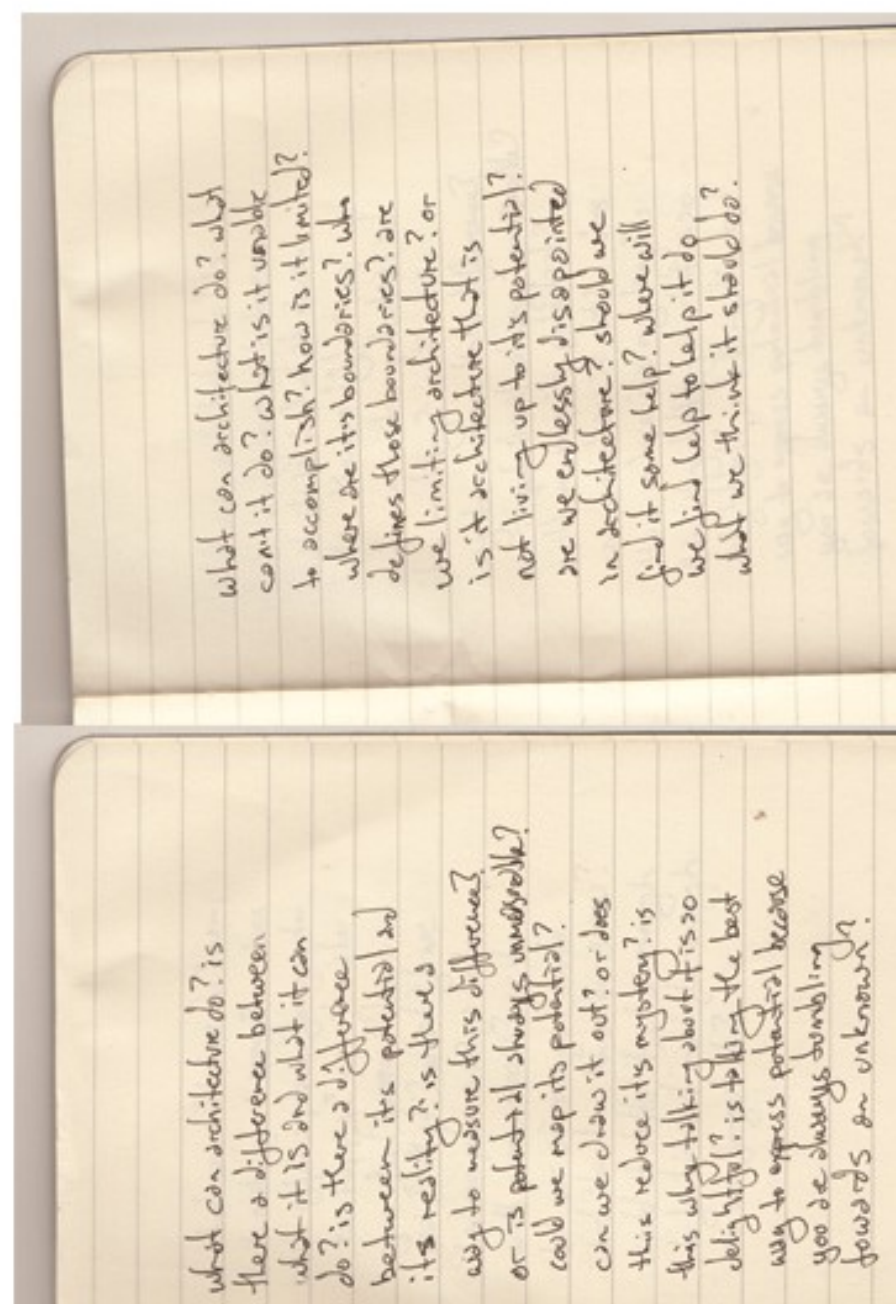

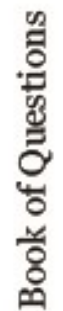

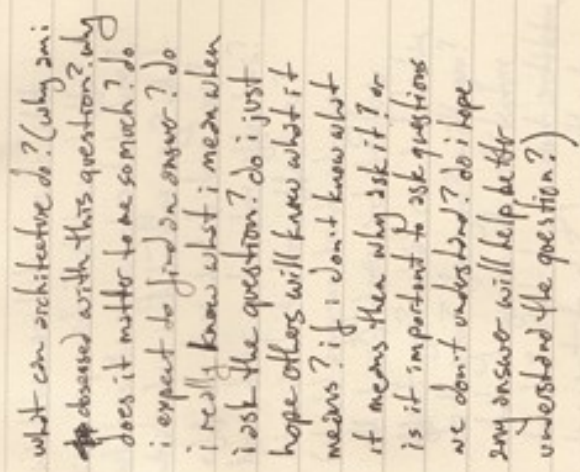



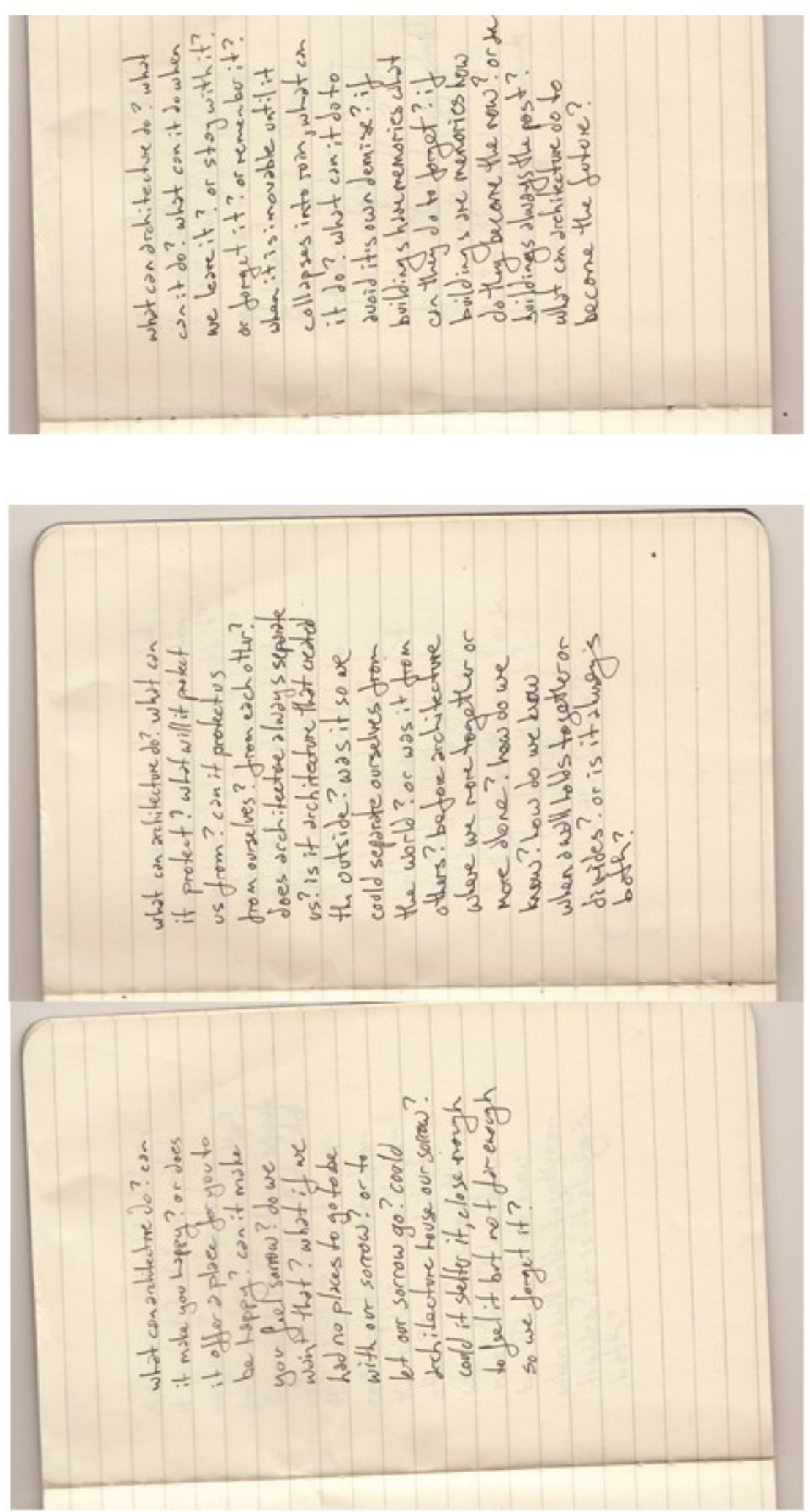

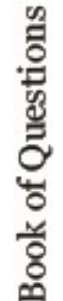



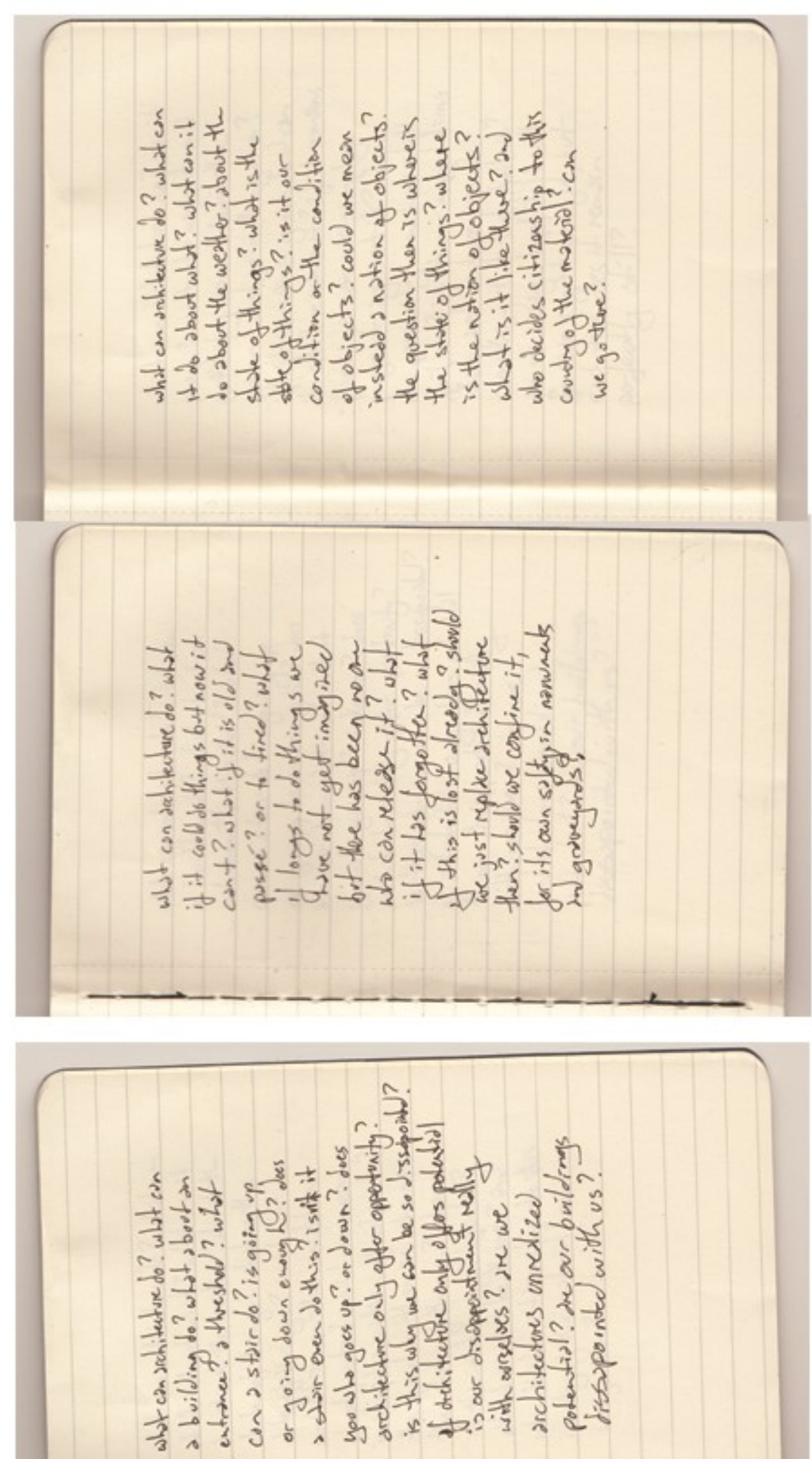

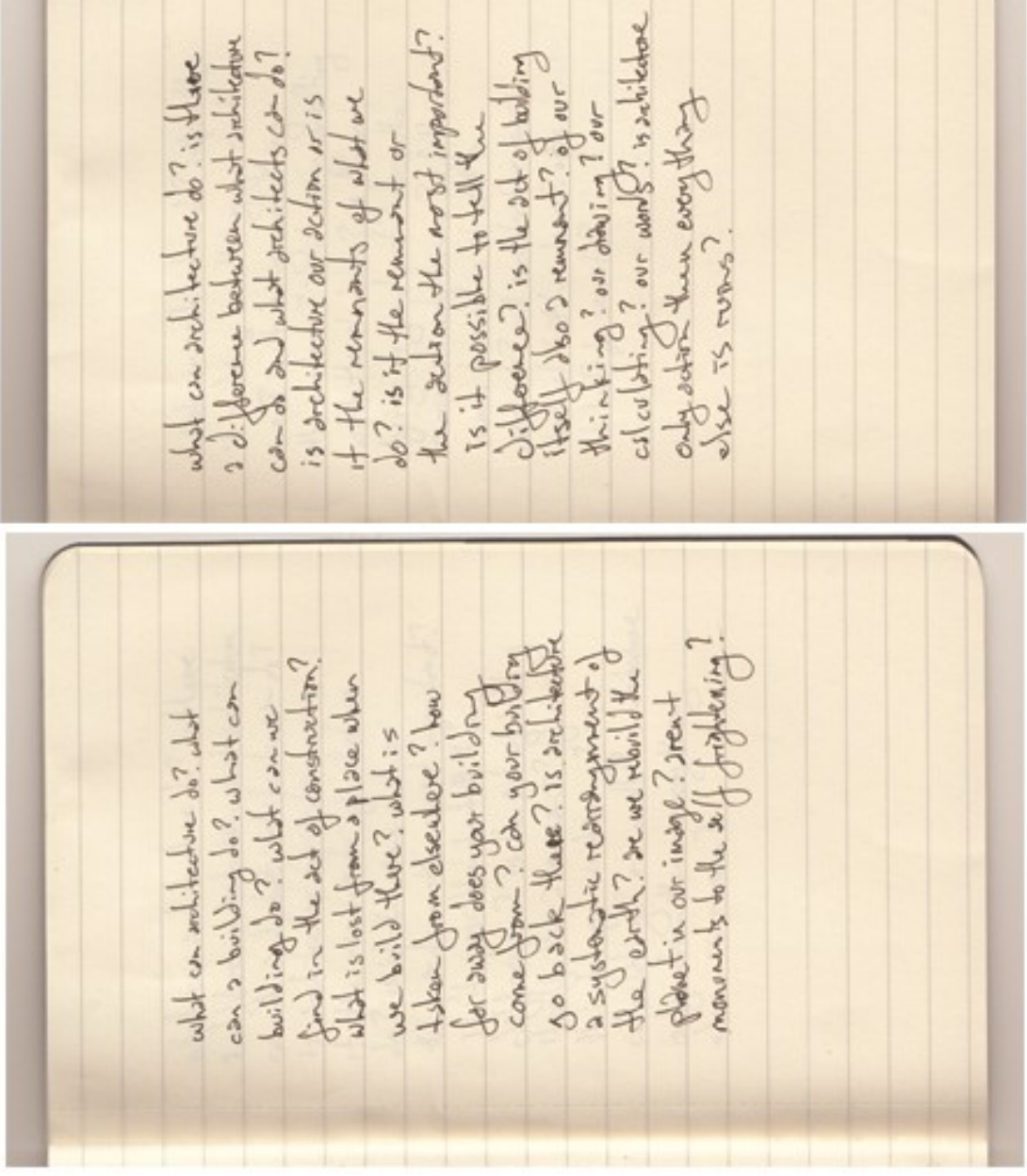

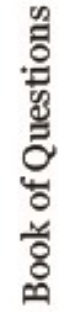

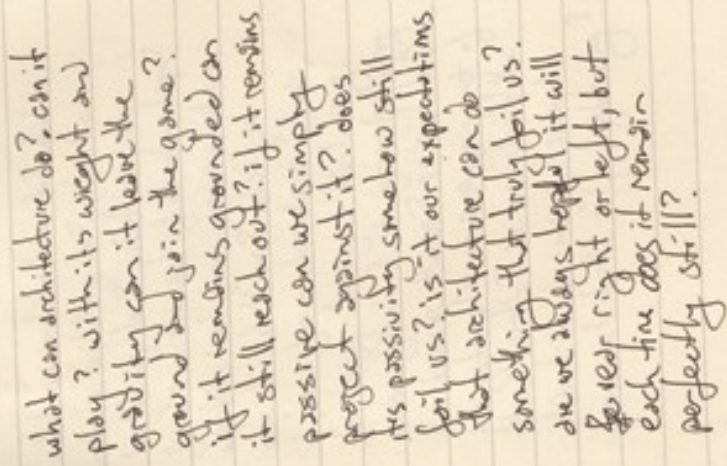



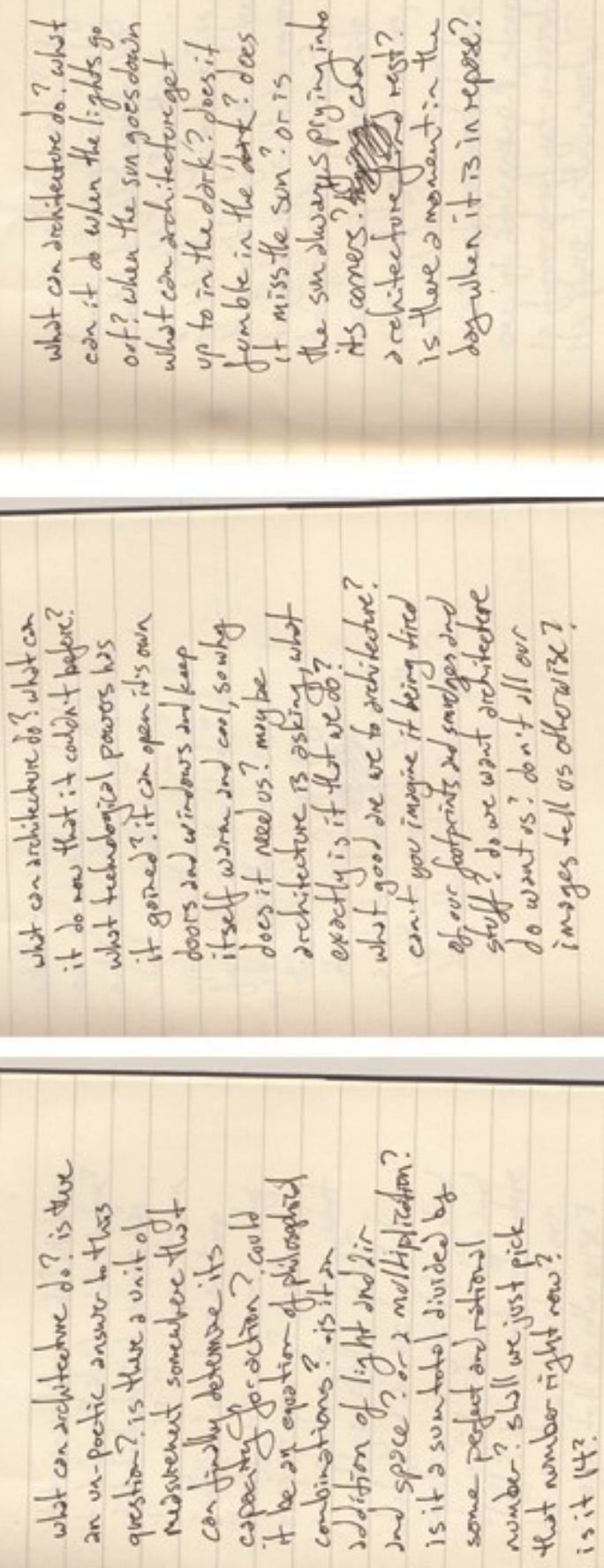

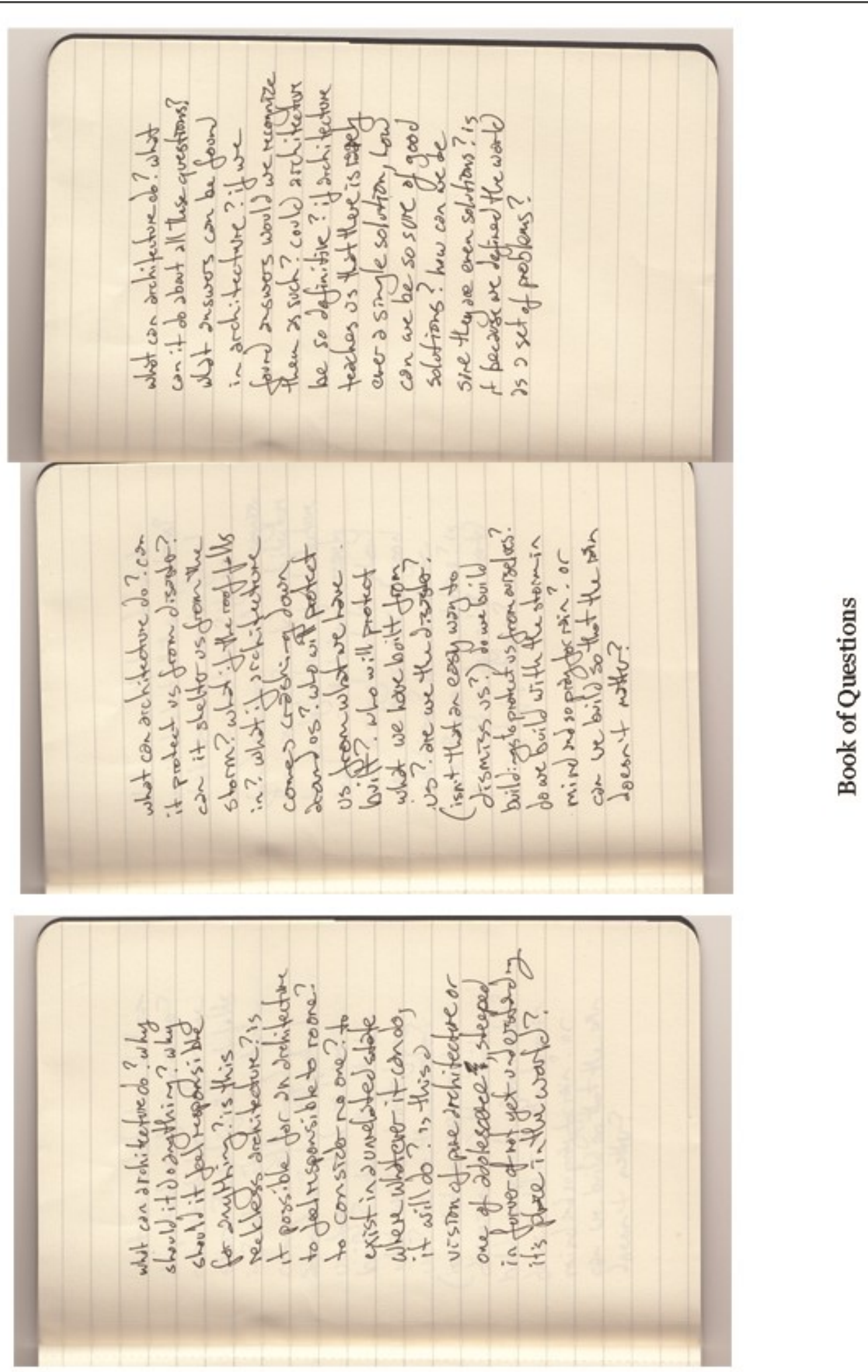


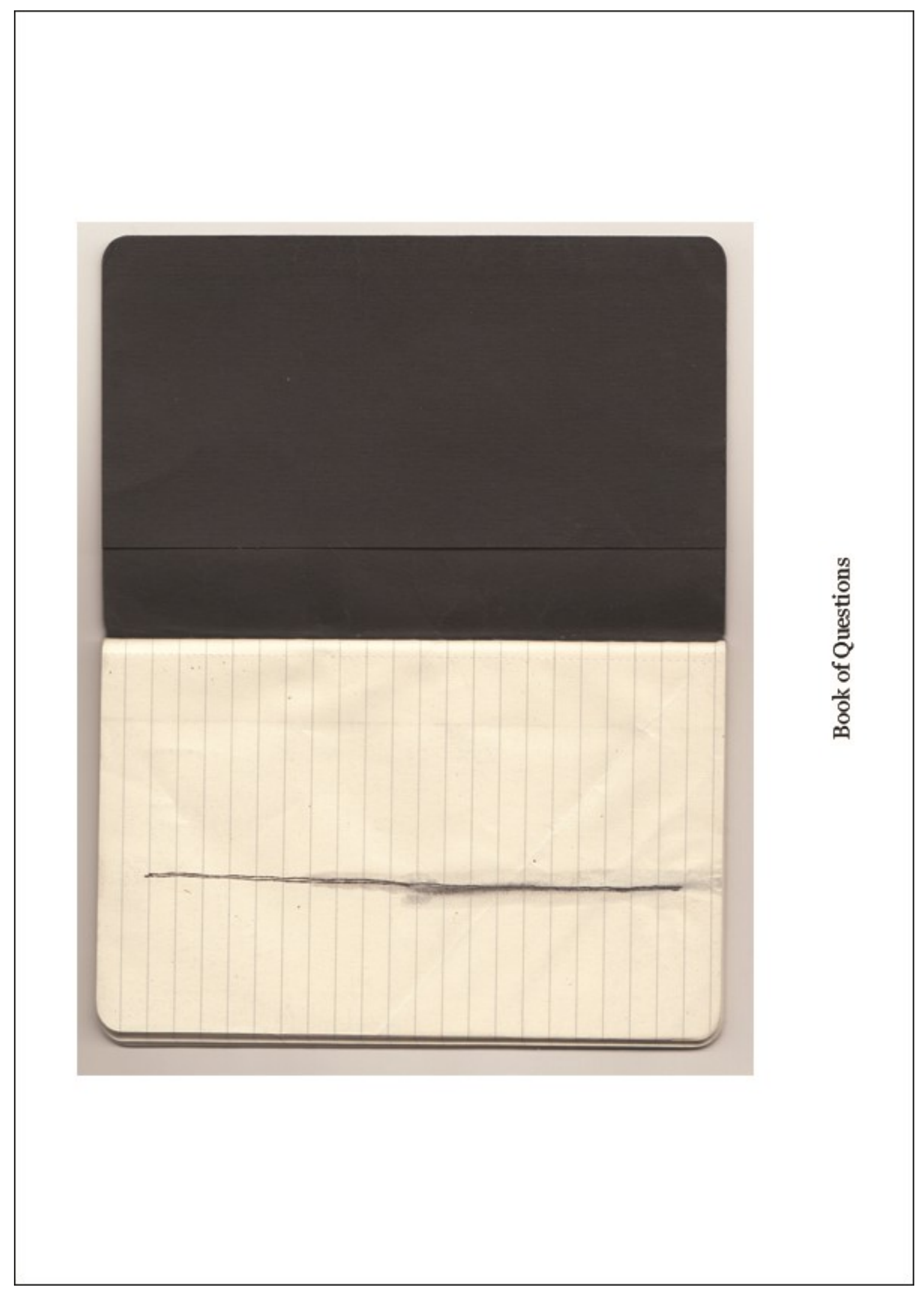




\title{
Appendix C
}

\author{
Useless Writing Exercise
}

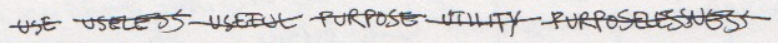

DESCRIBE GOING UP STAIRS. WHAT DO YOU DO TO MOVE UP? WHAT ARE YOU THINKING ABOUT? DO YOU HAVE TO THINK ABOUT HOW YOU GO UP? WHAT HAPPENS WHEN WE TRIP? LET'S GO BACK TO THE BOTTOM THOUGH. ARE YUU CLIMBING THE STAIRS BEFORE YOU REACH THEM? DO YOU ADJUST YOUR STRIDE? WHEN YOU RAISE YOUR FOOT THE STEP DO YOU THINK OR DO YOU ASSUME? DO YOU ALWAYS LEAD WITTP THE SAME FOOT? WHICH FOOT IS IT? WHY? WHAT IF THE OTHER FOOT WENT FIRST? DOES THAT CHANGE THINGS? WHY? WHAT HAPPENS WHEN YOUR FOOT TOUCHES THE STEP? IS THIS CONFIRMATION OF ASSUMPTIONS. THE STAIR LOOKS HARD ! $50 L 1 D, M Y$ FOOT A GREES. ARE YOU ONLY ALEARE OF THIS CONVERSATION IF THERE IS A DISACREZMENT? IF IT LOOKS SOUD BUT MOVES UNDERNEATH YOUR FOET WHAT CHANGES? DO YOU THINK YOU CAW MEMBER WHAT YOW WHERE THINK Wh JUST BE TARE THESTAIR MOVED? WHAT DO YOU THINK YOUR WSTINCT WOULD BE? TO KEEP COING UP? TO STAY? WE AREN'T GETIING VERY FAR. LET'S PRETEND THE STAIRS ARE FINE (FORTHE MOMENT) AND TRY THE SECOND STAIR. DO YOU FEEL HKHER? DO YOU THINK ABOUT LOING UP? OR ARE YOU ALREADY AT THE TOP? WHAT WOULD HEL YOU CONSIDER HHE STEPS? EACH STEP? WHATIFTHE STAIRS WENT FOREVER? WHAT IF YOU DIDN'T KNOW WHAT WHS AT THE TOP? WHAT IF THEY WENT KOOUH NOWHERE? WOULD YOU STILL CLIMB THEM? WHAT WOUWO YOU THINK ABOUT? 


\section{Appendix D}

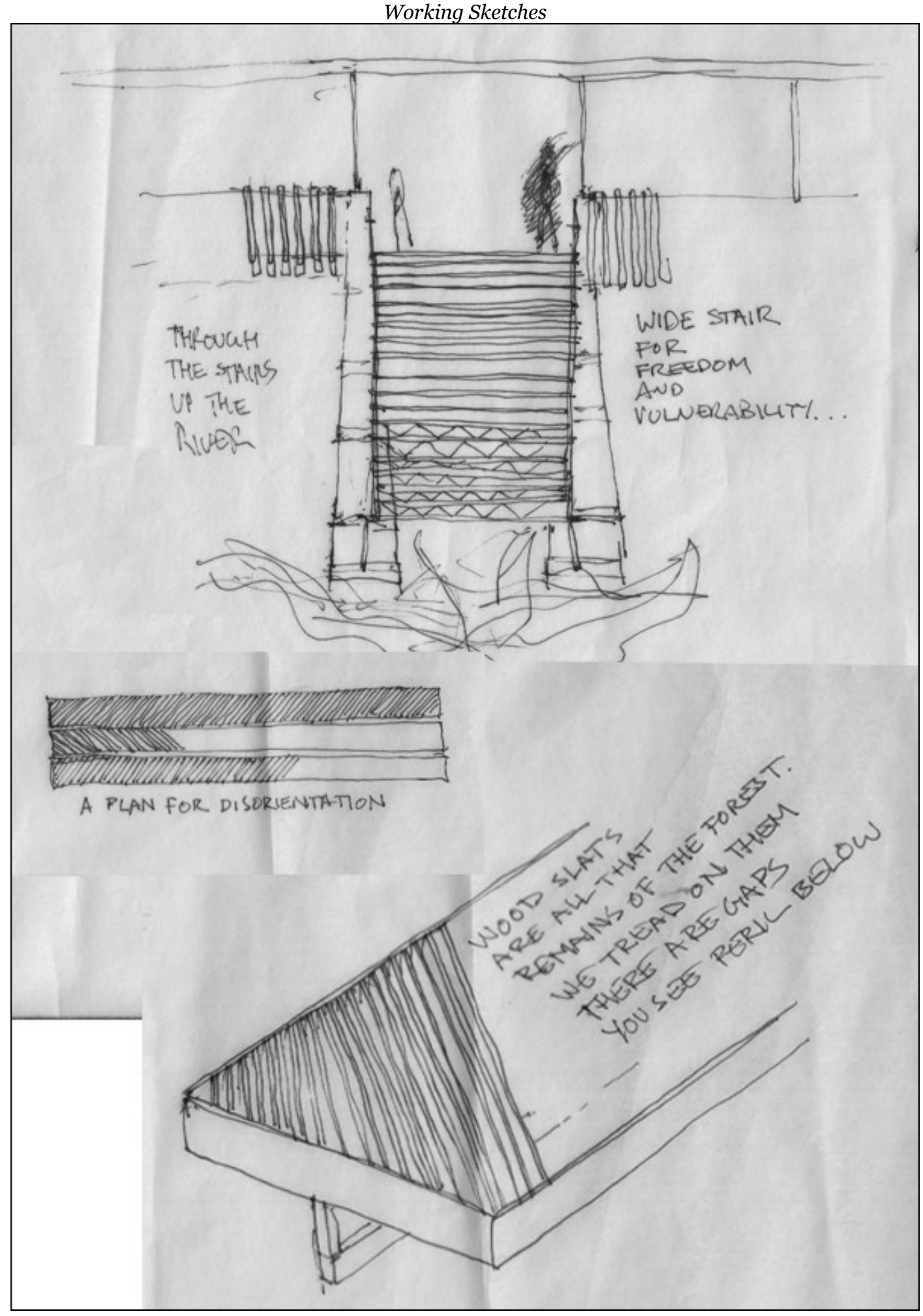



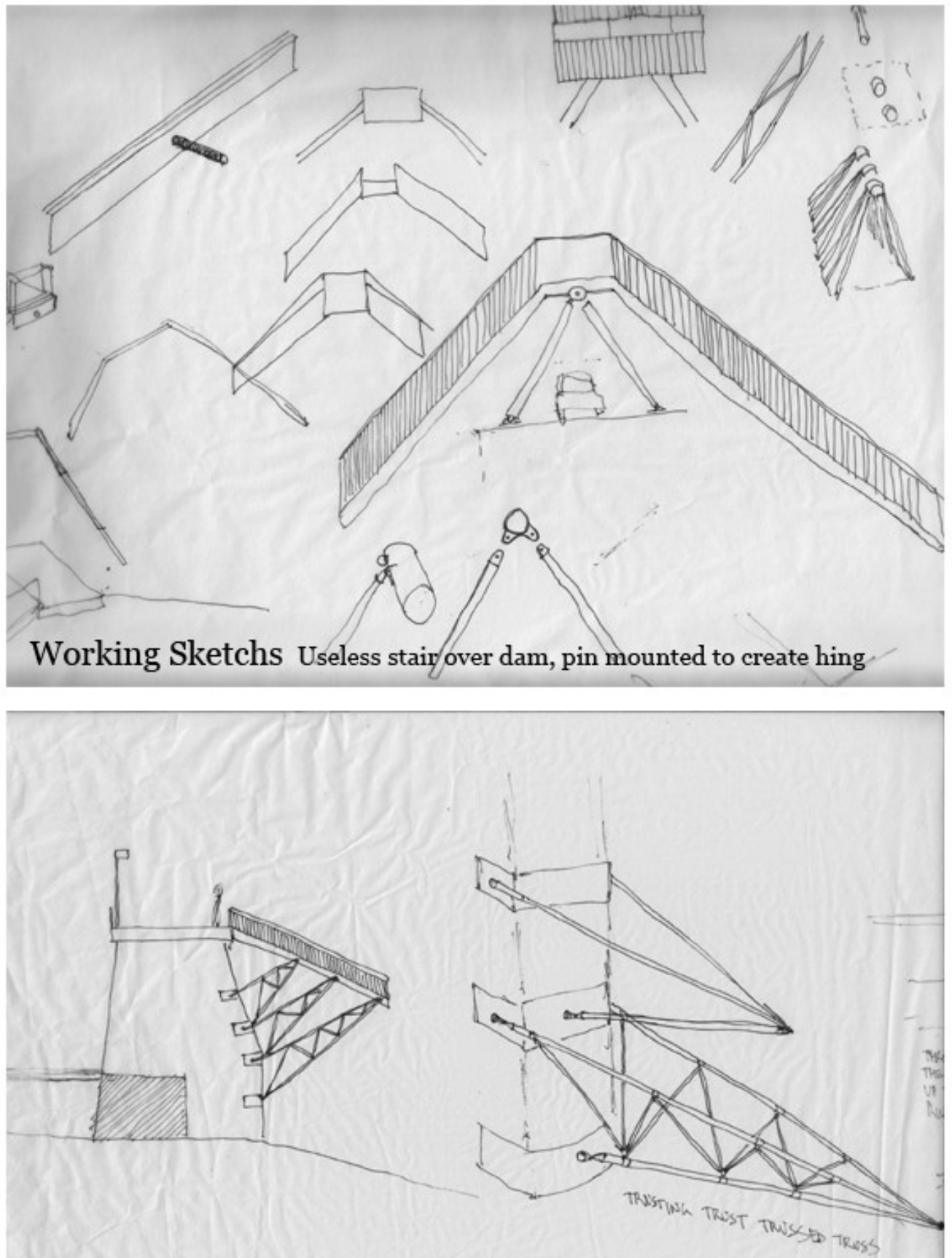

Working Sketchs Early structural support sketch 


\section{Appendix E}

Windmill Developments, Chaudière Map of proposed publicly accessible waterfront

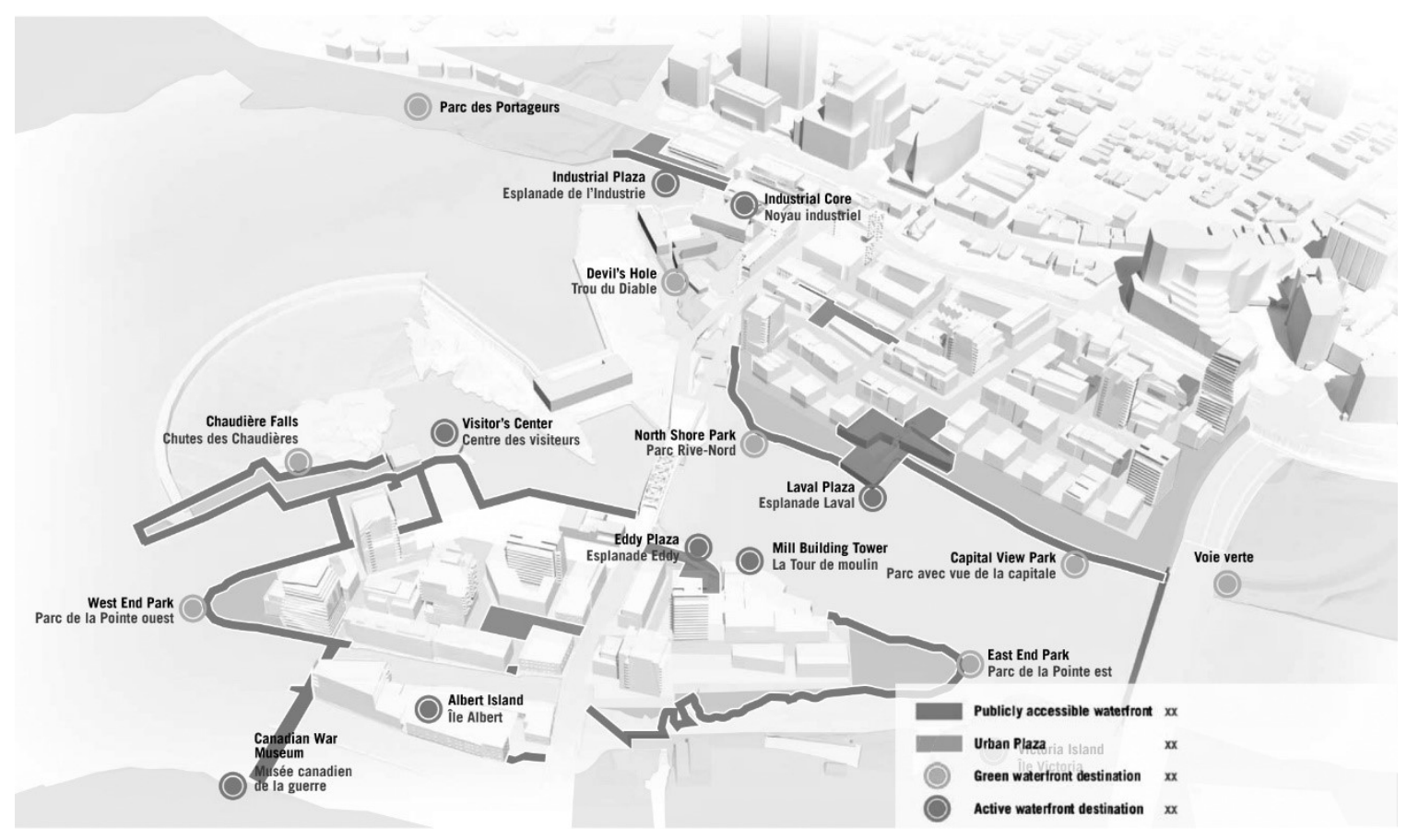




\section{Works Cited}

Arendt, Hannah. 2006. The Human Condition. New York: Penguin Books.

Atwood, Margaret. 1995. Morning in the Burned House. Boston: Houghton Mifflin Harcourt.

Baird, George. 1995. The Space of Appearance. Cambridge: MIT Press.

Bergdoll, Berry. 2000. European Architecture 1750-1890. Oxford: Oxford University Press.

Bhatt, Jigar. 2012. "We Are the 99 Percent" -- The Unlikely Journey of a Revolutionary Slogan. March 19. Accessed August 11, 2014. http://www.huffingtonpost.com/jigar-bhatt/we-are-the-99percent_b_1362141.html.

Cage, John. 2011. Silence: 5oth Anniversary Edition. Middletown, CT: Wesleyen University Press.

Caroll, Lewis. 1995. The Hunting of the Snark: An Agony in Eight Fits. New York: Penguin Books.

Champlain, Samuel de. 1906. The Voyages and Explorations of Samuel de Champlain. Edited by Edward Gaylord Bourne. Translated by Annie Nettleton Bourne. New York: A. S. Barnes \& Company.

CRTC. 2008. RIC-40: Frequently Asked Questions on Low Power FM Broadcasting. June. Accessed August 10, 2014. http://www.ic.gc.ca/eic/site/smtgst.nsf/eng/sfo2087.html\#q7.

Driver, Julia. 2009. History of Ultitarianism. Edited by Edward N. Zalta. Accessed July 29, 2014. http://plato.stanford.edu/archives/sum2009/entries/utilitarianismhistory/.

Eliasson, Olafur. 2004. Olafur Eliasson. Accessed August 11, 2014. http://www.olafureliasson.net/works/umschreibung_2.html.

Flusty, Steven. 1994. Building Paranoia: The Proliferation of Interdictory Space and the Erosion of Spatial Justice. Los Angeles.

Harbison, Robert. 1991. The Built, the unbuilt and the unbuildable: in pursuit of architectural meaning. Cambridge: MIT Press.

Heidegger, Martin. 1977. The Question Concerning Technology and other essays. Translated by William Lovitt. New York: Harper \& Row, Publishers, Inc.

Hejduk, John. 1993. Soundings. New York: Rizzoli International Publications, Inc.

Lambert, Lindsay. 2014. Let the Chaudière fall - freely. April 25. Accessed August 11, 2014 . 
http://www.ottawacitizen.com/Chaudi\%C3\%A8re+fall+freely/9778425/story.ht $\mathrm{ml}$.

Lee, Pamela M. 2001. Objects to be Destroyed: the work of Gordon Matta-Clark. Cambridge: MIT Press.

McAulay, Rose. 1966. The Pleasure of the Ruin. New York: Walker and Company.

Meier, Barry. 1993. "Reality and anxiety: crime and the fear of it." New York Times. February 18. Accessed August 10, 2014. http://www.nytimes.com/1993/02/18/us/reality-and-anxiety-crime-and-thefear-of-it.html.

Monahan, Gordon. 2011. Seeing Sound: Sound Art, Performance and Music, 1978-2011 : Gordon Monahan. Edited by Carsten Seiffarth Linda Jansma. Toronto: Doris McCarthy Gallery.

Now Magazine. 2013. Pride Parade 2013: a life in photos. July 1. Accessed August 11, 2014. http://www.nowtoronto.com/daily/story.cfm?content=193329.

OED Online. 2014. "instrumental, adj. and n.". June. Accessed August 11, 2014. http://www.oed.com/view/Entry/9716o?redirectedFrom=instrumental.

Patel, Raj. 2009. The Value of Nothing: why everything costs so much more than we think. Toronto: Harper Collins Pubishers Ltd.

Perec, Georges. 2008. Species of Spaces. London: Pengiun Books.

Phaidon. 2010. Didier Fizuza Faustino. November 11. Accessed August 11, 2014. http://ca.phaidon.com/agenda/architecture/picturegalleries/2010/november/11/didier-fiuza-faustino/.

Quebec-Labrador Foundation. 2005. "Background Study for the Nomination of the Ottawa River Under the Heritage Rivers System." Ottawa.

Ross, Sarah. 2008. "Action no. 38." In Actions: What you Can do With The City, edited by Mirko Zardini Giovanna Borasi, 66-67. Montreal: Canadian Centre for Architecture.

Sennett, Richard. n.d. The Public Realm. Accessed August 11, 2014. http://www.richardsennett.com/site/SENN/Templates/General2.aspx?pageid=1 6.

Smith, Eric L. 2011. An Urban Epicentre of Decolonization in Canada. Masters Thesis, Ottawa: Carleton University.

Stockdale, Peter. 2014. Free The Falls. Accessed August 11, 2014. http://www.change.org/en-CA/petitions/jim-watson-free-the-fallslib\%C3\%A9rer-les-chutes-let-s-get-rid-of-the-chaudiere-dam.

Turnbull, David. 1989. Maps are Territories: Science is an Atlas : a Portfolio of Exhibits. Chicago: Chicago University Press. 
Williams, Raymond. 1985. Keywords: a vocabulary of culture and society. New York: Oxford University Press.

Windmill Developments. 2014. "The Isles: Domtar Lands Redevelopment." Master Plan, Ottawa.

Wood, Denis. 2006. "Catalogue of Map Artists." Cartographic perspectives 53 61-68. 